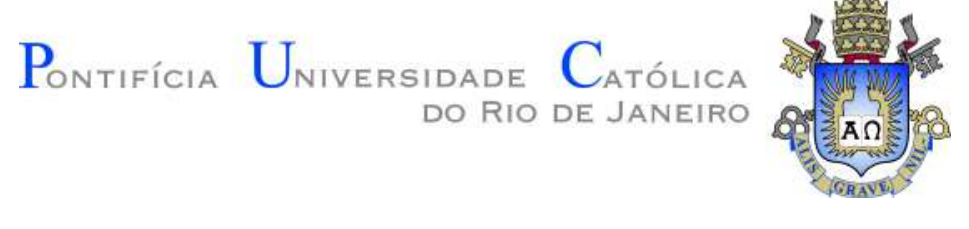

Wanderson Ferreira Braz

Síntese, funcionalização e caracterização de
nanocelulose e estudo da sua aplicação na
adsorção de cátions metálicos

Dissertação de Mestrado

Dissertação apresentada como requisito parcial para obtenção do grau de Mestre pelo Programa de Pós-graduação em Engenharia Química, de Materiais e Processos Ambientais, do Departamento de Engenharia Química e de Materiais da PUC-Rio.

Orientador : Prof. Rogério Navarro Correia de Siqueira Coorientador: Prof. Omar Ginoble Pandoli 


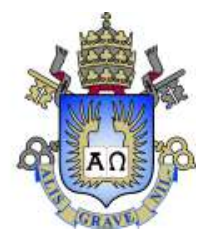

Wanderson Ferreira Braz

\section{Síntese, funcionalização e caracterização de nanocelulose e estudo da sua aplicação na adsorção de cátions metálicos}

Dissertação apresentada como requisito parcial para obtenção do grau de Mestre pelo Programa de Pós-graduação em Engenharia Química, de Materiais e Processos Ambientais da PUCRio. Aprovada pela Comissão Examinadora abaixo:

Prof. Rogério Navarro Correia de Siqueira

Orientador

Departamento de Engenharia Química e de Materiais - PUC-Rio

Prof. Omar Ginoble Pandoli

Coorientador

Departamento de Química - PUC-Rio

Prof. Francisco José Moura

Pontifícia Universidade Católica do Rio de Janeiro - PUC-Rio

Prof. José Brant de Campos

UERJ

Rio de Janeiro, 16 de Abril de 2020 
Todos os direitos reservados. A reprodução, total ou parcial do trabalho, é proibida sem a autorização da universidade, do autor e do orientador.

Wanderson Ferreira Braz

Graduou-se em Engenharia Química pela FAACZ Faculdades Integradas de Aracruz [2017]. (Aracruz, ES)

Ficha Catalográfica

Braz, Wanderson Ferreira

Síntese, funcionalização e caracterização de nanocelulose e estudo da sua aplicação na adsorção de cátions metálicos / Wanderson Ferreira Braz; orientador: Rogério Navarro Correia de Siqueira; coorientador: Omar Ginoble Pandoli. - 2020.

95 f: il. color. ; $30 \mathrm{~cm}$

Dissertação (mestrado) - Pontifícia Universidade Católica do Rio de Janeiro, Departamento de Engenharia Química e de Materiais, 2020.

Inclui bibliografia

1. Engenharia Química e de Materiais - Teses. 2. Celulose. 3. Nanocelulose. 4. Hidrólise ácida. 5. Ácido cítrico. 6. Adsorção. I. Siqueira, Rogério Navarro Correia de. II. Pandoli, Omar Ginoble. III. Pontifícia Universidade Católica do Rio de Janeiro. Departamento de Engenharia Química e de Materiais. IV. Título. 


\section{Agradecimentos}

Gostaria de agradecer primeiramente a Deus, autor da minha vida e força na minha caminhada, sempre me ajudando a não desistir dos meus sonhos.

Ao meu orientador professor Rogério por acreditar, incentivar, apoiar e se dedicar para a realização deste projeto.

Ao meu co-orientador professor Omar por abraçar este projeto e apoiar constantemente.

À CAPES e à PUC-Rio pelos auxílios concedidos, sem os quais este trabalho não poderia ter sido realizado.

Aos meus pais, irmãos e esposa pelo amor, carinho e encorajamento a buscar sempre mais.

Ao meu amigo de infância e companheiro de pesquisa Lucas por todo o apoio.

Aos amigos e funcionários da casa XXI e pós doutorandos do DEQM que foram essenciais nesta caminhada e se fizeram disponíveis em todos os momentos.

A todos aqueles que neste período estiveram presentes e contribuíram de alguma forma na minha caminhada.

"O presente trabalho foi realizado com apoio da Coordenação de Aperfeiçoamento de Pessoal de Nível Superior - Brasil (CAPES)- Código de Financiamento 001" 


\section{Resumo}

Braz, Wanderson Ferreira; Siqueira, Rogério Navarro Correia de; Pandoli, Omar Ginoble. Síntese, funcionalização e caracterização de nanocelulose e estudo da sua aplicação na adsorção de cátions metálicos. Rio de Janeiro, 2020. 95p. Dissertação de Mestrado - Departamento de Engenharia Química e de Materiais, Pontifícia Universidade Católica do Rio de Janeiro.

A celulose é um biopolímero abundante, renovável e altamente biodegradável com produção no Brasil de aproximadamente 20 milhões de toneladas em 2017. A obtenção de nanocelulose a partir de diversas fontes e sua utilização em uma variedade de aplicações tem sido objeto de uma grande quantidade de pesquisas, visto suas propriedades diferenciadas e possibilidade de modificações, a partir de reações com outras substâncias orgânicas e inorgânicas. Entre as potenciais aplicações que a nanocelulose apresenta está o tratamento de água e efluentes, por processos como separação por membranas, troca iônica e adsorção. O principal processo de obtenção de nano cristais de celulose é a hidrólise ácida da região amorfa, restando em sua maior parte as regiões cristalinas. Os procedimentos mais aplicados para a produção de nano cristais de celulose consistem na reação de material celulósico puro com ácidos fortes com temperatura, agitação e tempo controlados. A nanocelulose cristalina (CNC) foi obtida através de hidrólise ácida com ácido sulfúrico (40\%) e então modificada com ácido cítrico (1,2M), CNC-Mod, para posterior caracterização e ensaio de adsorção de cátions metálicos. As amostras produzidas foram caracterizadas por técnicas como MEV-EDS, AFM, DRX, FTIR e TGA. Soluções de nitrato de cobalto $\left(\mathrm{Co}\left(\mathrm{NO}_{3}\right)_{2}\right)$, cloreto de sódio $(\mathrm{NaCl})$ e cloreto de mercúrio $\left(\mathrm{HgCl}_{2}\right)$ foram colocadas em contato com amostras de celulose, CNC e CNC-Mod por um tempo máximo de 3h sendo o sólido e o sobrenadante separados. As amostras sólidas obtidas no processo de adsorção foram então submetidas a análises como DRX, MEV-EDS e TGA. Enquanto os sobrenadantes foram analisados por ICP-OES, os resultados indicam a ocorrência de adsorção para todas as amostras e cátions metálicos.

\section{Palavras-chave}

Celulose; Nanocelulose; Hidrólise ácida; Ácido cítrico; Adsorção. 


\section{Abstract}

Braz, Wanderson Ferreira; Siqueira, Rogério Navarro Correia de (Advisor); Pandoli, Omar Ginoble (Co-Advisor). Synthesis, functionalization and characterization of nanocellulose and study of its application in adsorption of metallic cations. Rio de Janeiro, 2020. 95p. Dissertação de Mestrado - Departamento de Engenharia Química e de Materiais, Pontifícia Universidade Católica do Rio de Janeiro.

Cellulose is an abundant, renewable and highly biodegradable biopolymer with production in Brazil of approximately 20 million tons in 2017. Obtaining nano-cellulose from different sources and using it in a variety of applications has been the subject of a great amount of research, given its differentiated properties and the possibility of modifications, based on reactions with other organic and inorganic substances. Among the potential applications that nanocellulose presents is the water and wastewater treatment, by processes such as membrane separation, ion exchange and adsorption. The main process for obtaining cellulose nanocrystals is the acid hydrolysis of the amorphous region, remaining more crystalline regions. The most applied production procedures for cellulose nanocrystals consist of the reaction of pure cellulosic material with strong acids with controlled temperature, stirring and time. The crystalline nano-cellulose (CNC) was obtained through acid hydrolysis with sulfuric acid (40\%) and then modified with citric acid (1.2M), CNC-Mod, for further characterization and adsorption test of metal cations. The samples produced were characterized by techniques such as STEM-EDS, AFM, XRD, FTIR and TGA. Cobalt nitrate $\left(\mathrm{Co}\left(\mathrm{NO}_{3}\right)_{2}\right)$, Sodium chloride $(\mathrm{NaCl})$ and mercury chloride $\left(\mathrm{HgCl}_{2}\right)$ solutions were placed in contact with cellulose, CNC and CNC-Mod samples for a maximum of 3 hours, then having the solid and supernatant separated. The solid samples obtained in the adsorption process were then subjected to analyzes such as XRD, STEM-EDS and TGA. While the supernatants were analyzed by ICP-OES and the results indicates the occurrence of adsorption for all samples and metallic cations.

\section{Keywords}

Cellulose; Nano-cellulose; Acid hydrolysis; Citric acid; Adsorptio. 


\section{Sumário}

1 Introdução $\quad 16$

$\begin{array}{lll}1.1 & \text { Objetivos } & 17\end{array}$

$\begin{array}{lll}1.2 & \text { Objetivos específicos } & 17\end{array}$

2 Revisão Bibliográfica $r$

$\begin{array}{lll}2.1 & \text { Celulose } & 19\end{array}$

2.2 Nanocelulose 20

2.3 Obtenção de Nanocelulose 20

2.4 Aplicações da Nanocelulose 23

2.5 Funcionalização de celulose e nanocelulose 24

2.5.1 Funcionalização com ácido cítrico 26

2.6 Adsorção de metais e tratamento de efluentes 27

3 Metodologia $\quad 29$

3.1 Obtenção da CNC 29

$\begin{array}{lll}3.2 & \text { Funcionalização da nanocelulose } & 29\end{array}$

3.3 Caracterização da nanocelulose e nanocelulose modificada 29

3.3.1 Microscopia eletrônica de varredura MEV-EDS 30

3.3.2 Análise de espectroscopia de infravermelho com transformada de $\begin{array}{ll}\text { Fourier (FTIR) } & 30\end{array}$

3.3.3 Análise Termogravimétrica (TGA) 30

3.3.4 Potencial zeta 31

3.3.5 Difração de Raios X (DRX) 31

3.3.6 AFM 32

3.4 Adsorção de $\mathrm{Hg}^{2+}, \mathrm{Na}^{+}$e $\mathrm{Co}^{2+} \quad 32$

3.5 Caracterização da nanocelulose após a adsorção 32

3.5.1 Análise elementar 33

3.5.2 Análise Termogravimétrica (TGA) 33

3.5.3 ICP-OES 33

4 Resultados $\quad 34$

4.1 Obtenção da CNC 34

4.2 Funcionalização da nanocelulose 34

4.3 Caracterização da nanocelulose 35

$\begin{array}{lll}\text { 4.3.1 AFM } & 35\end{array}$

4.3.2 Microscopia eletrônica de varredura 38

4.3.3 Análise da CNC por espectroscopia de infravermelho com transformada de Fourier (FTIR) 40

4.4 Caracterização da nanocelulose funcionalizada com ácido cítrico 42

4.4.1 AFM 42

4.4.2 Microscopia eletrônica de varredura 44

4.4.3 Análise da CNC-Mod por espectroscopia de infravermelho com transformada de Fourier (FTIR) 45

4.5 Caracterização via DRX 46 
4.6 Análise Termogravimétrica TGA/DTG 48

4.7 Adsorção 51

4.7.1 MEV e análise termogravimétrica após adsorção de cobalto 54

4.7.2 MEV e análise termogravimétrica após adsorção de sódio $\quad 59$

4.7.3 MEV e análise termogravimétrica após adsorção de mercúrio $\quad 64$

5 Conclusão $\quad 68$

$\begin{array}{lll}6 & \text { Trabalhos futuros } & 70\end{array}$

$\begin{array}{ll}\text { Referências bibliográficas } & 71\end{array}$

A Código Matlab da função do ajuste de sigmoide e cálculo $\begin{array}{ll}\text { de energia de ativação } & 80\end{array}$

B Gráficos do ajuste sigmoide e ajuste linear realizado na análise cinética de degradação Térmica da CEL, CNC e CNC-Mod.

C Gráficos do ajuste sigmoide e ajuste linear realizado na análise cinética de degradação térmica da CEL, CNC e CNC-Mod após a adsorção de cobalto.

D Gráficos do ajuste sigmoide e ajuste linear realizado na análise cinética de degradação térmica da CEL, CNC e CNC-Mod após a adsorção de sódio.

E Gráficos do ajuste sigmoide e ajuste linear realizado na análise cinética de degradação térmica da CEL, CNC e CNC-Mod após a adsorção de mercúrio. 


\section{Lista de figuras}

Figura 2.1 Estrutura química básica da celulose e numeração dos carbonos na unidade repetida da celulose (celobiose). Fonte: Elaborado pelo autor, Software Marvin Sketch Chemaxon.

Figura 2.2 Esquema da reação de hidrólise ácida da celulose. Fonte: Elaborado pelo autor, Software Marvin Sketch Chemaxon.

Figura 2.3 Esquema de modificação da CNC por N,N-Dialquilazetidina apresentado por Börjesson et al.[45]. Os radicais $\mathrm{R}$ podem ser $\mathrm{CH}_{3}$ ou $\left(\mathrm{CH}_{2}\right)_{4} \mathrm{CH}_{3}$. Fonte: Elaborado pelo autor, Software Marvin Sketch Chemaxon.

Figura 2.4 Modificação da celulose da madeira por ácido cítrico proposto por Rodrigues et al. [48]. Fonte: Elaborado pelo autor, Software Marvin Sketch Chemaxon.

Figura 4.1 Possíveis mecanismos de funcionalização da CNC com ácido cítrico. i) reação nos sítios com grupos hidroxilas nativos da celulose ou após possível remoção dos grupos sulfatos pela neutralização [48] ii) reação nos sítios com hidroxilas dos grupos sulfatos [45]. Fonte: Elaborado pelo autor, Software Marvin Sketch Chemaxon

Figura 4.2 Imagem AFM da CNC após tratamento no software Gwyddion 2.55.

Figura 4.3 Diagrama de distribuição de comprimento da CNC. $\quad 37$

Figura 4.4 Diagrama de distribuição de diâmetro da CNC. 37

Figura 4.5 Imagem AFM tridimensional.

Figura 4.6 a) película formada após a secagem de CNC b) Imagem de MEV da CNC com amplificacão de 500x.

Figura 4.7 Imagens de MEV e mapa de EDS dos elementos presentes na superfície da nanocelulose, após hidrólise com $\mathrm{H}_{2} \mathrm{SO}_{4}$ a) CNC com aumento de 2500x b) Mapa de EDS de carbono c) Mapa de EDS de oxigênio d) Mapa de EDS de enxofre.

Figura 4.8 Análise de FTIR da celulose (preto) e CNC (verde).

Figura 4.9 Imagem AFM da CNC-Mod tratada no software Gwyddion 2.55 .

Figura 4.10 Desenho gráfico tridimensional de uma região isolada da CNC-Mod.

Figura 4.11 Imagens de MEV da CNC-Mod a) Amplificação 500x b) Amplificação 2500x.

Figura 4.12 Análise de FTIR da CNC e CNC-Mod.

Figura 4.13 Difratogramas das amostras de a) CEL b) CNC c) CNCMod

Figura 4.14 Diagrama comparativo da degradação térmica das amostras CEL, CNC e CNC-Mod a) tempo de degradação b) DTG c) temperatura.

Figura 4.15 Análise de ICP-OES do sobrenadante pós adsorção de cobalto em CEL,CNC e CNC-Mod. 
Figura 4.16 Análise de ICP-OES do sobrenadante pós adsorção de sódio em CEL, CNC e CNC-Mod.

Figura 4.17 Análise de ICP-OES do sobrenadante pós adsorção de mercúrio em CEL,CNC e CNC-Mod.

Figura 4.18 Imagens de MEV e mapa de EDS da CNC após adsorção de cobalto a) CNC com aumento de 800x b) Mapa de EDS de carbono c) Mapa de EDS de oxigênio d) Mapa de EDS de enxofre e) Mapa de EDS do cobalto.

Figura 4.19 Região de mapeamento do espectro 2 da CNC-Mod-Co, amplificação de 500x.

Figura 4.20 Diagrama comparativo da degradação térmica da CELCo, CNC-Co e CNC-Mod-Co a) tempo de degradação b) DTG c) temperatura.

Figura 4.21 Região mapeada da CEL-Na, espectro 1, amplificação de 1000x.

Figura 4.22 MEV e mapa de EDS da CNC-Na a) CNC com aumento de 800x b) Mapa de EDS de carbono c) Mapa de EDS de oxigênio d) Mapa de EDS de enxofre e) Mapa de EDS do cobalto.

Figura 4.23 MEV e mapa de EDS da CNC-Mod-Na a) CNC-Mod-Na com aumento de 800x b) Mapa de EDS de carbono c) Mapa de EDS de oxigênio d) Mapa de EDS de enxofre e) Mapa de EDS do sódio.

Figura 4.24 Diagrama comparativo da degradação térmica das amostras CEL-Na, CNC-Na e CNC-Mod-Na a) tempo de degradação b) DTG c) temperatura.

Figura 4.25 Região da CNC-Hg mapeada pelo EDS, espectro 1. Amplificação 1000x.

Figura 4.26 Região mapeada, espectro 3, da CNC-Mod-Hg. Amplificação 800x.

Figura 4.27 Espectro pontual da CNC-Mod-Hg indicando a presença de cristais com sódio. Amplificação 800x.

Figura 4.28 Diagrama comparativo da degradação térmica das amostras CEL-Hg, CNC-Hg e CNC-Mod-Hg a) tempo de degradação b) DTG c) temperatura.

Figura B.1 Ajuste sigmoide e ajuste linear realizado na análise cinética de degradação térmica da celulose

Figura B.2 Ajuste sigmoide e ajuste linear realizado na análise cinética de degradação térmica da $\mathrm{CNC}$ a) primeiro pico b) segundo pico.

Figura B.3 Ajuste sigmoide e ajuste linear realizado na análise cinética de degradação térmica da CNC-Mod a) primeiro pico b) segundo pico.

Figura C.1 Ajuste sigmoide e ajuste linear realizado na análise cinética de degradação térmica da CEL-Co. 
Figura C.2 Ajuste sigmoide e ajuste linear realizado na análise cinética de degradação térmica da CNC-Co a) primeiro pico b) segundo pico.

Figura C.3 Ajuste sigmoide e ajuste linear realizado na análise cinética de degradação térmica da CNC-Mod-Co a) primeiro pico b) segundo pico.

Figura D.1 Ajuste sigmoide e ajuste linear realizado na análise cinética de degradação térmica da CEL-Na.

Figura D.2 Ajuste sigmoide e ajuste linear realizado na análise cinética de degradação térmica da CNC-Na.

Figura D.3 Ajuste sigmoide e ajuste linear realizado na análise cinética de degradação térmica da CNc-Mod-Na.

Figura E.1 Ajuste sigmoide e ajuste linear realizado na análise cinética de degradação térmica da CEL-Hg.

Figura E.2 Ajuste sigmoide e ajuste linear realizado na análise cinética de degradação térmica da CNC-Hg..

Figura E.3 Ajuste sigmoide e ajuste linear realizado na análise cinética de degradação térmica da CNC-Mod-Hg a) primeiro pico b) segundo pico. 


\section{Lista de tabelas}

Tabela 4.1 Dimensões apresentadas por amostras comerciais de CNC. Fonte: Reid, Villalobos e Cranston [68]

Tabela 4.2 Análise elementar semi-quantitativa da CNC. Todos os elementos são quantificados em porcentagem mássica.

Tabela 4.3 Principais números de onda e respectivas vibrações apresentadas pelo espectro FTIR para a CEL e CNC.

Tabela 4.4 Análise elementar semi-quantitativa da CNC-Mod. Todos os elementos são quantificados em porcentagem mássica.

Tabela 4.5 Principais números de onda e respectivas vibrações apresentadas pelo espectro FTIR para a CNC e CNC-Mod.

Tabela 4.6 Intensidades dos picos amorfo cristalino e índice de cristalinidade das amostras.

Tabela 4.7 Parâmetros cinétcos ajustados por regressão linear e sigmoide

Tabela 4.8 Resultados de água evaporada em diferentes temperaturas e massa residual após TGA.

Tabela 4.9 Concentração final de metais, em $\mathrm{mg} / \mathrm{L}$, após $3 \mathrm{~h}$ de adsorção.

Tabela 4.10 Resultados em porcentagem mássica da análise elementar semi-quantitativa da adsorção de cobalto pela CNC.

Tabela 4.11 Resultados em porcentagem mássica da análise elementar semi-quantitativa da adsorção de cobalto pela CNC-Mod

Tabela 4.12 Parâmetros cinétcos ajustados por regressão linear e sigmoide após a adsorção de cobalto.

Tabela 4.13 Resultados de água evaporada em diferentes temperaturas e massa residual após TGA.

Tabela 4.14 Porcentagem mássica da análise elementar após adsorção de sódio pela CEL.

Tabela 4.15 Porcentagem mássica da análise elementar após adsorção de sódio pela CNC.

Tabela 4.16 Porcentagem mássica da análise elementar após adsorção de sódio pela CNC-Mod.

Tabela 4.17 Parâmetros cinétcos ajustados por regressão linear e sigmoide após a adsorção de sódio.

Tabela 4.18 Resultados de perda água em diferentes temperaturas e massa residual após TGA das amostras CEL-Na, CNC-Na e CNC-Mod-Na.

Tabela 4.19 Parâmetros cinétcos ajustados por regressão linear e sigmoide após a adsorção de mercúrio.

Tabela 4.20 Resultados de perda água em diferentes temperaturas e massa residual após TGA das amostras CEL-Hg, CNC-Hg e CNC-Mod-Hg. 


\section{Lista de Abreviaturas}

UNESCO - United Nations Educational, Scientific and Cultural Organization

CEL - Celulose

CNC - Celulose Nanocristalina do inglês crystalline nanocellulose

CNC-Mod - Celulose Nanocristalina Modificada com Ácido Cítrico

AFM - Microscopia de Força Atômica

MEV - Microscopia Eletrônica de Varredura

EDS - Energia Dispersiva de Raios-X

TGA - Análise Termogravimétrica

FT-IR - Espectroscopia no Infravermelho com Transformada de Fourier

DRX - Difração de Raios-X

DEPEC - Departamento de Pesquisas e Estudos Econômicos

CNF - Celulose Nanofibrilada

CF - Filamentos de celulose do inglês Cellulose Filaments

MFC - Celulose Microfibrilada

HPH - Homogeneização em alta pressão

ATS - Advanced Technologies and Services

TEMPO - 2,2,6,6-tetrametil-piperidinil-N-oxil

PEC - Proposta de Emenda Constitucional

CONAMA - Conselho Nacional do Meio Ambiente

DEQM - Departamento de Engenharia Química e de Materiais

CBPF - Centro Brasileiro de Pesquisas Físicas

ICP-OES - Espectrometria de Emissão Ótica por Plasma Acoplado Indutivamente do inglês Inductively Coupled Plasma Optical Emission Spectrometry LAATOM - Laboratório de Absorção Atômica

GOF - Godness of Fit

DTG - Termogravimetria Derivada

RMN - Ressonância Magnética Nuclear

ICP-MS - Espectrometria de massa por plasma acoplado indutivamente do inglês Inductively coupled plasma mass spectrometry

CEL-Co - Celulose com Cobalto adsorvido

CNC-Co - Nanocelulose com Cobalto adsorvido

CNC-Mod-Co - Nanocelulose modificada com Cobalto adsorvido 
CEL-Hg - Celulose com Mercúrio adsorvido

CNC-Hg - Nanocelulose com Mercúrio adsorvido

CNC-Mod-Hg - Nanocelulose modificada com Mercúrio adsorvido

CEL-Na - Celulose com Sódio adsorvido

CNC-Na - Nanocelulose com Sódio adsorvido

CNC-Mod-Na - Nanocelulose modificada com Sódio adsorvido

UNESCO - United Nations Educational, Scientific and Cultural Organization

CEL - Celulose

CNC - Celulose Nanocristalina do inglês crystalline nanocellulose

CNC-Mod - Celulose Nanocristalina Modificada com Ácido Cítrico

AFM - Microscopia de Força Atômica

MEV - Microscopia Eletrônica de Varredura

EDS - Energia Dispersiva de Raios-X

TGA - Análise Termogravimétrica

FT-IR - Espectroscopia no Infravermelho com Transformada de Fourier

DRX - Difração de Raios-X

DEPEC - Departamento de Pesquisas e Estudos Econômicos

CNF - Celulose Nanofibrilada

CF - Filamentos de celulose do inglês Cellulose Filaments

MFC - Celulose Microfibrilada

HPH - Homogeneização em alta pressão

ATS - Advanced Technologies and Services

TEMPO - 2,2,6,6-tetrametil-piperidinil-N-oxil

PEC - Proposta de Emenda Constitucional

CONAMA - Conselho Nacional do Meio Ambiente

DEQM - Departamento de Engenharia Química e de Materiais

CBPF - Centro Brasileiro de Pesquisas Físicas

ICP-OES - Espectrometria de Emissão Ótica por Plasma Acoplado Indutivamente do inglês Inductively Coupled Plasma Optical Emission Spectrometry LAATOM - Laboratório de Absorção Atômica

GOF - Godness of Fit

DTG - Termogravimetria Derivada

RMN - Ressonância Magnética Nuclear

ICP-MS - Espectrometria de massa por plasma acoplado indutivamente do inglês Inductively coupled plasma mass spectrometry

CEL-Co - Celulose com Cobalto adsorvido

CNC-Co - Nanocelulose com Cobalto adsorvido 
CNC-Mod-Co - Nanocelulose modificada com Cobalto adsorvido CEL-Hg - Celulose com Mercúrio adsorvido CNC-Hg - Nanocelulose com Mercúrio adsorvido

CNC-Mod-Hg - Nanocelulose modificada com Mercúrio adsorvido CEL-Na - Celulose com Sódio adsorvido

CNC-Na - Nanocelulose com Sódio adsorvido

CNC-Mod-Na - Nanocelulose modificada com Sódio adsorvido 


\section{Introdução}

A água, recurso natural fundamental para praticamente todas as espécies vivas do planeta, apresenta entre suas principais funções o controle de temperatura e meio de intercâmbio de substâncias dos organismos [1].

As regulações acerca das aplicações, tratamentos e destinação das águas têm sido continuamente revisadas visando contornar uma iminente escassez deste recurso, visto as alarmantes evidências. O Relatório Mundial das Nações Unidas sobre Desenvolvimento dos Recursos Hídricos 2015, publicado pela UNESCO, indica a previsão de que até 2030 o planeta sofrerá um déficit de até $40 \%$ de água, caso a gestão deste recurso não seja melhorada significativamente. O relatório homônimo, datado de 2018, estima que cerca de $80 \%$ da água utilizada em diversos processos retorna ao meio ambiente sem o devido tratamento $[2,3]$.

Segundo Zhou et al. [4], tem ocorrido um aumento de problemas ambientais causados por despejos de substâncias químicas, principalmente em corpos hídricos superficiais, paralelamente ao desenvolvimento econômico. O autor afirma que os poluentes destinados aos ambientes aquáticos, oriundos de atividades humanas como galvanização, mineração e fabricação de tintas [5] são carregados com metais pesados tóxicos, como mercúrio, cromo, cádmio, cobre e chumbo.

As espécies metálicas liberadas no meio ambiente tendem a circular nos corpos hídricos e, consequentemente, se acumular nos organismos vivos, representando assim, uma ameaça ao meio ambiente, animais e seres humanos. Entre os efeitos causados pelo acúmulo de metais pesados no organismo humano podem ser citados danos cerebrais e retardo mental, e alguns metais são reconhecidos como potencialmente cancerígenos, mesmo em baixas concentrações [6]. Estes metais somente são removidos do sistema quando imobilizados de forma apropriada e o procedimento para a sua remoção de soluções aquosas geralmente retira uma fração significativa do metal [7].

As principais técnicas utilizadas para a remoção ou redução de metais de soluções aquosas são a precipitação química, a neutralização, a troca iônica, a separação por membranas, osmose inversa, extração por solvente, métodos eletrolíticos e adsorção. Contudo, a aplicação de vários destes métodos se torna 
inviável devido a altos custos operacionais [8]. A adsorção pode ser considerada uma opção de baixo custo e de eficiência elevada para soluções com baixas concentrações [4].

Alguns biopolímeros como a celulose e seus derivados possuem a capacidade de reduzir a concentração de metais em soluções aquosas. O diferencial na utilização de biopolímeros em processos de tratamento de águas e efluentes é o fato destes polímeros serem biodegradáveis e, portanto, seguros para o uso em tratamento de efluentes que retornarão ao meio ambiente. Um atrativo da celulose e derivados é a sua capacidade de sofrer alterações químicas nos grupos funcionais hidroxilas por meio de reação com outros compostos orgânicos e inorgânicos, aumentando assim, a eficiência de remoção de cátions metálicos em solução [9].

Deste modo, o presente trabalho propõe estudar e comparar a adsorção de íons metálicos a citar mercúrio, cobalto e sódio utilizando celulose, nanocelulose e sua derivada a partir da funcionalização com ácido cítrico. Espera-se avaliar a interação das cargas superficiais do adsorvente e os cátions presentes em solução aquosa visando sua potencial utilização para tratamento de águas, e analisar as alterações na resistência à degradação térmica do polímero.

\section{1 \\ Objetivos}

O presente trabalho tem como objetivo estudar as propriedades de adsorção de cátions metálicos por celulose (CEL), nanocelulose (CNC) e nanocelulose com superfície modificada com ácido cítrico (CNC-Mod). A obtenção dos nano cristais será por meio de hidrólise ácida com ácido sulfúrico. O estudo irá permitir a determinação e comparação da capacidade de adsorção de cátions metálicos como o mercúrio, sódio e cobalto usando a celulose, a nanocelulose obtida após hidrólise e após modificação. Os resultados obtidos neste trabalho permitirão realizar uma comparação das características da CEL, CNC e CNC-Mod, avaliar a capacidade de adsorção das amostras para diferentes metais em solução e as alterações nas propriedades destes biopolímeros após a adsorção dos cátions metálicos em questão.

\section{2}

\section{Objetivos específicos}

- Obtenção de nanocelulose por hidrólise ácida com ácido sulfúrico.

- Modificação da nanocelulose com ácido cítrico.

- Caracterização da nanocelulose: 
1. AFM, analisar morfologia e dimensões das fibras;

2. MEV com EDS, realizar análise elementar das amostras de CEL, CNC e CNC-Mod;

3. Potencial zeta, analisar a carga superficial da CNC e seu potencial de aglomeração em meio aquoso;

4. TGA, avaliar o comportamento térmico das amostras.

5. FTIR, analisar a alteração da estrutura química das amostras de CNC e CNC-Mod;

6. DRX, Observar a estrutura cristalina das amostras e determinar o tamanho médio de cristalito;

- Adsorção de mercúrio, sódio e cobalto na celulose, CNC e CNC-Mod observando:

1. Composição das amostras, de maneira semi-quantitativa, usando o MEV com EDS acoplado;

2. Potenciais alterações nas propriedades térmicas dos materiais pós adsorção por meio do TGA;

3. Comportamento dos espectros de FTIR. 


\section{2}

\section{Revisão Bibliográfica}

\section{1}

\section{Celulose}

A celulose é um polímero natural de glicose que tem sido utilizada por milhares de anos em diversos materiais e aplicações. Este biopolímero é a matéria orgânica renovável de maior abundância no mundo com produção nacional aproximada de 19 milhões de toneladas em 2017, 10,81\% da produção mundial. Deste total, 13,3 milhões de toneladas são destinadas à exportação. De acordo com o Departamento de Pesquisas e Estudos Econômicos [10], a produção de celulose segue em grande expansão apresentando consecutivos recordes nos últimos anos, principalmente devido à aquecida demanda na China e Europa [11].

A celulose é composta de 10 a 20 mil monômeros de glicose unidos por ligações glicosídicas $\beta$-1,4 e suas unidades estão torcidas num ângulo de $180^{\circ}$ com relação a sua vizinha, Figura 2.1 [12]. Cada monômero contém três grupos hidroxilas, sendo um grupo primário e dois secundários. Devido à posição equatorial destas hidroxilas, a glicose pode formar ligações de hidrogênio internas o que impede a rotação contribuindo para a rigidez das cadeias de celulose. Deste modo, a presença de ligações de hidrogênio intramolecular e intermolecular nos cristalitos tornam a estrutura bem ordenada, rígida e inacessível à agua e alguns reagentes. Enquanto que, na região amorfa por apresentar ligações fracas de hidrogênio, contribuem para a maior hidrofilicidade e acessibilidade dos materiais celulósicos [13].

$\mathrm{Na}$ natureza a celulose não é encontrada como uma macromolécula individual, mas sim em forma de cadeias. De modo geral, a união de cerca de 36 polímeros de celulose forma as nano fibrilas elementares, que em conjunto geram micro fibrilas que dão origem as fibras de celulose. A nanofibrila elementar é formada por nanocristalitos e defeitos pontuais, como locais vagos entre as fibrilas, que atuam como defeitos estruturais, os quais estão susceptíveis a reações químicas e processos mecânicos que levam à quebra das ligações glicosídicas nestes pontos, resultando na liberação das partículas cristalinas. [14, 13]. 


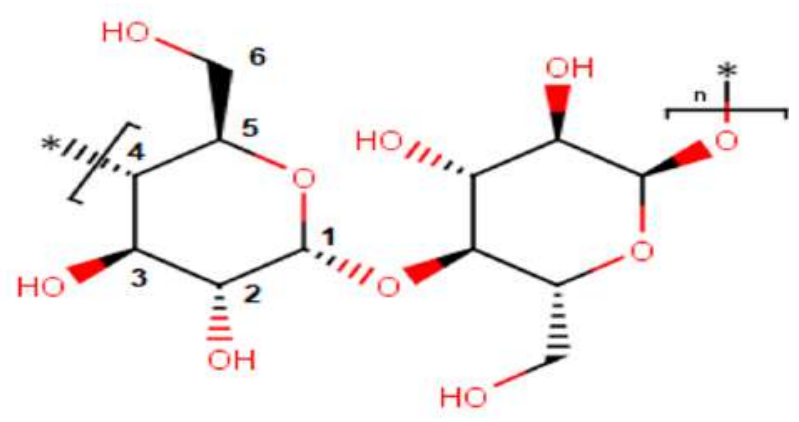

Figura 2.1: Estrutura química básica da celulose e numeração dos carbonos na unidade repetida da celulose (celobiose). Fonte: Elaborado pelo autor, Software Marvin Sketch Chemaxon.

\section{2}

\section{Nanocelulose}

A nanocelulose tem sido objeto de diversos estudos com publicações em áreas distintas como tratamento de água e efluentes, médica, alimentícia e materiais. O Brasil participa com $5,2 \%$ do total de publicações referentes à nanocelulose [15]. De acordo com Daud e Lee [16], o interesse de pesquisar a nanocelulose se dá pelas propriedades químicas e físicas da celulose e a possibilidade de ser quimicamente funcionalizada por diversas reações devido a presença dos grupos hidroxilas em sua estrutura.

Por definição, a nanocelulose tem ao menos uma dimensão inferior a 100 nm. Dois tipos de nanocelulose se encaixam nessa definição: nanocristais de celulose (CNC), e nanofibrilas de celulose (CNF). Alguns materiais são referidos como nanocelulose, mas não estão em nanoescala, por exemplo filamentos de celulose $(\mathrm{CF})$ e celulose microfibrilada (MFC) que se encontram em microescala. Estes materiais são mencionados em conjunção com a nanocelulose e são destinados para algumas das mesmas aplicações da CNC e CNF [17].

\section{3}

\section{Obtenção de Nanocelulose}

A nanocelulose pode ser obtida a partir de diversas fontes, pode-se citar como exemplos de matéria prima, a planta de milho [18], pseudocaule da bananeira [19], bagaço de cana-de-açúcar [20], fibras naturais como sisal [21], [22] e algodão [23]. Entretanto, a fonte principal é a polpa de celulose kraft obtida a partir de eucalipto.

Diversos métodos têm sido estudados para a obtenção de nanocelulose. Estes podem promover modificações de caráter químico, físico-químico e físico da celulose resultando em possíveis alterações da sua estrutura cristalina e 
amorfa. A MFC pode ser produzida a partir da celulose purificada por meio de refino mecânico intenso [24] e por homogeneização em alta pressão (HPH) [25]. A CNF é geralmente produzida por refino mecânico da celulose por homogeneização de alta pressão (HPH) sem pré-tratamento [26]. As suspensões resultantes exibem um claro aumento na viscosidade após várias passagens pelo homogeneizador. A CNF tende a formar um gel aquoso em baixa concentração, devido ao forte aumento na área de superfície específica em comparação com o das fibras de celulose nativas [14].

Li et al. [27] realizaram a produção de CNF a partir de polpa de celulose de bagaço-de-cana. A HPH foi realizada utilizando uma solução $1 \%(\mathrm{~m} / \mathrm{m})$ de celulose/líquido iônico de cloreto de 1-butil-3-metilimidazolio, em um homogeneizador AH100D, ATS Engineering Inc., Canada, sob pressões de 40 a $140 \mathrm{MPa}$ e por até 50 ciclos de homogeneização. A celulose foi então precipitada pela adição de água e seca a vácuo. Os resultados apresentados, considerando as dimensões das partículas e fatores econômicos, indicam que a condição ótima para o processo é em pressão de $80 \mathrm{MPa}$ e com 30 ciclos de homogeneização. Este processo resultou em redução do tamanho médio de partícula de 1300nm para 300nm. Visto o alto consumo de energia do processo de homogeneização em alta pressão, a oxidação mediada por 2,2,6,6-tetrametil-piperidinil-N-oxil (TEMPO), a carboximetilação, a hidrólise enzimática e outros pré-tratamentos podem ser utilizados para diminuir este consumo durante o subsequente refino [28].

Nunes [29] produziu CNF a partir de fibras de pinho e polpa kraft de eucalipto branqueada realizando pré-tratamento com oxidação mediada por TEMPO seguida de homogeneização mecânica. Para a oxidação, utilizou-se 0,016g de TEMPO, além de $\mathrm{NaClO} 4$ a 6 mmol, NaBR 0,1g e $\mathrm{NaOH}$ em quantidade variável para manter o $\mathrm{pH}$ do meio reacional próximo a 11 . A homogeneização em alta pressão foi realizada em um equipamento GEA Niro Soavi do tipo PANDA PLUS 2000, o qual atinge pressão de até 2000 bar. Os resultados obtidos indicam que o refino mecânico reduz o comprimento das fibras, permanecendo o diâmetro semelhante ao obtido após a oxidação com TEMPO. Além disso, constatou-se que a CNF produzida a partir de pinho apresenta dimensões maiores que as produzidas por eucalipto.

A CNC é gerada pela divisão de domínios amorfos e pela quebra de contatos cristalinos locais entre nano fibrilas, através de hidrólise com ácidos concentrados como $\mathrm{HCl}$ e $\mathrm{H}_{2} \mathrm{SO}_{4}$. Este processo é seguido por tratamentos mecânicos ou ultra-sônicos. Uma característica importante do uso do ácido sulfúrico é a carga negativa gerada na CNC devido à formação de grupos éster de sulfato, promovendo um aumento da estabilidade de fase em meio aquoso 
[14].

O processo de hidrólise ácida, Figura 2.2, se dá devido à diferença na cinética da reação para as regiões cristalina e amorfa da celulose. Neste processo, a região amorfa e os defeitos são preferencialmente hidrolisados, permanecendo apenas as regiões cristalinas. Os procedimentos mais aplicados para a produção de nano cristais de celulose consistem na reação de material celulósico puro com ácidos fortes com temperatura e tempo de reação controlados [30].

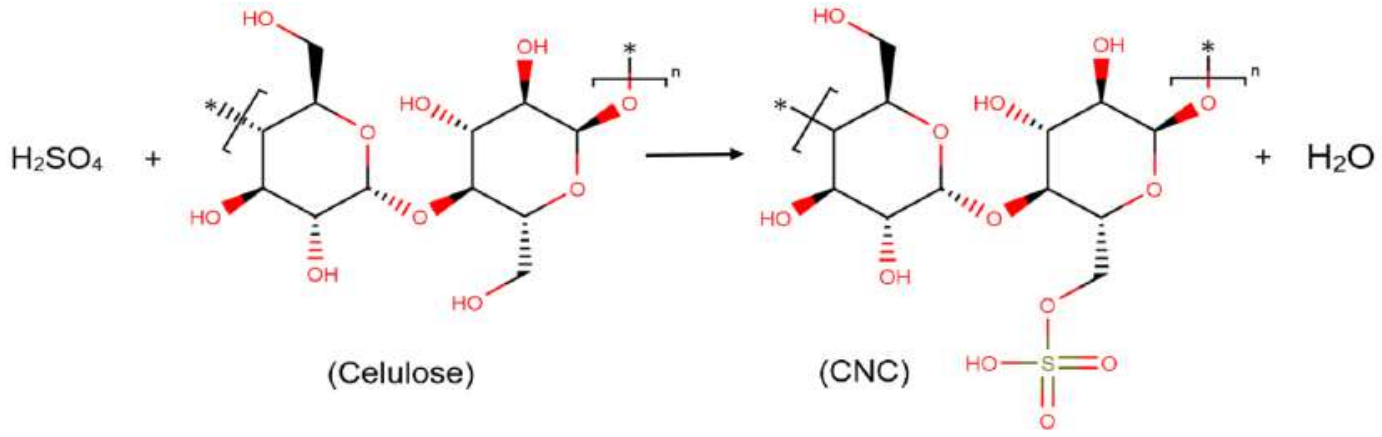

Figura 2.2: Esquema da reação de hidrólise ácida da celulose. Fonte: Elaborado pelo autor, Software Marvin Sketch Chemaxon.

Para a produção de CNC, a celulose deve ser hidrolisada de maneira direta. Assim, exceto para os casos de celulose de alta pureza como algodão, polpa branqueada e celulose bacteriana, deve-se realizar diferentes pré-tratamentos para a remoção de impurezas como extrativos e lignina. Um processo de purificação alcalina, com $\mathrm{NaOH}$ ou $\mathrm{KOH}$, seguido por branqueamento (que pode ser com compostos clorados, $\mathrm{Cl}_{2}$ e $\mathrm{ClO}_{2}$, ou compostos oxidantes contendo oxigênio como $\mathrm{O}_{2}, \mathrm{O}_{3}$, e $\mathrm{H}_{2} \mathrm{O}_{2}$ ) é realizado para purificar a celulose. O processo alcalino solubiliza as pectinas e hemicelulose. Enquanto que, o branqueamento quebra os compostos presentes na lignina e remove os coprodutos do processo [13].

Teodoro et al. [21] produziram a CNC, a partir de fibra de sisal branqueada, por hidrólise com solução $60 \%(\mathrm{~m} / \mathrm{m})$ de ácido sulfúrico em três diferentes condições de temperatura e tempos de reação: $45^{\circ} \mathrm{C}$ e 60 minutos (WS45_60); $45^{\circ} \mathrm{C}$ e 75 minutos (WS45_75) e, $60^{\circ} \mathrm{C}$ e 30 minutos (WS60_30). De acordo com Habibi, Lucia e Rojas [30], a concentração de ácido sulfúrico em processos de hidrólise ácida pode variar de $40 \%$ a $65 \%$ em massa, e o tempo de reação varia de acordo com a temperatura do processo, que pode chegar a $70^{\circ} \mathrm{C}$. Com o aumento da temperatura e com tempos de reação prolongados ocorre a redução do comprimento do nanocristal e aumento na carga superficial. Wulandari et al. [20] afirmam que quando a concentração de ácido utilizada no processo de hidrólise é muito alta, acima de $60 \%$ por exemplo, a região cristalina pode 
ser danificada e o índice de cristalinidade diminuir. Os resultados apresentados por Teodoro et al. [21] indicam que a amostra WS60_30 apresenta menores dimensões e maior razão de aspecto, relação comprimento/diâmetro (L/D), além de índice de cristalinidade maior e carga superficial de $-25 \mathrm{mV}$.

Teixeira et al. [23] utilizaram fibras de algodão comercial para a obtenção de CNC. O processo de hidrólise ácida foi conduzido a $45^{\circ} \mathrm{C}$ e 75 minutos sob condições distintas (ácido sulfúrico $60 \%$ (m/m), ácido clorídrico 1M e mistura $\mathrm{H}_{2} \mathrm{SO}_{4}: \mathrm{HCl}[1: 1 ;(\mathrm{v} / \mathrm{v})]$. Os autores observaram uma relação direta entre a carga superficial e a dispersão da suspensão devido às repulsões eletrostáticas. Este efeito, pôde ser observado pela aglomeração das partículas nas amostras produzidas a partir do $\mathrm{HCl}$, que apresentou carga superficial de -6,29 $\mathrm{mV}$. Enquanto que, as amostras produzidas a partir do $\mathrm{H}_{2} \mathrm{SO}_{4}$ apresentaram carga superficial de $-31 \mathrm{mV}$, e -15,7 mV para a solução $\mathrm{H}_{2} \mathrm{SO}_{4} / \mathrm{HCl}$.

Ioelovich [31] realizou estudo da conversão da polpa kraft de celulose e fibras algodão em micro e nanocelulose durante o processo de hidrólise ácida. Para este estudo, utilizou-se soluções diluídas (1-3M) e concentradas (7-9M) de ácido sulfúrico, em temperatura de ebulição e entre $40-60^{\circ} \mathrm{C}$ respectivamente, todos com duração de 1h. Constatou-se, a partir dos resultados obtidos, uma redução significativa no grau de polimerização, entre 140 e 180, para a polpa kraft e fibras de algodão, das amostras que sofreram processo com ácido diluído. E redução entre 100 e 120 após processo com ácido concentrado. Observou ainda, aumento no índice de cristalinidade de 0,63 da celulose kraft para até 0.8 no processo com concentração de $9 \mathrm{M}$.

\section{4}

\section{Aplicações da Nanocelulose}

As propriedades físicas, químicas e biológicas apresentadas pela nanocelulose como grande área superficial, alta resistência mecânica (Módulo de Young de até 160 GPa e resistência a tensão de 3 GPa), além de acessibilidade para funcionalizações indicam um alto potencial para diversas aplicações [16].

Os materiais à base de nanocelulose em geral apresentam propriedades morfológicas, físicas, térmicas, elétricas, ópticas e químicas que podem ser alteradas, podem apresentar efeitos antimicrobianos e biocompatibilidade com baixa toxicidade. Além disso, são materiais renováveis, com alta disponibilidade e de baixo custo, a depender do processo de obtenção e da matéria-prima. Deste modo, os materiais de nanocelulose se apresentam como promissores para diversas aplicações industriais, tecnológicas e biomédicas [32].

No setor energético, algumas aplicações industrias da nanocelulose estudadas são o seu uso como separador poroso em baterias íon-lítio [33, 34] e em 
forma de compósito com grafeno e sílica para uso como anodo para baterias recarregáveis flexíveis de lítio [35]. Outro destaque neste setor são os estudos para a utilização da nanocelulose em materiais supercapacitores. Kang et al. [36] produziram películas de nanocelulose e eletrólitos de gel de polímero à base de líquido iônico recoberto por nano tubos de carbono para aplicação como supercapacitores visando sua utilização em dispositivos de armazenamento de energia flexíveis e de alta performance.

Um alto número de estudos tem sido realizado na aplicação de nanocelulose em tratamento de água e efluentes como adsorvente em soluções aquosas [37], em forma de membranas de ultra filtração para separação de partículas e moléculas [38], de bactérias e vírus [39, 40], e membranas para separação de emulsão óleo/água [41]. Há ainda, diversos estudos de aplicações de membranas em áreas médicas como na hemodiálise [42].

\section{5}

\section{Funcionalização de celulose e nanocelulose}

A presença dos três grupos hidroxilas na unidade de glicose, torna a celulose uma molécula quimicamente ativa. As reações que podem ocorrer com a celulose são as mesmas descritas para o grupo funcional dos álcoois, podendo formar derivados como ésteres, éteres e aldeídos dependendo da classificação do grupo álcool. Na celulose, a hidroxila ligada ao carbono 6 é classificada como álcool primário enquanto as hidroxilas ligadas aos carbonos 2 e 3 são classificadas como álcoois secundários [13].

Algumas das aplicações mais importantes para a celulose atualmente são a produção de papel, papelão e embalagens biodegradáveis, membranas, tecidos e têxteis, explosivos e materiais estruturais. Entretanto, uma maior amplitude de aplicações se torna limitada uma vez que o polímero se apresenta insolúvel diante de certos solventes. O mesmo se aplica à nanocelulose, Daud Lee [16] afirmam que devido à presença das hidroxilas, a nanocelulose tende a formar agregados em diversos solventes apolares. Deste modo, uma maneira de tornar tanto a celulose quanto a nanocelulose hidrofóbicas é promover a substituição dos grupos hidroxilas por outros grupos funcionais[12].

De acordo com Hokkanen et al. [43], o processo de enxertar monômeros, inserir grupos funcionais por ligação covalente, à estrutura da celulose, é considerada uma ferramenta importante na modificação deste polímero. Além disso, diferentes propriedades são adicionadas ou melhoradas pela inserção de novos grupos funcionais.

A finalidade de cada modificação está intrinsecamente ligada à propriedade que se deseja obter com o produto final. Segundo Ferreira et al. [44], 
derivados carboxilados de microcelulose cristalina são adequados para diversas aplicações, entre elas cosméticas, farmacêuticas, em concretos, além de utilização em adsorção de metais em solução aquosa como $\mathrm{Cu}^{2+}, \mathrm{Cd}^{2+} \mathrm{Cr}^{6+}$, $\mathrm{Co}^{2+}, \mathrm{Ni}^{2+}, \mathrm{Ca}^{2+}$ e $\mathrm{Mg}^{2+}$. Hokkanen et al., [43] indicam, para obtenção de propriedades de adsorção, a modificação da nanocelulose com grupos funcionais carbonila, amina, nitrila entre outros.

Börjesson et al. [45] realizaram a funcionalização da CNC, obtida por hidrólise com $\mathrm{H}_{2} \mathrm{SO}_{4}$, utilizando sais de azetidina para estudo de um possível aumento da estabilidade térmica de compósitos de nanocelulose. A estabilidade térmica foi avaliada por análise termogravimétrica e os resultados indicam um aumento na temperatura inicial de degradação em até mais de $100^{\circ} \mathrm{C}$. O modelo proposto pelo autor indica a substituição do hidrogênio da hidroxila do grupo sulfato pela molécula azetidina, Figura 2.3.
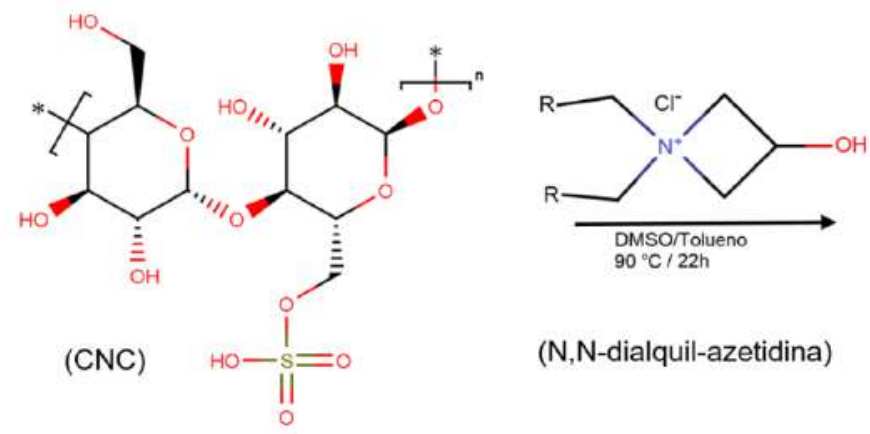

(N,N-dialquil-azetidina)

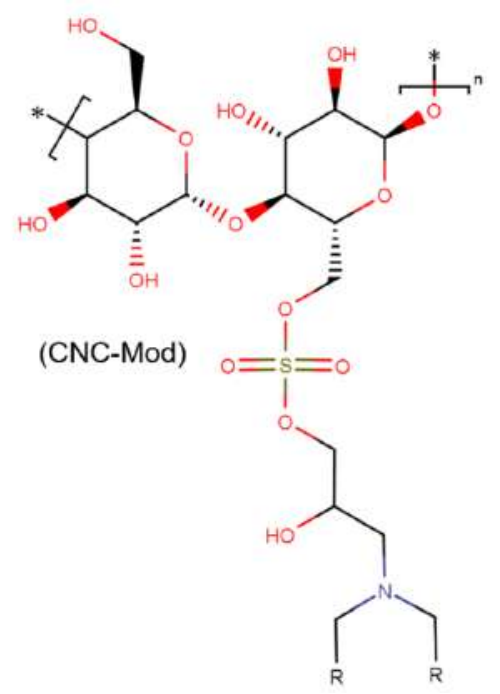

Figura 2.3: Esquema de modificação da CNC por N,N-Dialquil-azetidina apresentado por Börjesson et al.[45]. Os radicais $\mathrm{R}$ podem ser $\mathrm{CH}_{3}$ ou $\left(\mathrm{CH}_{2}\right)_{4} \mathrm{CH}_{3}$. Fonte: Elaborado pelo autor, Software Marvin Sketch Chemaxon.

Bansal et al. [46] funcionalizaram a CNF com L-Cisteína visando a posterior adsorção de mercúrio. De acordo com os autores, a introdução de grupos (-SH) na estrutura da celulose é uma maneira de produzir adsorventes eficientes pois este grupo se liga fortemente a cátion $\mathrm{Hg}^{2+}$. A modificação foi bem-sucedida e ocorreu pela reação dos grupos carboxila da L-cisteína gerando um éster, de modo similar ao apresentado por Börjesson et al. [45]. Os resultados indicaram o uso de $\mathrm{pH}$ do meio menor que 7 para evitar a precipitação do mercúrio. 


\subsection{1}

\section{Funcionalização com ácido cítrico}

A modificação de madeira, Pinus merkussii, com ácido cítrico foi estudada por Low, Lee e Mark [47] para a adsorção de $\mathrm{Cu}^{2+}$ e $\mathrm{Pb}^{2+}$. Nenhum pré-tratamento foi reportado e a madeira foi diretamente reagida em tempo e temperatura variável, e em diferentes proporções ácido/madeira. As condições ótimas determinadas pelos autores foram de temperatura de $140^{\circ} \mathrm{C}$, tempo de reação de 30 minutos e concentração de ácido cítrico de 1,2M. As condições de adsorção foram definidas em temperatura ambiente, com proporção solução/madeira de 20/0,1 e agitação a 150rpm. Os autores citam o processo de esterificação entre os grupos carboxila do ácido cítrico e as hidroxilas da superfície da madeira o que aumenta a quantidade de grupos carboxilas em sua superfície e, consequentemente, aumenta a capacidade de adsorção de cátions metálicos.

Rodrigues et al. [48] realizaram a modificação de serragem de madeira de Paraju (Manilkara longifoli), pré-tratada com NaOH. O processo de funcionalização foi realizado com ácido cítrico 1,2 M em temperatura ambiente, numa proporção de 8,3 mL de solução para $1 \mathrm{~g}$ de madeira e com tempo de contatto de 30 min. O produto da reação foi utilizado em processo de adsorção de metais pesados (cádmio e cobre). Os autores descrevem que a reação ocorre pela a substituição do hidrogênio do grupo hidroxila por grupos citrato na superfície da celulose contida no resíduo de madeira, o que pode ser comprovado por meio da espectroscopia de infravermelho com transformada de Fourier (FTIR). O modelo de reação proposto pelo autor é apresentado na Figura 2.4.

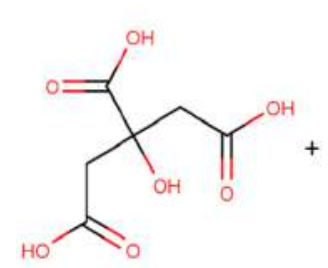

(Ácido Cítrico)

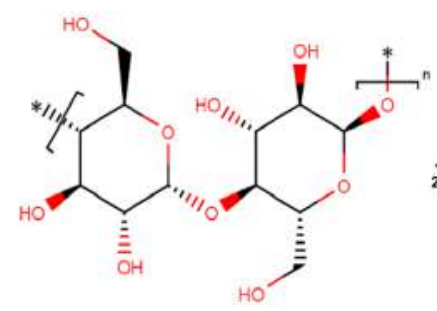

(Celulose)

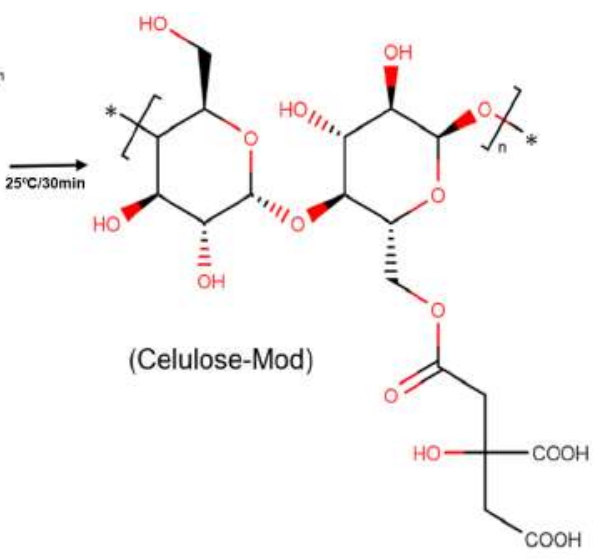

Figura 2.4: Modificação da celulose da madeira por ácido cítrico proposto por Rodrigues et al. [48]. Fonte: Elaborado pelo autor, Software Marvin Sketch Chemaxon. 


\section{6}

\section{Adsorção de metais e tratamento de efluentes}

De acordo com Aith e Rothbarth [49] a água, se caracteriza como um bem essencial para a subsistência humana e seu reconhecimento como um direito social obrigatório é um fato recente e ainda necessita melhor definição regulamentar, sendo somente protegida de forma genérica. No Brasil, a constituição Federal de 1988 [50] não reconhece o acesso à água entre os direitos sociais obrigatórios. Entretanto, a PEC 258/2016 [51] tem por objetivo incluir a água no Art. $6^{\mathrm{o}}$ da Constituição Federal como direito fundamental.

Os valores limites de emissões de metais pesados em corpos hídricos em território brasileiro são regulamentados pelas resoluções 357/2005 e 430/2011 do Conselho Nacional de Meio Ambiente (CONAMA). Estas normas ambientais exigem que as águas residuais sejam devidamente tratadas, respeitando os limites legais estabelecidos [52].

Os limites estabelecidos para a emissão de metais em ambiente aquático dependem de fatores como a classificação do corpo hídrico receptor. Esta classificação é definida pela resolução 357/2005 e é subdividida em, classe especial, classe I, classe II, classe III, classe IV e classe V. Sendo suas caracteriscas váriaveis de acordo com o tipo de água, que podem ser doce, salina e salobra. O uso das águas em suas diferentes classes variam de preservação dos ambientes aquáticos em unidades de conservação de proteção integral (classe especial) a águas somente para navegação e harmonia paisagística (classe V).

A resolução 430/2011 estabelece em seu Art. $5^{\circ}$ que os efluentes não podem alterar as características de qualidade definidas, com parâmetros específicos, para o corpo receptor. E, estabelece ainda as condições e padrões para a emissão de efluentes. O valor estipulado para a emissão de mercúrio total pela resolução 430/2011 é de $0.01 \mathrm{mg} / \mathrm{L}$, não havendo menção às emissões de cobalto e níveis tolerantes de sódio nesta resolução.

A resolução 357/2005 estabelece a classificação de corpos hídricos, diretrizes, condições e padrões para o enquadramento de águas superficiais. Esta resolução estabelece ainda, limites individuais para cada substância em cada classe. Os índices de cobalto que determinam o enquadramento na classificação de qualidade de corpos hídricos de água doce são de $0,05 \mathrm{mg} / \mathrm{L}$ em águas de classe I e II, e 0,2 mg/L em águas de classe III. Não há índices de cobalto para a classificação nas condições de água salina e salobra. Os parâmetros de mercúrio são definidos para classe I e II em 0,0002 mg/L e para classe III em 0,002 mg/L. E para águas salinas e salobras, o mercúrio tem limite de 0,0002 $\mathrm{mg} / \mathrm{L}$ para classe I e 1,8 $\mathrm{\mu g} / \mathrm{L}$ para a classe II.

Em nenhuma das resoluções citadas, que estabelecem os parâmetros de 
emissão (430/2011) e as condições e padrões de classificação dos corpos hídricos (357/2005), são mencionados níveis limites de sódio. A resolução 357/2005 somente define a classificação de águas salinas e salobras de acordo com o grau de salinidade da água, relação entre os sais dissolvidos e massa de água. As águas salinas são definidas como águas com salinidade igual ou superior a $30 \%$ e águas salobra como águas com salinidade superior a 0,5\% e inferior a $30 \%$.

As principais técnicas utilizadas para a remoção ou redução de metais de soluções aquosas são a precipitação química, a neutralização, a troca iônica, a separação por membranas, osmose inversa, extração por solvente, métodos eletrolíticos e adsorção [8]. Comparando os métodos supracitados, cada um possui diferentes vantagens e limitações, a precipitação química, por exemplo, é um método de relativo baixo custo, entretanto não é capaz de remover íons metálicos a níveis de traço. A troca iônica, é uma técnica bem desenvolvida e de bom custo benefício que reduz os íons metálicos a nível de ppm, porém apresenta certa ineficácia quando em soluções com diversos íons mono e bivalentes.

A adsorção se mostra uma opção econômica, além de ser uma técnica de fácil manuseio e eficiência relativamente alta na remoção de íons em soluções aquosas, principalmente quando as concentrações dos íons se encontram em níveis médios ou baixos [4, 9]. A adsorção se baseia no conceito de transferência de massa na qual os sólidos acumulam certas substâncias em sua superfície promovendo a separação dos componentes em solução, adsorvatos. Um fator importante nos processos de adsorção é a superfície externa do adsorvente por quantidade de massa do mesmo. Assim, quanto maior a área superficial, mais favorecida será a adsorção [53]. Entretanto, fatores como efeito estérico, incompatibilidade do sítio com o adsorvato e possíveis modificações na superfície do material podem reduzir consideravelmente o potencial de adsorção de um sólido, mesmo que este possua uma grande área superficial [54].

Os processos de adsorção podem ser classificados, com relação à sua intensidade, em fisissorção e quimissorção. Na primeira, a interação do adsorvato com a superfície do sólido adsorvente envolve um mecanismo físico o qual possui ligação relativamente fraca sendo relacionada às forças de Van der Waalls, um característica deste tipo de adsorção é a rapidez do processo e sua reversibilidade [53, 55]. A segunda, envolve uma reação química, ligação mais forte, entre o adsorvato e os sítios ativos do adsorvente [53].

A celulose,e seus diferentes derivados pós modificação química têm se apresentado como potenciais agentes de adsorção de íons metálicos como chumbo [5, 47, 56, 57, 58], mercúrio [4, 59], cromo [60, 61], cádmio [5, 56], cobre $[47,62,63]$, zinco [56], prata [62], ferro [62], níquel [63] e cobalto [59, 64]. 


\section{Metodologia}

\section{1}

\section{Obtenção da CNC}

A obtenção de nanocelulose foi realizada por hidrólise ácida com solução de ácido sulfúrico $\left(\mathrm{H}_{2} \mathrm{SO}_{4}\right) 40 \%(\mathrm{~m} / \mathrm{m}) .20 \mathrm{~mL}$ do ácido foi aquecido à $60^{\circ} \mathrm{C}$ e em seguida adicionou-se, sob agitação constante, 1 g de $\alpha$-celulose Sigma Aldrich. Após 30 minutos de reação, adicionou-se $50 \mathrm{~mL}$ de água deionizada, aproximadamente $4^{\circ} \mathrm{C}$, para interromper o processo de hidrólise. Completou-se o volume para $100 \mathrm{~mL}$ com água deionizada e o material foi centrifugado em centrífuga Cientec CT-6000, do departamento DEQM PUC-Rio, por 8 minutos a $5800 \mathrm{rpm}$ sendo o sobrenadante descartado e a nanocelulose lavada com a adição de $200 \mathrm{~mL}$ de água deionizada. O processo de lavagem foi realizado duas vezes. Após a centrifugação e lavagem, a nanocelulose passou por processo de ultrassom em banho Ultronic, Q1.8/40A por 10 minutos.

\section{2}

\section{Funcionalização da nanocelulose}

A modificação da nanocelulose foi realizada com solução de ácido citríco 1,2 M. Para o procedimento, ajustou-se o pH da nanocelulose para aproximadamente 7, visando a uma possível substituição dos grupos sulfato por hidroxilas. Então, realizou-se a lavagem com água destilada seguida de centrifugação, para a remoção dos excessos de sulfato em solução. Em seguida, em um erlenmeyer, adicionou-se $1 \mathrm{~g}$ da CNC úmida e $20 \mathrm{~mL}$ de ácido cítrico. A suspensão resultante foi misturada em Shaker de bancada Cientec CT-712RNT a $150 \mathrm{rpm}$ e temperatura ambiente por 30 minutos. Decorrido o tempo de reação, a amostra de nanocelulose modificada (CNC-Mod) foi centrifugada, em centrífuga Cientec CT-6000, por 8 minutos a 5800rpm e, posteriormente, lavada com água deionizada.

\section{3}

\section{Caracterização da nanocelulose e nanocelulose modificada}




\subsection{1}

\section{Microscopia eletrônica de varredura MEV-EDS}

Após o processo de obtenção por hidrólise ácida, para a análise da morfologia das fibras secas, a verificação dos elementos presentes na superfície da nanocelulose e para a confirmação da modificação da superfície da CNC, de forma semi-quantitativa, utilizou-se o MEV TM3000 Hitachi com periférico acoplado do tipo EDS Swift ED 3000, ambos pertencentes ao DEQM PUC-Rio. Uma alíquota da amostra de CNC foi seca em temperatura ambiente por 3648 horas, e então uma pequena quantidade foi depositada sobre a fita adesiva de carbono aderida ao porta-amostras. A análise foi realizada utilizando-se o Software SwiftED 1.7.3.0 da Oxford Instruments Analytical Limited.

\subsection{2}

\section{Análise de espectroscopia de infravermelho com transformada de Fourier (FTIR)}

A nanocelulose, seca em temperatura ambiente foi pesada $(0,002 \mathrm{~g})$, macerada com 0,198 g de KBr e, em seguida, prensada para a obtenção das pastilhas. As pastilhas foram analisadas utilizando um espectrômetro Perkin Elmer Frontier FT-IR, pertencente ao DEQM PUC-Rio. Os espectros de transmitância por número de onda obtidos foram avaliados de acordo com a sua relação com grupos funcionais específicos da cadeia celulósica.

\subsection{3}

\section{Análise Termogravimétrica (TGA)}

Por meio da análise termogravimétrica, TGA, avaliou-se a temperatura de degradação das amostras CEL, CNC e CNC-Mod com equipamento do DEQM PUC-Rio Netzsch STA 449 F3 Jupiter TGA, em atmosfera de nitrogênio, com taxa de aquecimento de $20 \mathrm{~K} /$ min e intervalo de temperatura de $25^{\circ} \mathrm{C}$ a $600^{\circ} \mathrm{C}$, com camada protetiva. A cinética de reação de degradação térmica da CNC foi calculada de acordo com a equação 1 [65].

$$
\left(\phi+T_{r}\right)^{2} \frac{d^{2} f}{\frac{d t^{2}}{d t}}=-n\left[\frac{\left(\phi+T_{r}\right)^{2}\left(\frac{d f}{d t}\right)}{1-f}\right]+\frac{E_{a} \phi}{R}
$$

Onde:

$\mathrm{T}_{r}=$ Temperatura ambiente (definida como a temperatura onde a taxa de reação é infinitamente pequena);

$\phi=$ taxa de aquecimento utilizada no equipamento;

$\left(\phi+\mathrm{T}_{r}\right)=$ é a função da temperatura $\mathrm{T}$ em um dado tempo t;

$\mathrm{n}=$ ordem da reação de decomposição da amostra; 
$E_{a}=$ energia de ativação da reação;

$\mathrm{f}=$ conversão cujo o cálculo é dado pela razão entre a perda de massa em um ponto $(\mathrm{w})$ e a máxima perda de massa $\left(\mathrm{w}^{\infty}\right)$

$$
f=\frac{w}{w^{\infty}}
$$

$\frac{d f}{d t}$ e $\frac{d^{2} f}{d t^{2}}=$ obtidos através de ajuste em uma função sigmoidal por rotina de Fminsearch (Matlab R2019b), Apendice A.

Os gráficos de ajuste do sigmoide e ajuste linear nos picos são apresentados nos resultados de TGA/DTG, Apêndice B. A linearização dos ajustes permite a determinação dos valores relacionados a Eq.1 sendo o coeficiente linear $\frac{\left(E_{a} \phi\right)}{R}$, e a partir deste, obteve-se o valor calculado da energia de ativação. Os valores dos coeficientes angulares, de acordo com a equação 1, são os valores calculados da ordem da reação, n.

A partir dos resultados de TGA, determinou-se a porcentagem de água perdida em $50^{\circ} \mathrm{C}[21,22]$ e em $100^{\circ} \mathrm{C}[66,67]$, como também a quantidade de massa residual [67].

\subsection{4}

\section{Potencial zeta}

A análise de potencial zeta foi realizada visando monitorar a variação do potencial elétrico na interface CNC-solução. Para este fim, utilizou-se o equipamento Nano-ZS, Nano series, Zetasizer do DEQM-PUC-Rio. O pH da suspensão de nanocelulose foi ajustado para próximo de 10. Em seguida, uma alíquota de $15 \mathrm{ml}$ da suspensão de CNC, com concentração aproximada de 200 ppm, foi depositada no equipamento. As medidas foram realizadas, para a CNC no intervalo de $\mathrm{pH}$ entre 10 e 3.

\subsection{5}

\section{Difração de Raios X (DRX)}

Realizou-se a Difração de Raios X em Difratômetro X'Pert PRO PANalytical B.V.), localizado no Laboratório de Cristalografia e Difração de Raio-X do Centro Brasileiro de Pesquisas Físicas, CBPF. Os dados obtidos foram ajustados no software TOPAS, Bruker AXS, versão 5 por implementação do método de Rietveld para a determinação do tamanho médio do cristalito e índice de cristalinidade. O índice de cristalinidade (IC) foi calculado usando a Equação 2 [68].

$$
C I(\%)=\frac{I_{22,5}-I_{18}}{I_{22,5}} x 100
$$


Neste método, para a celulose I, relaciona-se as intensidade dos picos em $2 \theta=22,5^{\circ}$ (região cristalina) $\left(I_{22,5}\right)$ e em $2 \theta=18^{\circ}\left(I_{18}\right)[68,69]$.

\subsection{6}

AFM

Alíquotas de 0,5 mL das amostras de CNC e CNC-Mod foram diluídas em $100 \mathrm{~mL}$ de água deionizada e homogeneizadas em banho ultrassom Ultronic, Q1.8/40A por 8 minutos. Em seguida, depositou-se em suporte de silício uma gota de $20 \mu \mathrm{L}$, a amostra foi seca a vácuo por $3 \mathrm{~h}$.

A análise foi realizada em Microscópio de Força Atômica (AFM) Bruker AFM multi mode 8, operado por software Nanoscope $V$ controller versão 7.3 e Nanoscope software 8.1. O equipamento utilizado pertence ao Departamento de Química da PUC-Rio.

O tratamento das imagens obtidas para a remoção de ruídos e a análise de dimensões das partículas foi realizado pelo software de distribuição livre Gwyiddion versão 2.55 .

\section{4}

\section{Adsorção de $\mathrm{Hg}^{2+}, \mathrm{Na}^{+}$e $\mathrm{Co}^{2+}$}

Para os ensaios de adsorção, utilizou-se amostras de celulose (CEL), nanocelulose, (CNC) e nanocelulose modificada com ácido cítrico (CNC-Mod). Uma amostra de $1 \mathrm{~g}$ de celulose foi submetida a um processo de hidratação em $50 \mathrm{~mL}$ de água deionizada por 12 h. A suspensão das amostras CEL, CNC e CNC-Mod com o pH devidamente ajustado foram centrifugadas em centrifuga refrigerada Cientec CT-6000R por 8 minutos a 5800 rpm, sendo o sobrenadante descartado. Em diferentes erlenmeyers de $250 \mathrm{~mL}$ adicionou-se $1 \mathrm{~g}$ de cada amostra úmida e $100 \mathrm{~mL}$ de solução $0,5 \mathrm{~g} / \mathrm{L}$ de cloreto de mercúrio, $\mathrm{HgCl}_{2}$. A solução foi mantida sob agitação constante por diferentes tempos, 45 min, $90 \mathrm{~min}, 135 \mathrm{~min}$ e $180 \mathrm{~min}$ a $150 \mathrm{rpm}$ em incubadora Shaker de bancada Cientec CT-712RNT em temperatura ambiente. Após finalizado cada tempo predefinido de adsorção a mistura foi centrifugada sendo o sobrenadante e o adsorvente separados para posterior análise e o último lavado e seguido de centrifugação por duas vezes para a remoção de solução remanescente.

O mesmo procedimento foi realizado para o ensaio de adsorção de sódio e cobalto a partir de solução $1 \mathrm{~g} / \mathrm{L}$ de cloreto de sódio, $\mathrm{NaCl}$ e $0,5 \mathrm{~g} / \mathrm{L}$ nitrato de cobalto, $\mathrm{Co}\left(\mathrm{NO}_{3}\right)_{2}$ respectivamente.

\section{5}

\section{Caracterização da nanocelulose após a adsorção}




\subsection{1}

\section{Análise elementar}

As amostras de CEL, CNC e CNC-Mod obtidas após a adsorção foram secas a vácuo em temperatura ambiente. Utilizou-se o MEV TM3000 Hitachi com periférico acoplado do tipo EDS Swift ED 3000, ambos pertencentes ao DEQM PUC-Rio, para verificar, de forma semi-quantitativa, a presença dos cátions adsorvidos nos respectivos adsorventes, a possível presença de impurezas e a morfologia dos materiais. Uma pequena quantidade da amostra foi depositada sobre a fita adesiva de carbono aderida ao porta amostras. A análise foi realizada utilizando-se o Software SwiftED 1.7.3.0 da Oxford Instruments Analytical Limited.

\subsection{2}

\section{Análise Termogravimétrica (TGA)}

As análises de TGA após a adsorção, foram realizadas de maneira similar à descrita para a caracterização da celulose, CNC e CNC-Mod no item 3.3.3.

\subsection{3}

\section{ICP-OES}

O sobrenadante, separado após a centrifugação no processo de adsorção, item 3.4, foi analisado por Espectrometria de Emissão Óptica por Plasma Acoplado Indutivamente ICP-OES em equipamento 7300DV, Perkin Elmer do Laboratório de Absorção Atômica (LAATOM) do Departamento de Química da PUC-Rio, A partir dos resultados plotou-se a isoterma de adsorção tendo como tempo zero as amostras iniciais de cada solução. 


\section{4 \\ Resultados}

\section{1}

\section{Obtenção da CNC}

Em análises preliminares, realizou-se obtenção com diferentes concentrações de ácido sulfúrico, 60, 55, 50 e 40\%. Visto que as concentrações mais altas resultaram em rápida degradação e aparente queima da celulose, com o surgimento de uma solução escurecida em poucos minutos de reação, definiu-se que a obtenção de CNC seria realizada com solução de ácido sulfúrico 40\%. Esta degradação pode ser explicada pela alta pureza da $\alpha$-celulose Sigma Aldrich, em comparação com as polpas normalmente utilizadas na literatura, isoladas a partir de bagaço de cana de açúcar, casca de banana, e outras diversas fontes vegetais que podem conter resíduos de lignina e hemicelulose além de substancias inorgânicas.

\section{2}

\section{Funcionalização da nanocelulose}

A partir dos resultados de Börjesson et al. [45] em conjunto com o apresentado por Rodrigues et al. [48] , pode-se sugerir que a reação de funcionalização pode ocorrer por meio de diferentes mecanismos e possívelmente em diversos sítios no material celulósico, sendo estes nos sítios não afetados pela hidrólise (estrutura original da celulose), nos sítios onde ocorreram a hidrólise ácida na obtenção da CNC (ésteres de sulfato) e nos locais de possível substituição dos grupos sulfatos por hidroxilas durante a neutralização com $\mathrm{NaOH}$, Figura 4.1. Sugere-se, deste modo, que o processo de hidrólise não promove a substituição em todos os grupos hidroxilas ao longo da cadeia celulósica e alguns sítios permanecem intactos. Estudos posteriores, como a análise de espectroscopia por ressonância magnética nuclear, podem ser realizados para avaliar a estrutura do produto da funcionalização e determinar se a mesma ocoore na hidroxilas dos grupos sulfatos ou pelos grupos hidroxilas nativos da celulose. 


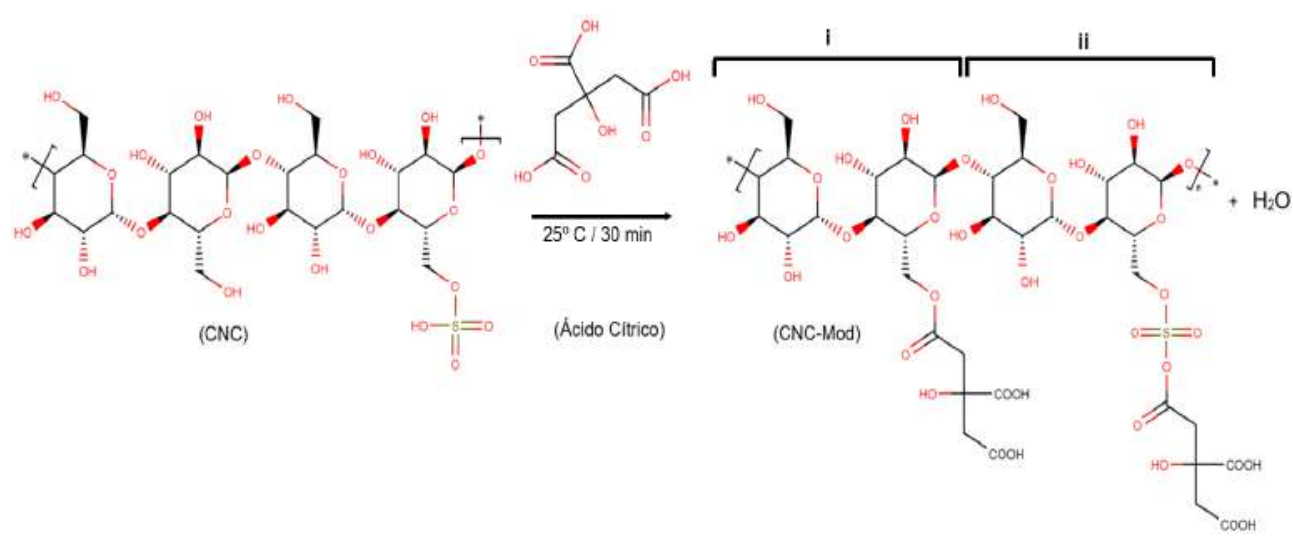

Figura 4.1: Possíveis mecanismos de funcionalização da CNC com ácido cítrico. i) reação nos sítios com grupos hidroxilas nativos da celulose ou após possível remoção dos grupos sulfatos pela neutralização [48] ii) reação nos sítios com hidroxilas dos grupos sulfatos [45]. Fonte: Elaborado pelo autor, Software Marvin Sketch Chemaxon

\section{3}

\section{Caracterização da nanocelulose}

\subsection{1}

AFM

A figura 4.2 apresenta as imagens de AFM da nanocelulose obtida por hidrólise ácida. O formato dos nanocristais, na forma de agulhas finas, é característico do material como apresentado na literatura [18, 70, 71, 72].

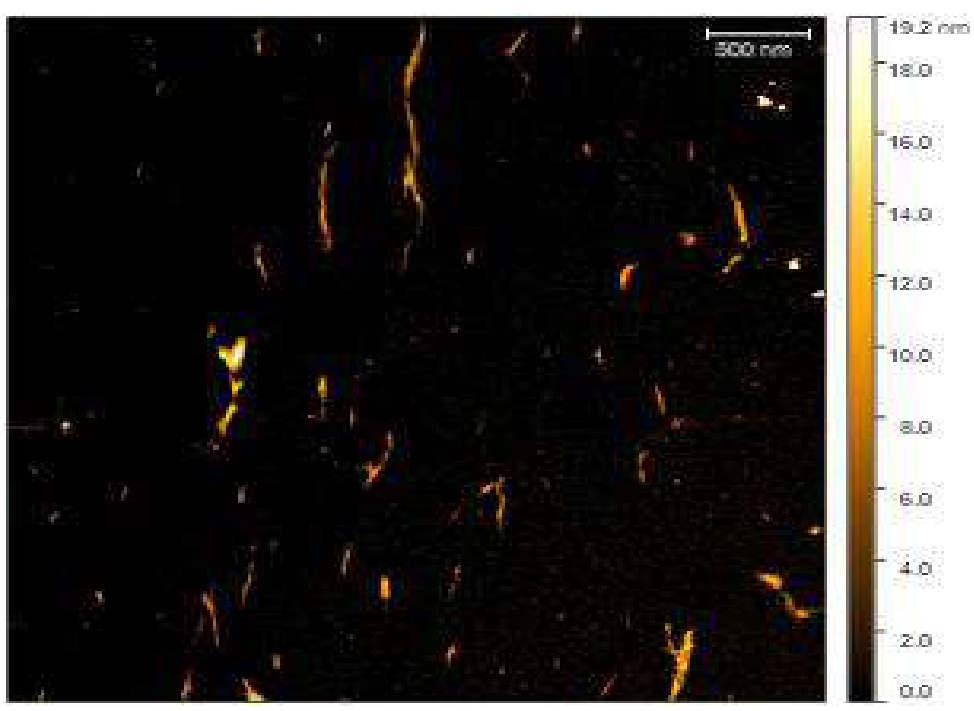

Figura 4.2: Imagem AFM da CNC após tratamento no software Gwyddion 2.55 .

Utilizando o software Gwyddion 2.55 obteve-se as dimensões dos nano cristais, sendo o diâmetro médio das partículas de 9,99 $\pm 2,58 \mathrm{~nm}$ e comprimento médio de $63,89 \pm 41,51 \mathrm{~nm}$. A razão de aspecto, razão entre compri- 
mento e o diâmetro da fibra, foi de 6,39. Os resultados obtidos se encontram acima dos valores apresentados por Mathias et al.[18] que apresentaram diâmetro de 2,7 nm, comprimento de 49,5 nm e razão de aspecto 18,3. O diâmetro médio foi menor que o apresentado por Morán et al. [71] de 30,9 $\pm 12,5 \mathrm{~nm}$ e o comprimento foi menor do que os valores apresentados por amostras comerciais de CNC, obtidas por diferentes rotas, avaliadas por Reid, Villalobos \& Cranston [70], apresentadas na Tabela 4.1.

Tabela 4.1: Dimensões apresentadas por amostras comerciais de CNC. Fonte: Reid, Villalobos e Cranston [68]

\begin{tabular}{cccc} 
Amostras & $\begin{array}{c}\text { Comprimento } \\
(\mathbf{n m})\end{array}$ & $\begin{array}{c}\text { Diâmetro } \\
(\mathbf{n m})\end{array}$ & $\begin{array}{c}\text { Razão de } \\
\text { aspecto }\end{array}$ \\
\hline Lab-Made & $132 \pm 55$ & $8 \pm 3$ & 16 \\
\hline CelluForce & $183 \pm 88$ & $6 \pm 2$ & 31 \\
\hline AITF & $134 \pm 56$ & $8 \pm 2$ & 17 \\
\hline FPL & $134 \pm 52$ & $7 \pm 2$ & 19 \\
\hline
\end{tabular}

Teodoro et al. [21] indicam que a análise de AFM pode sobrestimar as dimensões promovendo um alargamento nas imagens das fibras. Kvien et al. [72] atribuem esse alargamento à agulha utilizada para a análise, que ao passar por uma superfície com dimensões aproximadas a da agulha, influencia na imagem obtida. Entretanto, a figura 4.2 não apresenta este efeito. Para o procedimento de análise das dimensões da CNC Reid, Villalobos \& Cranston [70] desconsideraram partículas com dimensões abaixo de $20 \mathrm{~nm}$, indicando que as medidas são influenciadas pelos efeitos de estreitamento das pontas. No presente trabalho, utilizou-se a mesma restrição nas medidas de comprimento.

Os diagramas de distribuição de comprimento e diâmetro, obtidos a partir da análise da figura 4.2, são apresentados respectivamente nas figuras 4.3 e 4.4. Utilizou-se a imagem AFM para a obtenção de uma imagem tridimensional da mesma, Figura 4.5.

As amostras de CNC exibem uma distribuição estreita de comprimento com maior faixa entre 20 e $50 \mathrm{~nm}$. Com relação ao diâmetro, as amostras apresentam uma distribuição estreita, com a maioria das partículas entre 7 e $10 \mathrm{~nm}$.

A partir do desenho gráfico tridimensional da imagem AFM da CNC pode-se constatar o diâmetro máximo da fibra de aproximadamente $22 \mathrm{~nm}$. 


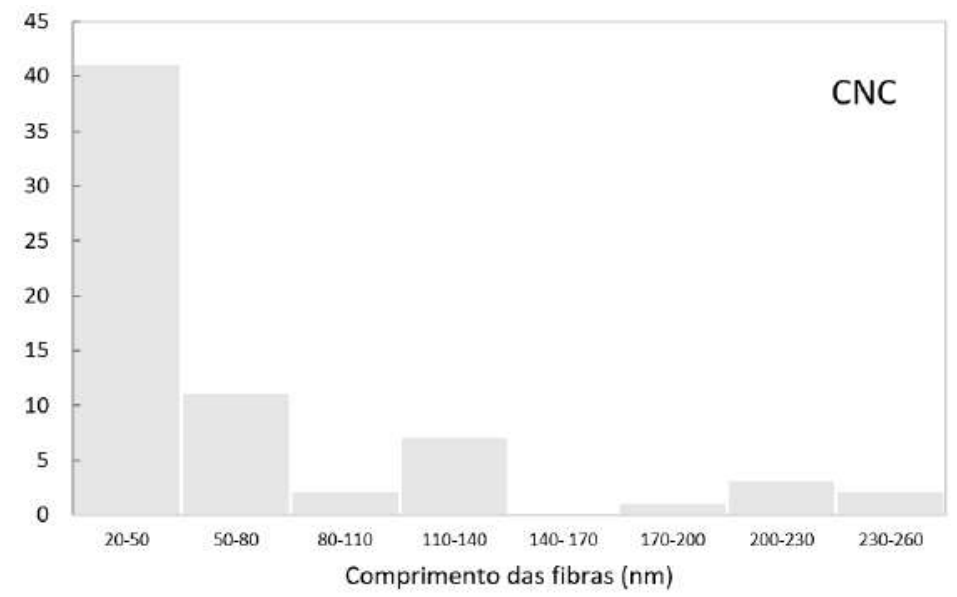

Figura 4.3: Diagrama de distribuição de comprimento da CNC.

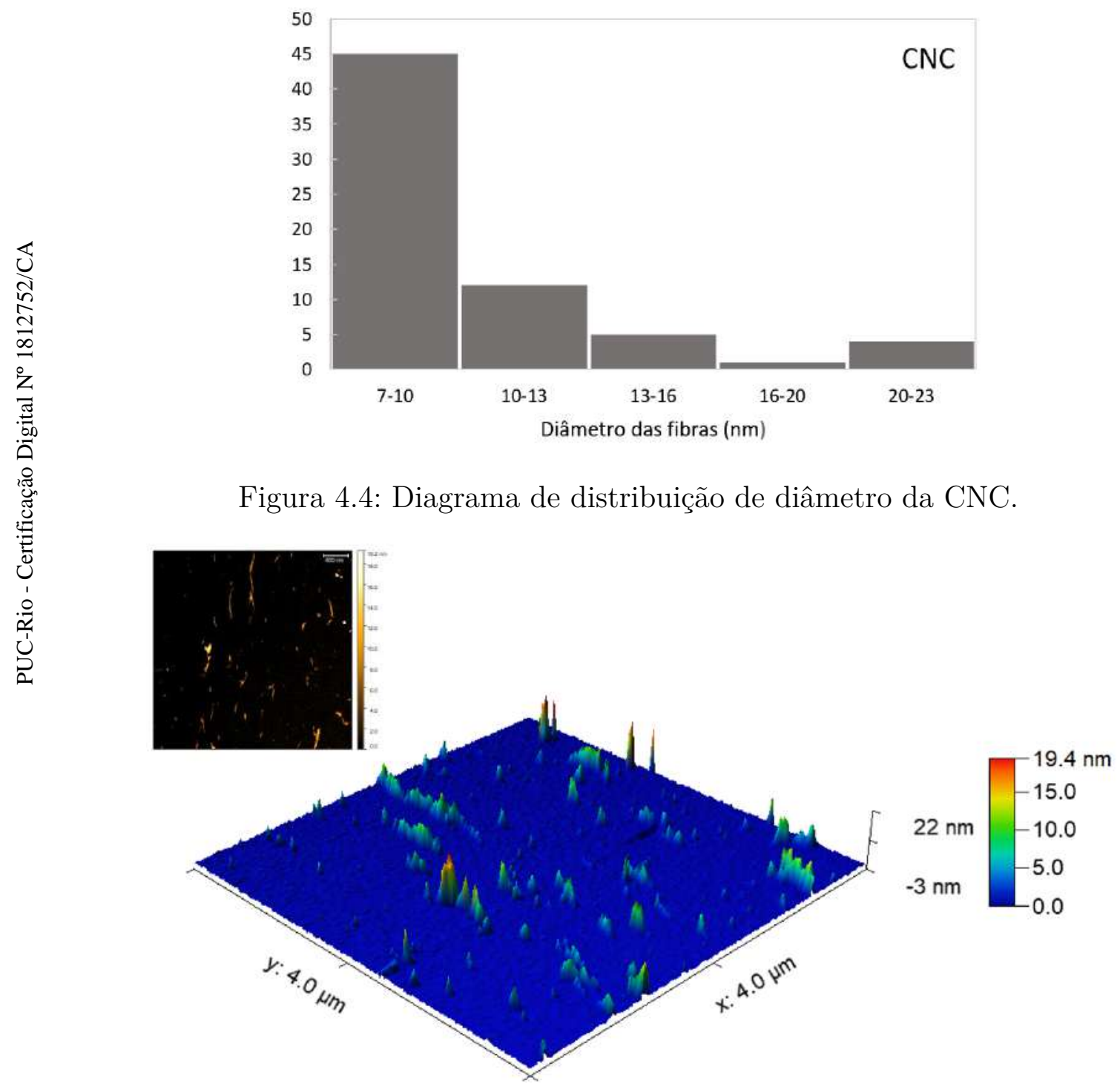

Figura 4.5: Imagem AFM tridimensional. 


\subsection{2 \\ Microscopia eletrônica de varredura}

As figuras 4.6.b e 4.7.a demonstram a aglomeração da nanocelulose após o processo de secagem. Estes aglomerados apresentam a característica de placas depositadas umas sobre as outras gerando uma espécie de membrana cristalina como apresentada na figura 4.6.a. Verifica-se ainda, a ausência de impurezas na amostra, indicando a eficiência do processo de lavagem da amostra, eliminando possíveis resíduos do meio reacional. O mapa de EDS apresentado nas figuras 4.7.b, 4.7.c e 4.7.d mostra os elementos carbono e oxigênio, constituintes da celulose pura, e a presença de enxofre, que pode indicar a inserção de grupos $\mathrm{OSO}_{3}^{-}$no processo de hidrólise de acordo com a reação apresentada na figura 2.2. Foram realizados diversos mapeamentos em diferentes regiões e utilizou-se a quantificação do EDS Tabela 4.2, para a confirmação da reação.

Tabela 4.2: Análise elementar semi-quantitativa da CNC. Todos os elementos são quantificados em porcentagem mássica.

\begin{tabular}{ccccc} 
Região & $\mathbf{C}$ & $\mathbf{O}$ & $\mathbf{A l}$ & $\mathbf{S}$ \\
\hline Espectro 1 & 46,80 & 50,97 & 0,81 & 1,41 \\
Espectro 2 & 46,04 & 51,81 & 0,91 & 1,24 \\
Espectro 3 & 46,34 & 51,63 & 0,71 & 1,31 \\
Espectro 4 & 46,15 & 51,76 & 0,91 & 1,18 \\
Espectro 5 & 46,57 & 51,20 & 0,75 & 1,50 \\
\hline Média & 46,38 & 51,47 & 0,82 & 1,33 \\
Desvio padrão & 0,28 & 0,33 & 0,08 & 0,12 \\
\hline
\end{tabular}

A partir do mapeamento e análise elementar, pode-se verificar, mesmo que semi-quantitativamente, uma consistência nos valores resultantes de diversas regiões mapeadas, com um valor médio de porcentagem mássica de enxofre de 1,32\%. Este resultado pode indicar uma homogeneidade na distribuição dos grupos $\mathrm{OSO}_{3}^{-}$adicionados, o que pode ser verificado no mapa do enxofre, figura 4.7.c, que apresenta uma distribuição do elemento pela CNC. Pode-se sugerir que a hidrólise foi bem-sucedida e que as porcentagens reais dos elementos podem ser aproximadas das obtidas pela análise em questão, sendo necessário outros métodos analíticos, como o ICP-MS, para se obter uma quantificação mais confiável, ou a confirmação deste resultado. A presença de alumínio nos resultados ocorre devido à composição do porta amostra. 


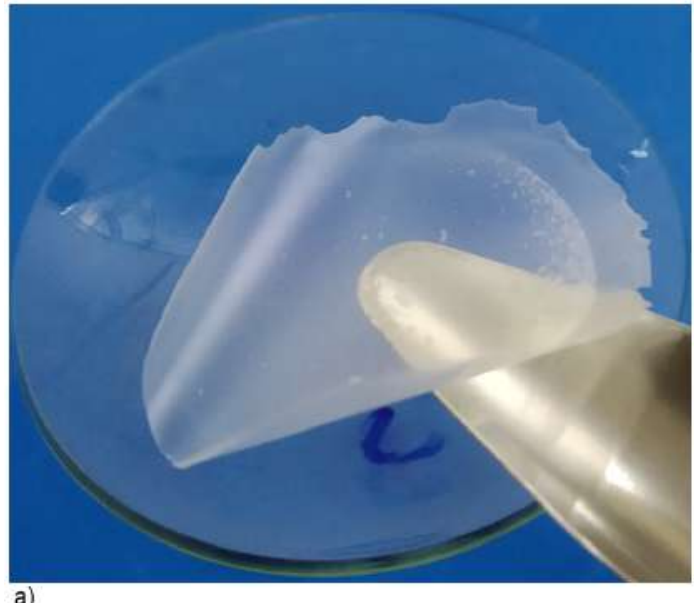

a)

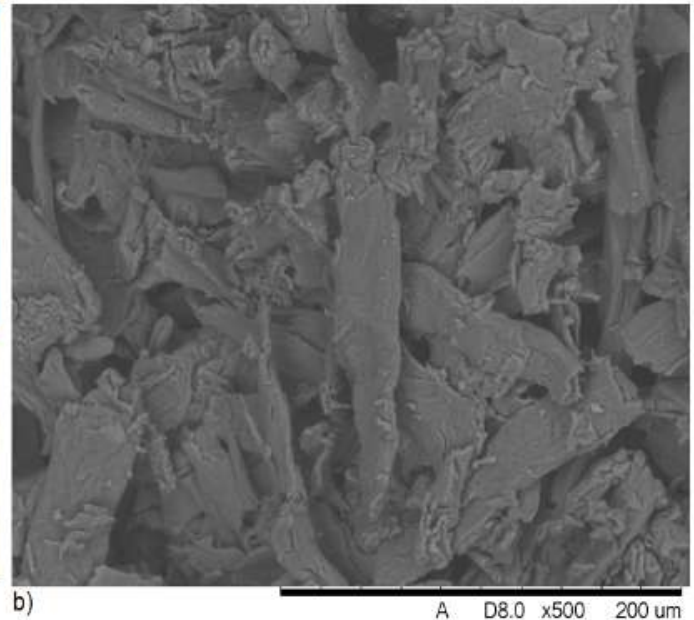

b)

Figura 4.6: a) película formada após a secagem de CNC b) Imagem de MEV da CNC com amplificacão de 500x.
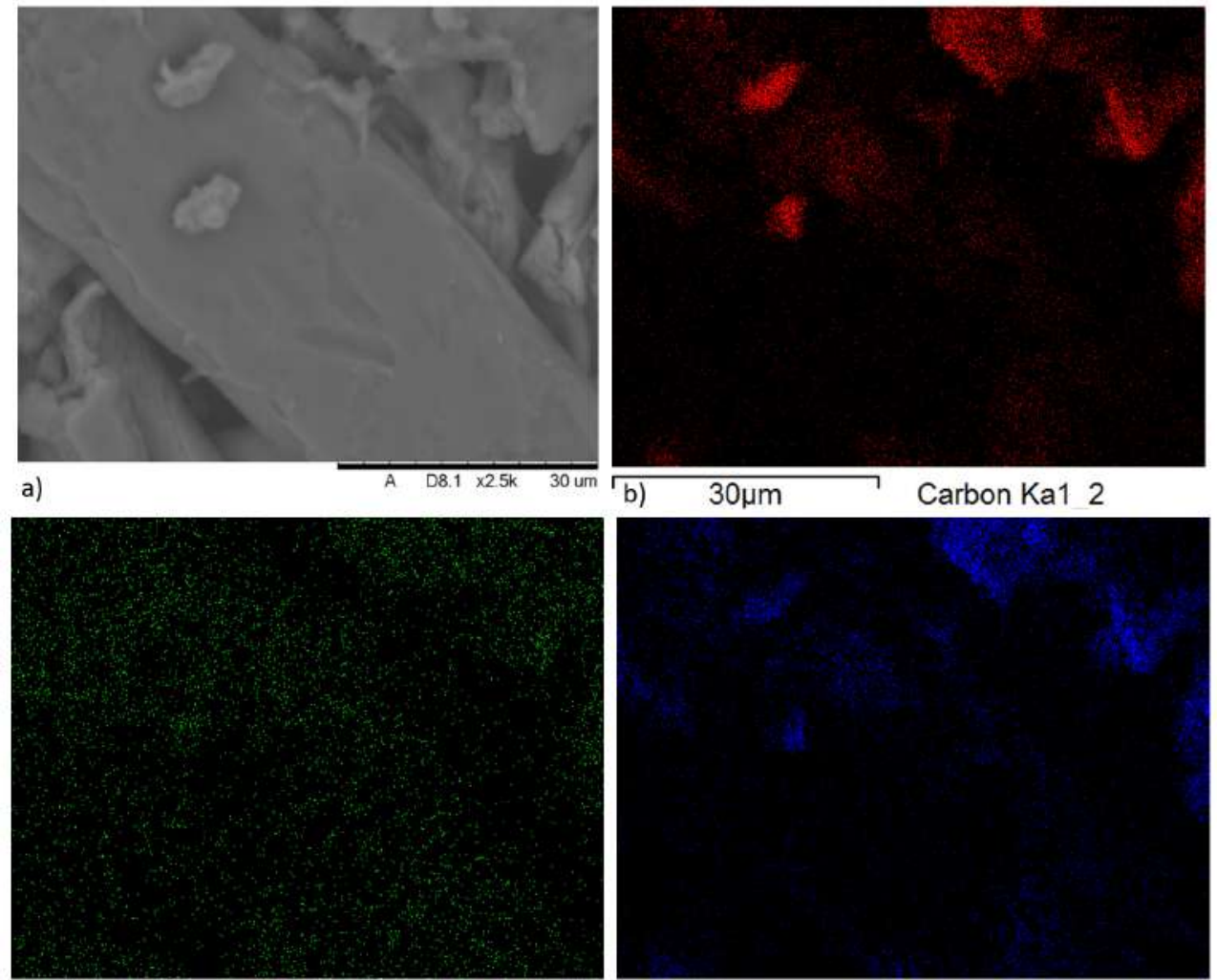

c)

$30 \mu \mathrm{m}$

Sulfur Ka1

d) $30 \mu \mathrm{m} \quad$ Oxygen Ka1

Figura 4.7: Imagens de MEV e mapa de EDS dos elementos presentes na superfície da nanocelulose, após hidrólise com $\mathrm{H}_{2} \mathrm{SO}_{4}$ a) $\mathrm{CNC}$ com aumento de 2500x b) Mapa de EDS de carbono c) Mapa de EDS de oxigênio d) Mapa de EDS de enxofre. 


\subsection{3}

\section{Análise da CNC por espectroscopia de infravermelho com transformada de Fourier (FTIR)}

O espectro de transmitância por número de onda, obtido pelo software OriginPro 8, é apresentado na figura 4.8. A figura permite uma avaliação comparativa da $\mathrm{CNC}$ em relação à celulose. $\mathrm{O}$ espectro relacionado à CNC foi transladado verticalmente em um valor de $+11,5$ para facilitar a visualização e comparação dos picos.

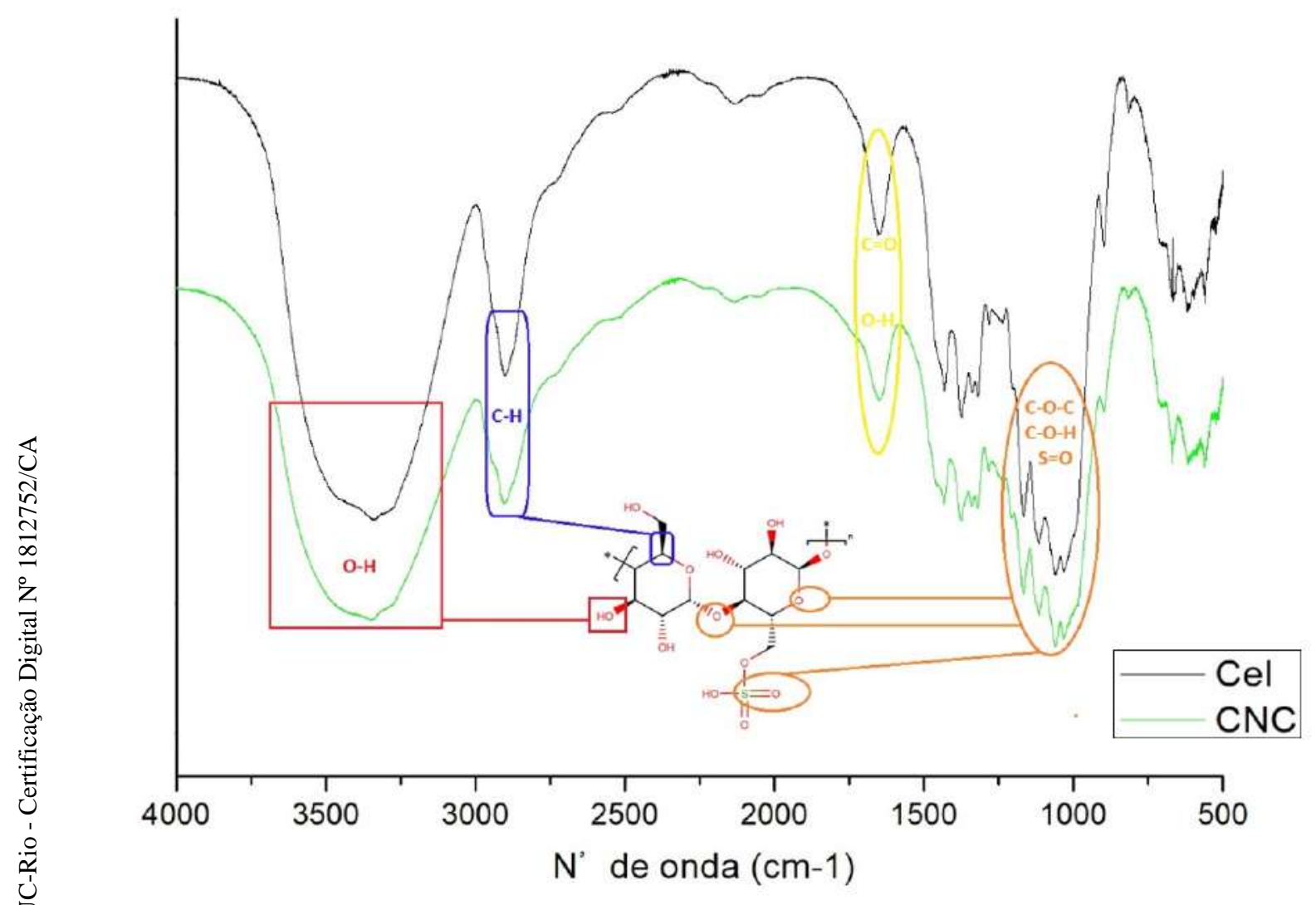

Figura 4.8: Análise de FTIR da celulose (preto) e CNC (verde).

Por meio da avaliação do espectro da celulose, pode-se constatar a presença dos grupos funcionais hidroxilas que tendem a formar ligações de hidrogênio, justificados pelas bandas características com picos entre $3220 \mathrm{~cm}^{-1}$ e $3500 \mathrm{~cm}^{-1}$, que representam vibrações de estiramento da ligação O-H. As vibrações de estiramento simétrico da ligação $\mathrm{C}$-H podem ser verificadas pela banda $2900 \mathrm{~cm}^{-1}$ e pelos dois ombros em $2945 \mathrm{~cm}^{-1}$ e $2968 \mathrm{~cm}^{-1}$.

O pico na banda de $1650 \mathrm{~cm}^{-1}$, presente tanto na celulose quanto na $\mathrm{CNC}$, está relacionado a vibrações de estiramento das ligações $\mathrm{C}=\mathrm{O}$ o que poderia indicar a presença de grupos carboxilatos caracterizando assim, uma carboximetilcelulose e não $\alpha$-celulose $[73,74]$. Entretato, em trabalho realizado por Mohamed et al. [75] há a relação desta banda com as vibrações de 
dobramento das ligações O-H da água absorvida pela amostra. Assim, visto o grau de pureza da $\alpha$-celulose usada nos procedimentos, $99 \%$, pode-se inferir que esta banda esteja possivelmente relacionada as ligações O-H da água absorvida do ambiente.

Algumas alterações notáveis, ao comparar os dois espectros, podem ser analisadas com uma ligeira alteração na intensidade do conjunto de bandas entre 1280 e $980 \mathrm{~cm}^{-1}$. Essas alterações em bandas como $1245 \mathrm{~cm}^{-1}, 1235 \mathrm{~cm}^{-1}$, $1165 \mathrm{~cm}^{-1}, 1114 \mathrm{~cm}^{-1}$, e $1026 \mathrm{~cm}^{-1}$, podem estar relacionadas a vibrações de estiramento simétricos e assimétricos da ligação C-O-C que juntamente com a redução na intensidade do pico em $898 \mathrm{~cm}^{-1}$, que é relacionado as vibrações de estiramento C-O-C nas ligações glicosídicas $\beta-1,4$, podem indicar uma possível redução no grau de polimerização da celulose. A banda em $1060 \mathrm{~cm}^{-1}$ indica as vibrações de estiramento da ligação C-O-C dos anéis de piranose [76, 75].

As bandas vibracionais relacionadas às ligações do grupo funcional $\mathrm{OSO}_{3} \mathrm{H}$, especificamente vibramentos de estiramento das ligações $\mathrm{S}=\mathrm{O}$, são esperadas entre $1245 \mathrm{~cm}^{-1}$ e $1045 \mathrm{~cm}^{-1}$ [77]. Pela comparação dos espectros FTIR da Celulose e CNC, Figura 4.8, observa-se que há uma alteração no pico nesta região, com o surgimento de um pequeno ombro. Esta sutil ateração pode estar relacionada com a inserção dos grupos $\mathrm{OSO}_{3} \mathrm{H}$, sendo um possível indicativo da ocorrencia da hidrólise ácida. Como as vibrações de ligações C-O-O e C-O-H se localizam entre $1300 \mathrm{~cm}^{-1}$ e $1000 \mathrm{~cm}^{-1}$, os picos referentes as vibrações de estiramento $\mathrm{S}=\mathrm{O}$ podem não estar aparentes no espectro, uma vez que o os grupos C-O-O e C-O-H são abundantes em polissacarídeos como a celulose. Para uma melhor compreensão da estrutura orgânica das amostras, sugere-se a realização de análises complementares como a ressonância magnética nuclear, RMN. Os números de onda e vibrações encontradas no espectro são apresentadas na tabela 4.3 . 
Tabela 4.3: Principais números de onda e respectivas vibrações apresentadas pelo espectro FTIR para a CEL e CNC.

\begin{tabular}{c|c}
$\mathbf{N}^{o}$ de onda & Tipo de vibração \\
\hline $3220-3500 \mathrm{~cm}^{-1}$ & Estiramento O-H \\
$2968 \mathrm{~cm}^{-1}$ & Estiramento assimétrico C-H \\
$2945 \mathrm{~cm}^{-1}$ & Estiramento simétrico C-H \\
$2900 \mathrm{~cm}^{-1}$ & Estiramento simétrico C-H \\
$1650 \mathrm{~cm}^{-1}$ & Estiramento C=O / estiramento O-H \\
$1245 \mathrm{~cm}^{-1}$ & Estiramento $\mathrm{S}=\mathrm{O}$ no OSO ${ }_{3} \mathrm{H}$ \\
$1240 \mathrm{~cm}^{-1}$ & Estiramento assimétrico C-O-C \\
$1235 \mathrm{~cm}^{-1}$ & Estiramento assimétrico C-O-C \\
$1165 \mathrm{~cm}^{-1}$ & Estiramento simétrico C-O-C \\
$1114 \mathrm{~cm}^{-1}$ & Estiramento simétrico C-O-C \\
$1060 \mathrm{~cm}^{-1}$ & Estiramento C-O-C dos anéis de piranose \\
$1026 \mathrm{~cm}^{-1}$ & Estiramento simétrico C-O-C \\
$898 \mathrm{~cm}^{-1}$ & Estiramento C-O-C ligações glicosídicas $\beta-1,4$ \\
\hline
\end{tabular}

\section{4}

\section{Caracterização da nanocelulose funcionalizada com ácido cítrico}

\subsection{1}

AFM

A figura 4.9 apresenta a imagem obtida através da AFM da CNCMod. Diferente da CNC, a amostra apresentou maior tendência à formação aglomerados. Deste modo, estes agregados de CNC-Mod não foram medidos visto que os limites das dimensões exatas das partículas individuais não podem ser distinguidos [70].

De maneira análoga ao item 4.3.1, a partir do corte de uma imagem AFM com a disposição de uma região isolada de fibras de CNC-Mod, obteve-se uma imagem tridimensional, Figura 4.9, constatando-se a altura aproximada da fibra de 23,3 $\mathrm{nm}$. 


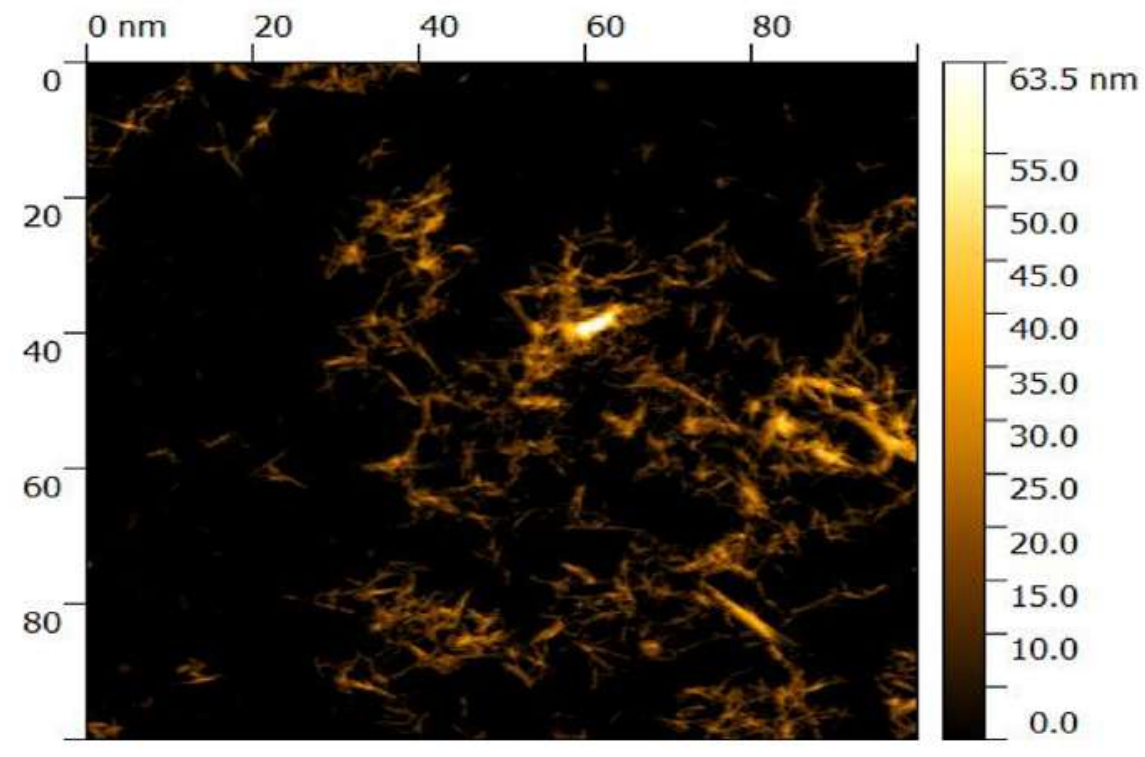

Figura 4.9: Imagem AFM da CNC-Mod tratada no software Gwyddion 2.55.

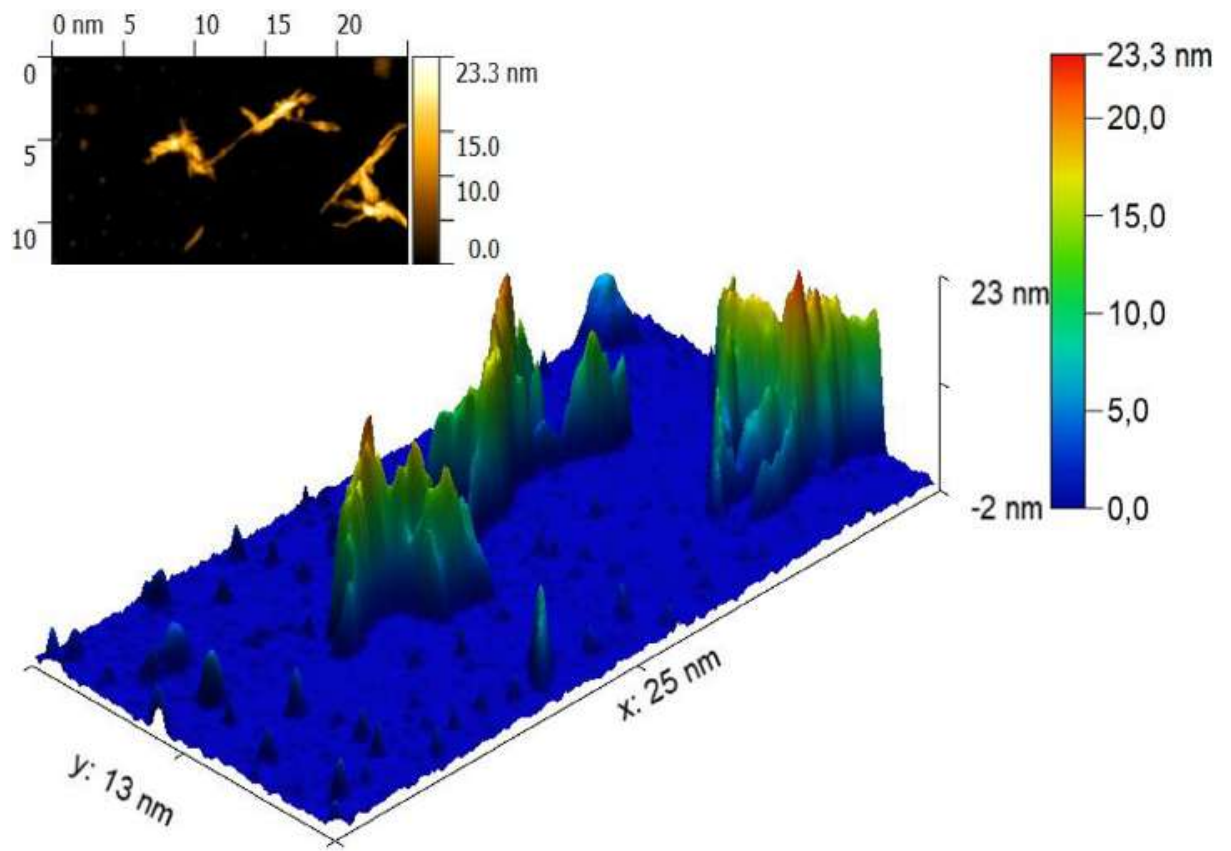

Figura 4.10: Desenho gráfico tridimensional de uma região isolada da CNCMod. 


\subsection{2 \\ Microscopia eletrônica de varredura}

Os mapeamentos da amostra foram realizados em diferentes regiões, Figura 4.11, e utilizou-se a quantificação do EDS para avaliar a composição da amostra da CNC-Mod, de forma semi-quantitativa, Tabela 4.4.
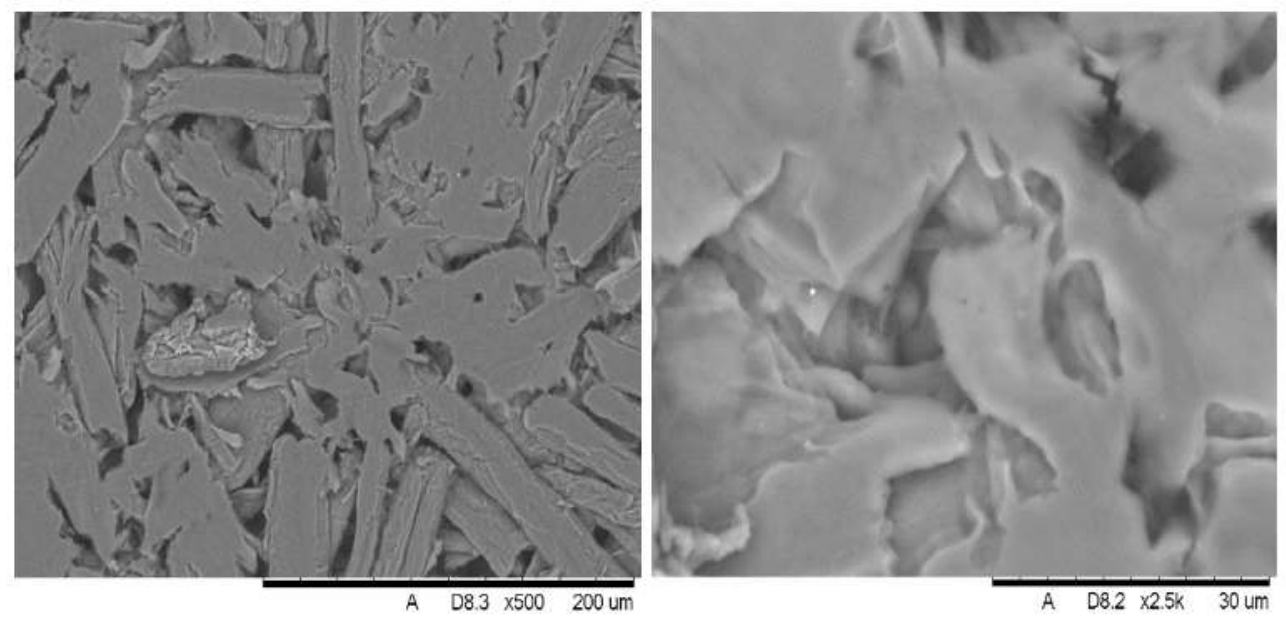

Figura 4.11: Imagens de MEV da CNC-Mod a) Amplificação 500x b) Amplificação 2500x.

Pela figura 4.11, observa-se a maior tendência de aglomeração, durante a secagem, em relação à CNC, figura 4.6, confirmando o verificado na análise de AFM. A superfície da CNC-Mod também se apresenta mais plana e densa do que a CNC, o que pode justificar estudos posteriores de aplicação da CNC-Mod em produção de membranas de separação. O mapa de EDS não foi realizado visto que somente indicaria a presença dos elementos carbono, oxigênio e enxofre, e não seria indicativo da modificação da CNC.

Tabela 4.4: Análise elementar semi-quantitativa da CNC-Mod. Todos os elementos são quantificados em porcentagem mássica.

\begin{tabular}{c|cccc} 
Região & $\mathbf{C}$ & $\mathbf{O}$ & $\mathbf{A l}$ & $\mathbf{S}$ \\
\hline Espectro 1 & 46,57 & 53,01 & 0,10 & 0,32 \\
Espectro 2 & 46,50 & 53,12 & 0,09 & 0,28 \\
Espectro 3 & 46,41 & 53,23 & 0,08 & 0,28 \\
Espectro 4 & 46,17 & 53,46 & 0,09 & 0,28 \\
Espectro 5 & 46,59 & 53,05 & 0,09 & 0,27 \\
\hline Média & 46,45 & 53,17 & 0,09 & 0,29 \\
Desvio padrão & 0,15 & 0,16 & 0,01 & 0,02 \\
\hline
\end{tabular}

A partir dos resultados da análise elementar sugere-se, de forma semiquantitativa, que houve uma redução, $78 \%$ em média, da presença dos grupos $\mathrm{OSO}_{3}^{-}$na estrutura da CNC-Mod em comparação com a CNC tabela 4.3 e 4.4. 
Isto pode ser explicado por uma provável substituição dos grupos ésteres de sulfato por citrato, figura 4.1.

\subsection{3}

\section{Análise da CNC-Mod por espectroscopia de infravermelho com transfor- mada de Fourier (FTIR)}

A figura 4.12 apresenta o espectro de transmitância por número de onda, obtido pelo software OriginPro 8 utilzado para a avaliação comparativa da CNC-Mod em relação à CNC. O espectro da CNC-Mod foi transladado verticalmente em um valor dy de $+7,00$ para melhor visualização e comparação dos picos. A tabela 4.5 apresenta os principais picos do espectro FTIR discutidos.

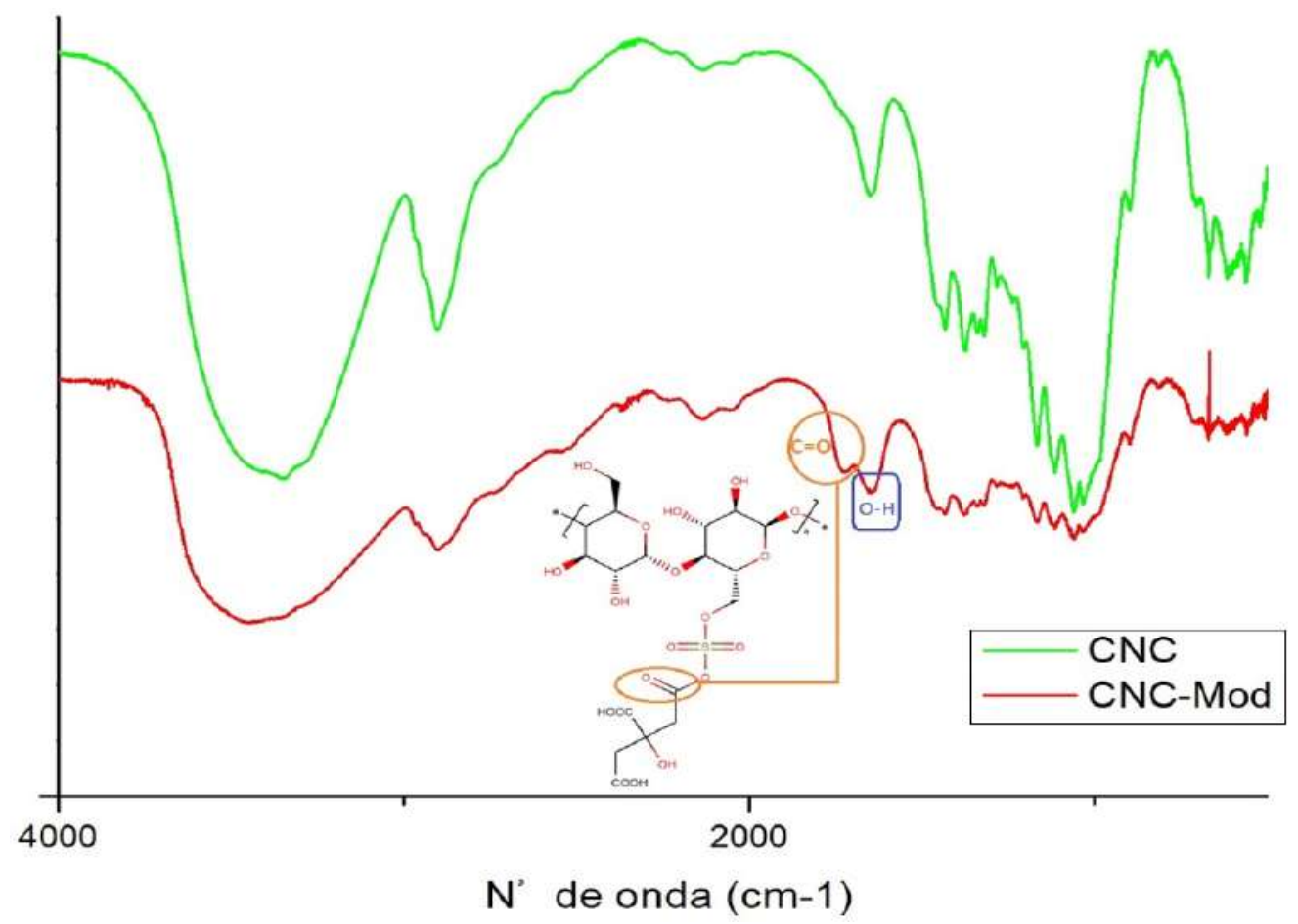

Figura 4.12: Análise de FTIR da CNC e CNC-Mod.

De maneira similar ao do espectro da celulose e da CNC, verifica-se na CNC-Mod a presença dos grupos funcionais hidroxilas que formam ligações de hidrogênio, pelas bandas vibrações de estiramento da ligação O-H com picos entre $3220 \mathrm{~cm}^{-1}$ e $3500 \mathrm{~cm}^{-1}$. Entretanto, pode-se verificar um alargamento deste pico. Uma explicação para esta alteração pode ser atribuída ao aumento de grupos hidroxilas, que realizam ligações de hidrogênio, pela sua reação com o ácido cítrico, sendo os grupos $\mathrm{OH}$ em regiões menos acessíveis substituídos pela molécula de ácido cítrico com duas novas hidroxilas em regiões mais acessíveis [22, 78]. 
A CNC-Mod também apresenta as bandas de vibrações de estiramento simétrico da ligação C-H em $2900 \mathrm{~cm}^{-1}$ e dois ombros em $2945 \mathrm{~cm}^{-1}$ e 2968 $\mathrm{cm}^{-1}$ porém, com pequena redução na intensidade. Nota-se ainda, uma redução na intensidade de alguns picos, que pode estar relacionada ao impedimento estérico em função da adição de um maior grupo funcional, proveniente do ácido cítrico, na estrutura da celulose, como também pela possível existência de dímeros do grupo cítrico, uma vez que esta espécie restringe o movimento dos grupos CO-OH [79].

A alteração de maior importância ocorre no aparecimento do pico em $1732 \mathrm{~cm}^{-1}$ que está relacionado juntamente com o pico em $1650 \mathrm{~cm}^{-1}$ (presente em todas as amostras avaliadas, figura 4.7) às vibrações de estiramento das ligações $\mathrm{C}=\mathrm{O}$, o que pode indicar a presença de grupos carboxilatos podendo, deste modo, confirmar a modificação da nanocelulose com a ácido cítrico. Quellmalz e Mihranyan [80] também identificam o pico em $1730 \mathrm{~cm}^{-1} \mathrm{e}$ o relacionam tanto com a carbonila quanto com grupos esteres, a confirmação pelos autores do grupo carbonila é realizada pela conversão em grupos carboxilatos, com o aparecimento de um pico em $1590 \mathrm{~cm}^{-1}$. A presença do pico em $1650 \mathrm{~cm}^{-1}$, pode confirmar o proposto por Mohamed et al. [75] e Schwanninger et al. [81] que relacionam esta banda com as vibrações de dobramento das ligações $\mathrm{O}-\mathrm{H}$, podendo ser da água absorvida do ambiente pela celulose, $\mathrm{CNC}$ e CNC-Mod.

Tabela 4.5: Principais números de onda e respectivas vibrações apresentadas pelo espectro FTIR para a CNC e CNC-Mod.

\begin{tabular}{c|c}
$\mathbf{N}^{o}$ de onda & Tipo de vibração \\
\hline $3220-3500 \mathrm{~cm}^{-1}$ & Estiramento O-H \\
$2968 \mathrm{~cm}^{-1}$ & Estiramento assimétrico C-H \\
$2945 \mathrm{~cm}^{-1}$ & Estiramento simétrico C-H \\
$2900 \mathrm{~cm}^{-1}$ & Estiramento simétrico C-H \\
$1732 \mathrm{~cm}^{-1}$ & Estiramento C=O \\
$1650 \mathrm{~cm}^{-1}$ & Estiramento C=O / estiramento O-H \\
\hline
\end{tabular}

\section{5}

\section{Caracterização via DRX}

Os difratogramas de raio-x das amostras CEL, CNC e CNC-Mod, Figura 4.13, apresentam picos similares em $15^{\circ}, 18^{\circ}, 22,5^{\circ}$ e $34,5^{\circ}$ indicando que em todos os casos a celulose presente nas amostras é do tipo I [82, 23, 69]. Os valores de intensidade do pico em $18^{\circ}$ e do pico em $22,5^{\circ}$, os valores calculados dos índices de cristalinidade das amostras e o tamanho médio dos cristalitos encontram-se na Tabela 4.6. 

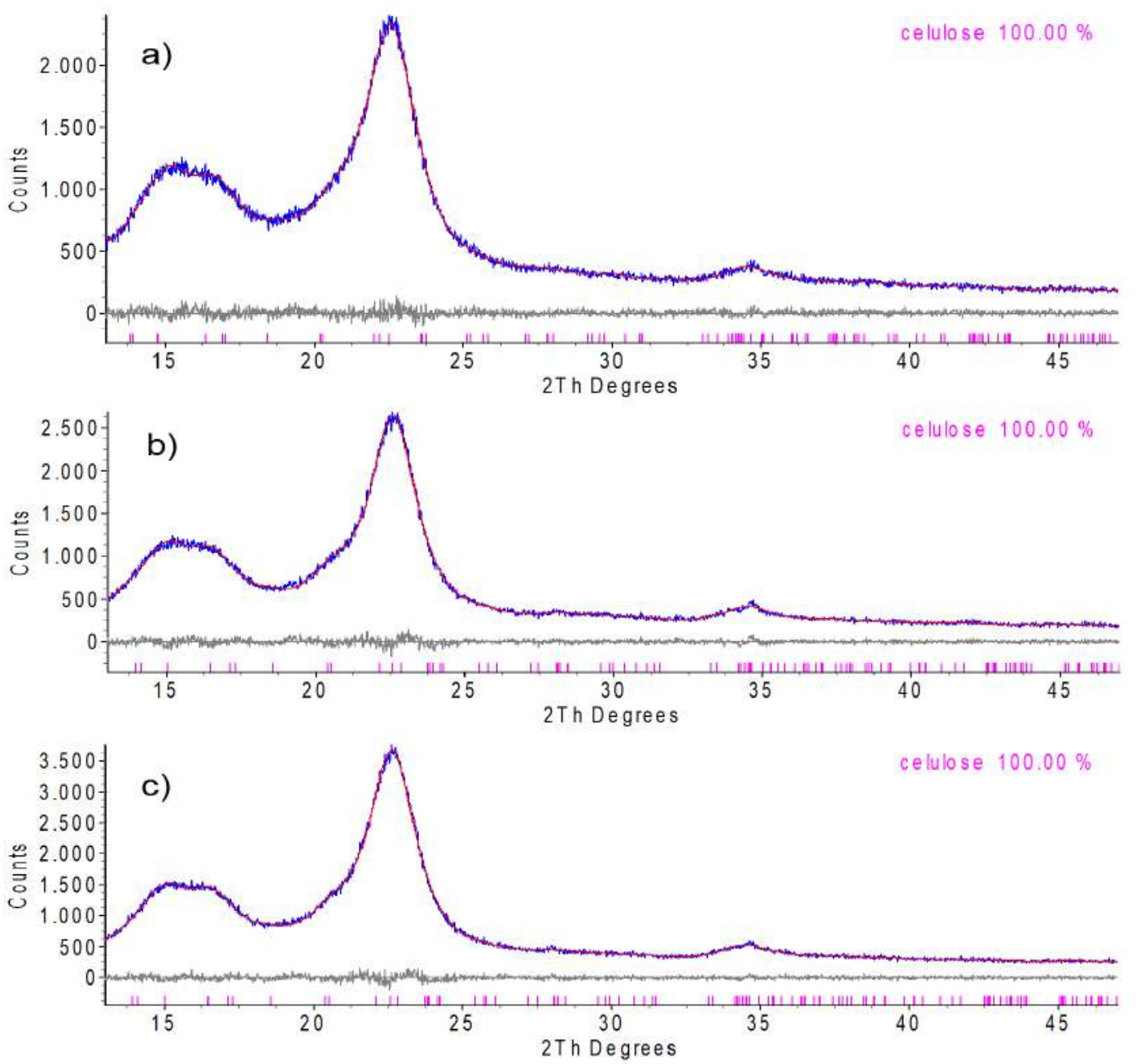

Figura 4.13: Difratogramas das amostras de a) CEL b) CNC c) CNC-Mod

O índice de cristalinidade da celulose de 0,66 se mostrou relativamente alto para a celulose branqueada. Valores da literatura indicam que o índice de cristalinidade da celulose pode variar de 0,39 a 0,67 dependendo do método de análise utilizado [83]. Nota-se um aumento significativo no índice de cristalinidade da CNC em relação a CEL, o que pode indicar a redução de regiões amorfas pela hidrólise ácida [66]. Os valores de índice de cristalinidade da CNC apresentados na literatura variam entre 0,54 e 0,94 [70]. Wulandari e colaboradores [20] obtiveram valores de IC entre 0,68 e 0,76 para diferentes amostras de CNC. Os autores atribuem essa diferença as concentrações utilizadas de ácido entre 60 e $50 \%$ respectivamente e indicam que concentrações altas de ácido sulfúrico tendem a danificar os domínios cristalinos da celulose. A funcionalização da CNC promoveu um aumento da intensidade de ambos os picos amorfo, $18^{\circ}$, e cristalino, $22,5^{\circ}$, porém o índice de cristalinidade permaneceu similar ao da CNC. Estudos mais detalhados devem ser realizados para compreender este fenômeno. 
Tabela 4.6: Intensidades dos picos amorfo cristalino e índice de cristalinidade das amostras.

\begin{tabular}{c|ccc} 
& CEL & CNC & CNC-Mod \\
\hline $18^{\circ}$ & 817 & 649 & 904 \\
$22,5^{\circ}$ & 2409 & 2648 & 3591 \\
IC & 0,66 & 0,75 & 0,75 \\
Tamanho médio do cristalito $(\mathrm{nm})$ & 4,1 & 4,6 & 4,5 \\
\hline
\end{tabular}

A partir do software TOPAS, Bruker AXS, obteve-se o ajuste das difrações medidas aos modelos da celulose disponíveis na base de dados. Os valores de Godness of fit (GOF) são de 1,09 para a CEL, e 1,13 para ambas a CNC e CNC-Mod. A proximidade do GOF de 1 indica que os resultados das amostras avaliadas se aproximam do modelo. Os tamanhos dos cristalitos obtidos para a CEL, CNC e CNC-Mod, não apresentam diferença significativa entre as amostras.

\section{6}

\section{Análise Termogravimétrica TGA/DTG}

A estabilidade térmica das amostras de Celulose, CNC e CNC-Mod pode ser verificada através das curvas TGA/DTG apresentadas na Figura 4.14. A partir da análise dos resultados, observa-se uma alteração no perfil de degradação entre a celulose, a CNC e a CNC-Mod. A celulose, como visto na figura 4.14.c, apresenta maior resistência térmica com início de degradação por volta de $260,5^{\circ} \mathrm{C}$ (11 min e $51 \mathrm{~s}$ ). A degradação térmica da CNC-Mod se inicia próximo a $127,8^{\circ} \mathrm{C}$ ( $\left.7 \mathrm{~min}\right)$ e a $\mathrm{CNC}$ inicia sua degradação em torno de $116,05^{\circ} \mathrm{C}(6 \mathrm{~min}$ e $39 \mathrm{~s})$.

Ao avaliar os resultados de TGA de amostras de CNC com conteúdo variável de sulfato, Börjesson et al. [45] observaram que quanto maior a quantidade de sulfato na CNC, menor será a sua estabilidade térmica. Um efeito catalítico é atribuído à presença de grupos sulfatos na CNC [23], resultando assim em temperaturas inferiores de degradação da CNC quando comparada à celulose. Nos resultados apresentados por Börjesson et al. [45] as amostras menos sulfatadas apresentaram temperatura inicial de degradação de $155^{\circ} \mathrm{C}$ enquanto as amostras sem grupos sulfatos apresentaram temperatura de $277^{\circ} \mathrm{C}$ [45]. Deste modo, a resistência térmica apresentada pelas amostras pode ser avaliada em termos de quantidade de sulfato uma vez que a CNCMod apresenta uma menor quantidade, ou proporção, de grupos $\mathrm{OSO}^{-}$em sua estrutura como constatado pela análise de EDS.

Observa-se a alteração do mecanismo de degradação térmica na CNC e CNC-Mod com relação à celulose com um comportamento apresentado em 

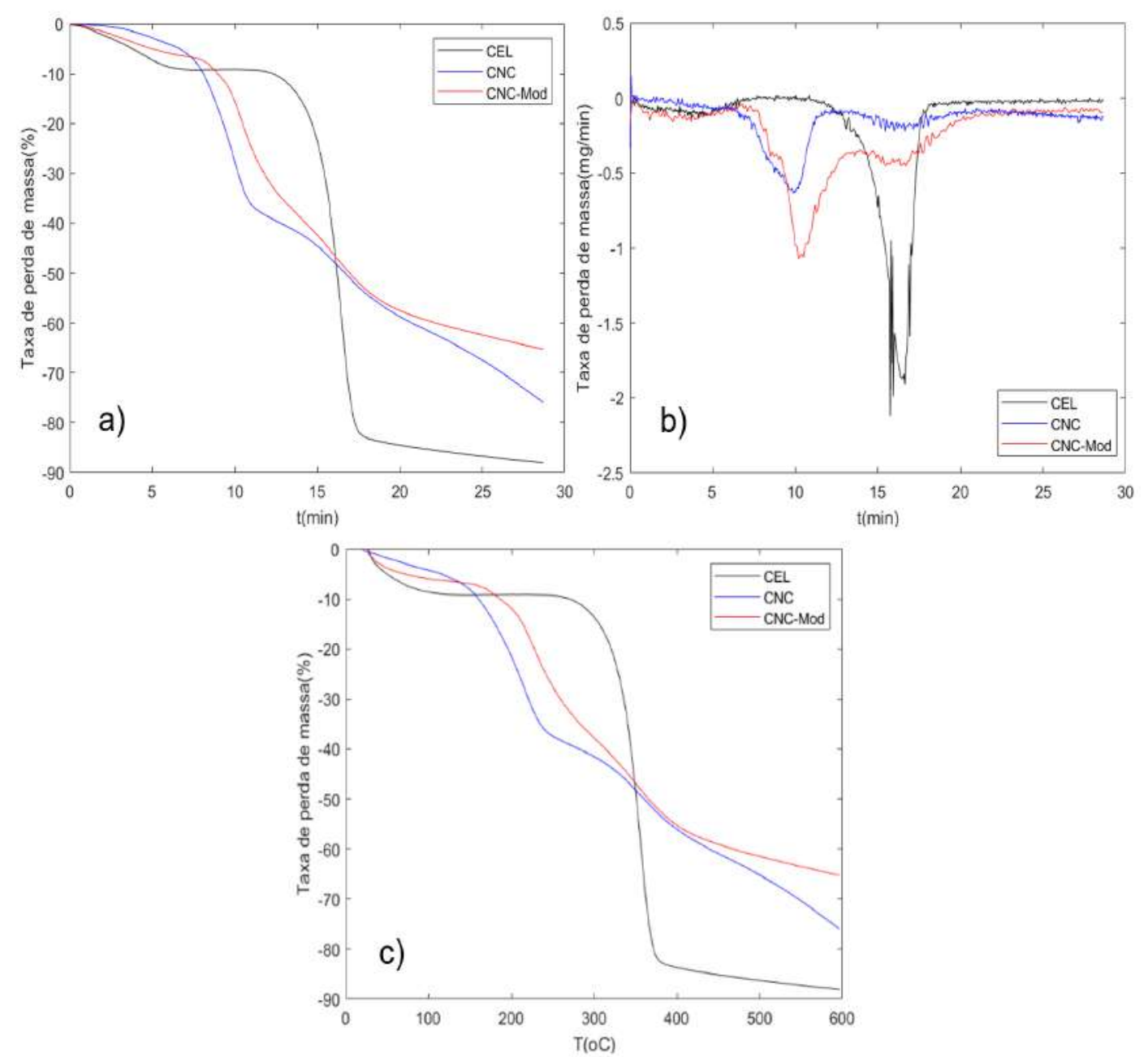

Figura 4.14: Diagrama comparativo da degradação térmica das amostras CEL, CNC e CNC-Mod a) tempo de degradação b) DTG c) temperatura.

dois estágios. Esta alteração pode ser identificada pela presença de dois picos nas curvas de TGA/DTG para a CNC com segundo pico em torno de 307,16 ${ }^{\circ} \mathrm{C}$ (14 min) e para a CNC-Mod com segundo pico em $313,4{ }^{\circ} \mathrm{C}$ (14min e 18s). O aumento do conteúdo de sulfato além de reduzir a temperatura de degradação, promove um alargamento da faixa de temperatura de degradação como observado nas curvas de TGA/DTG da CNC e CNC-Mod [84]. A presença destes picos pode ser relacionada com a diferença nos níveis de incorporação dos grupos ésteres de sulfato [23]. De acordo com Li et al. [85], o primeiro estágio de degradação pode estar relacionado às regiões amorfas e com maior conteúdo de sulfato enquanto que o segundo estágio indica a degradação das regiões cristalinas e com menor quantidade de sulfato.

A figura 4.14.b indica os picos de máxima degradação das amostras, quando há maior taxa de perda de massa. $\mathrm{Na}$ CNC o primeiro estágio apresenta máxima degradação em $208,6^{\circ} \mathrm{C}$ (9 min e 45 s) e o segundo estágio em $367^{\circ} \mathrm{C}$ (17 min). A CNC-Mod apresenta a máxima degradação no primeiro estágio em 
$241^{\circ} \mathrm{C}$ (11 min) e segundo estágio em temperatura e tempo similar ao da CNC. A celulose por possuir maior resistência térmica, o estágio único de degradação ocorre em 369,6 ${ }^{\circ} \mathrm{C}$ (17 min e 09 s). De maneira similar à degradação inicial, o primeiro pico de máxima degradação da CNC ocorre antes da CNC-Mod e, em seguida, a celulose, indicando a maior resistência térmica da celulose e CNC-Mod com relação à CNC. Este resultado pode confirmar o verificado pela análise elementar da CNC-Mod, item 4.4.2, indicando haver possível substituição dos grupos sulfatos pela estrutura do ácido cítrico. Observa-se ainda, que o segundo pico de degradação da CNC e CNC-Mod são similares ao pico de máxima degradação da celulose, porém com menor intensidade. Isto pode indicar a degradação das regiões que permaneceram intactas tanto na hidrólise como na modificação com ácido cítrico, podendo ser indicadas com parte da estrutura original da celulose.

A cinética de decomposição térmica das amostras de celulose, CNC e CNC-Mod foi avaliada a partir da metodologia apresentada no item 3.3.3. Para os casos da CNC e CNC-Mod onde ocorrem dois picos, duas energias de ativação são calculadas para as amostras. Os valores de energia de ativação e ordem de reação são apresentados na Tabela 4.7.

Tabela 4.7: Parâmetros cinétcos ajustados por regressão linear e sigmoide

\begin{tabular}{ccc} 
Amostra & $\begin{array}{c}\text { Energia de ativação } \\
\text { Ea }(\mathbf{k J} / \mathbf{m o l})\end{array}$ & $\begin{array}{c}\text { Ordem de reação } \\
\mathbf{n}\end{array}$ \\
\hline CEL & 58,81 & 1,6396 \\
\hline CNC Pico 1 & 14,03 & 1,44 \\
CNC Pico 2 & 41,98 & 1,58 \\
\hline CNC-Mod P1 & 16,10 & 1,45 \\
CNC-Mod P2 & 44,82 & 1,59 \\
\hline
\end{tabular}

O processo de pirólise da celulose possui energia de ativação muito superior às energias da pirólise da CNC e CNC-Mod sulfatadas (pico 1), confirmando o proposto por Börjesson et al. [45] de que os grupos sulfatos reduzem a resistência térmica. Os gráficos dos ajustes obtidos e as respectivas equações são apresentados no Apêndice B.

A porcentagem de água perdida por evaporação, e o resíduo de biocarvão (Char residue) após a degradação térmica são apresentados na tabela 4.8. A perda de massa por evaporação pode ser menor do que a apresentada, uma vez que, em alguns casos, amostras com maior conteúdo de sulfato tendem a iniciar a degradação abaixo de $150^{\circ} \mathrm{C}$ [84] como é o caso da CNC em estudo, que inicia sua degradação por volta de $116,5^{\circ} \mathrm{C}$. Outras literaturas indicam que a evaporação ocorre em temperaturas inferiores a $100^{\circ} \mathrm{C}$ e por volta de $50^{\circ} \mathrm{C}$ $[21,22,66,67]$. 
Tabela 4.8: Resultados de água evaporada em diferentes temperaturas e massa residual após TGA.

\begin{tabular}{c|ccc} 
Amostra & $\begin{array}{c}\text { Perda de } \\
\text { água }\end{array} \mathbf{5 0}^{\circ} \mathbf{C}(\boldsymbol{\%})$ & $\begin{array}{c}\text { Perda de } \\
\text { água }\end{array}$ & $\begin{array}{c}\text { Massa } \\
\mathbf{1 0 0} \mathbf{C}\end{array}$ \\
\hline CEL & 5,46 & 9,61 & 4,89 \\
residual & $(\%)$ \\
CNC & 1,98 & 5,04 & 17,94 \\
CNC-Mod & 2,52 & 6,68 & 29,48 \\
\hline
\end{tabular}

A CNC e CNC-Mod apresentaram valores altos de resíduos de carvão com relação a amostra de celulose. Li e Wang [67] indicam que as amostras hidrolisadas apresentam maior conteúdo de massa residual, e confirmam o proposto por Roman e Winter [84] e Wang et al. [86] que a degradação da celulose catalisada com ácido sulfúrico tende a gerar mais resíduos do que a celulose. Este efeito pode indicar que o grupo sulfato possui ação retardadora de chamas na CNC e CNC-Mod [85, 84].

\section{7 \\ Adsorção}

A partir do resultado de análise de potencial zeta, o pH da adsorção foi definido como entre 6 e 7 , uma vez que nesta faixa foram obtidos os maiores valores de potencial (-19 a -22 mV), valores próximos aos obtidos por Teodoro et al. [21], -25 mV. Nesta faixa de pH a CNC apresenta uma maior dispersão da suspensão, como apresentado por Teixeira et al. [23].

Os resultados apresentados pela análise de ICP-OES do sobrenadante das adsorções de cobalto, sódio e mercúrio com CEL, CNC e CNC-Mod serviram como indicativo de que a adsorção foi bem-sucedida para os metais em questão. Os resultados para os respectivos metais são apresentados nas figuras 4.15, 4.16 e 4.17 .

Observou-se ligeira diferença de adsorção de cobalto, sendo na CNC, $86,3 \%$, na celulose $82,5 \%$ e na CNC-Mod o percentual de remoção de cobalto foi de $85 \%$. Os resultados de adsorção do sódio nas amostras de celulose, CNC e CNC-Mod são menores que os de cobalto, com percentuais de 59,3\% para a celulose, $61,8 \%$ para a CNC e $63,3 \%$ para a CNC-Mod.

Para o mercúrio, os valores percentuais de remoção são de 55,9\% para a celulose e 55,3\% para a CNC e 35,2\% para a CNC-Mod. Indicando uma alteração significativa no potencial de adsorção de mercúrio após a modificação da CNC.

Em nenhum dos casos, através da adsorção, obteve-se a redução dos níveis para valores abaixo do limites estabelecidos pelas resolucões CONAMA, item 2.6. O Cobalto foi o metal que apresentou maior adsorção para a CNC com 


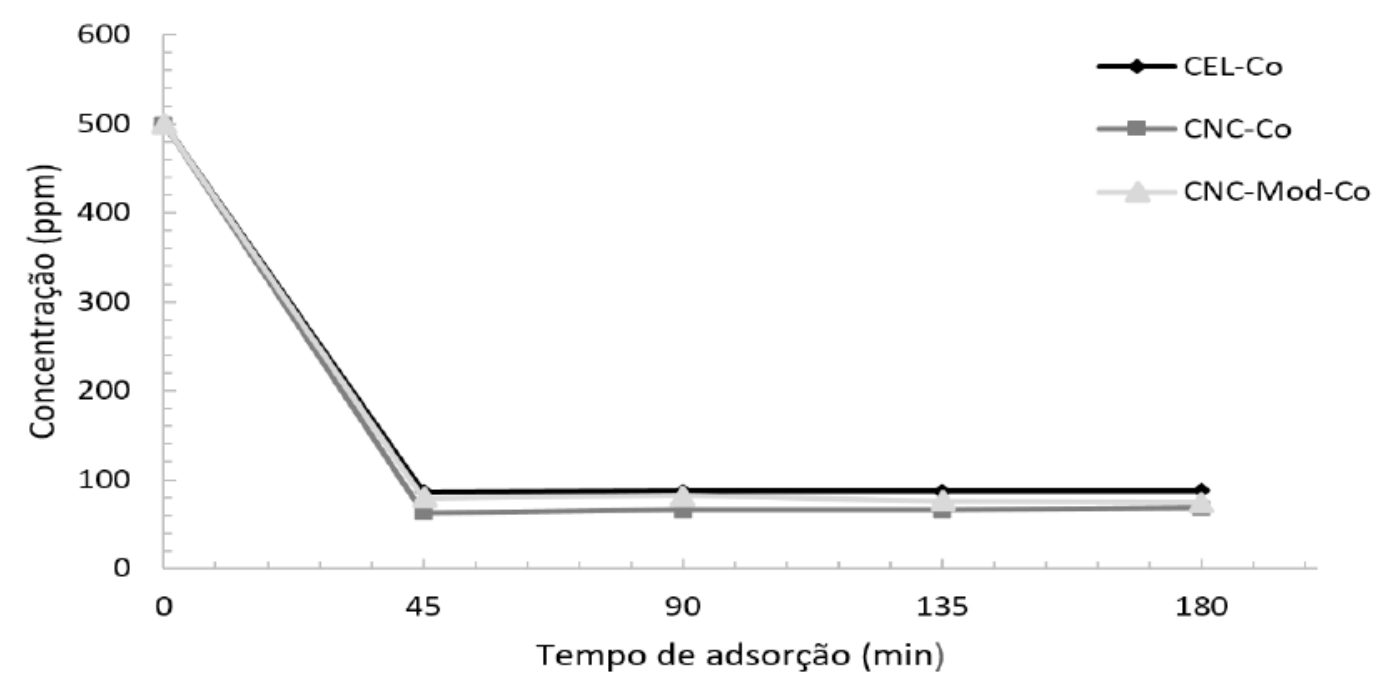

Figura 4.15: Análise de ICP-OES do sobrenadante pós adsorção de cobalto em CEL,CNC e CNC-Mod.

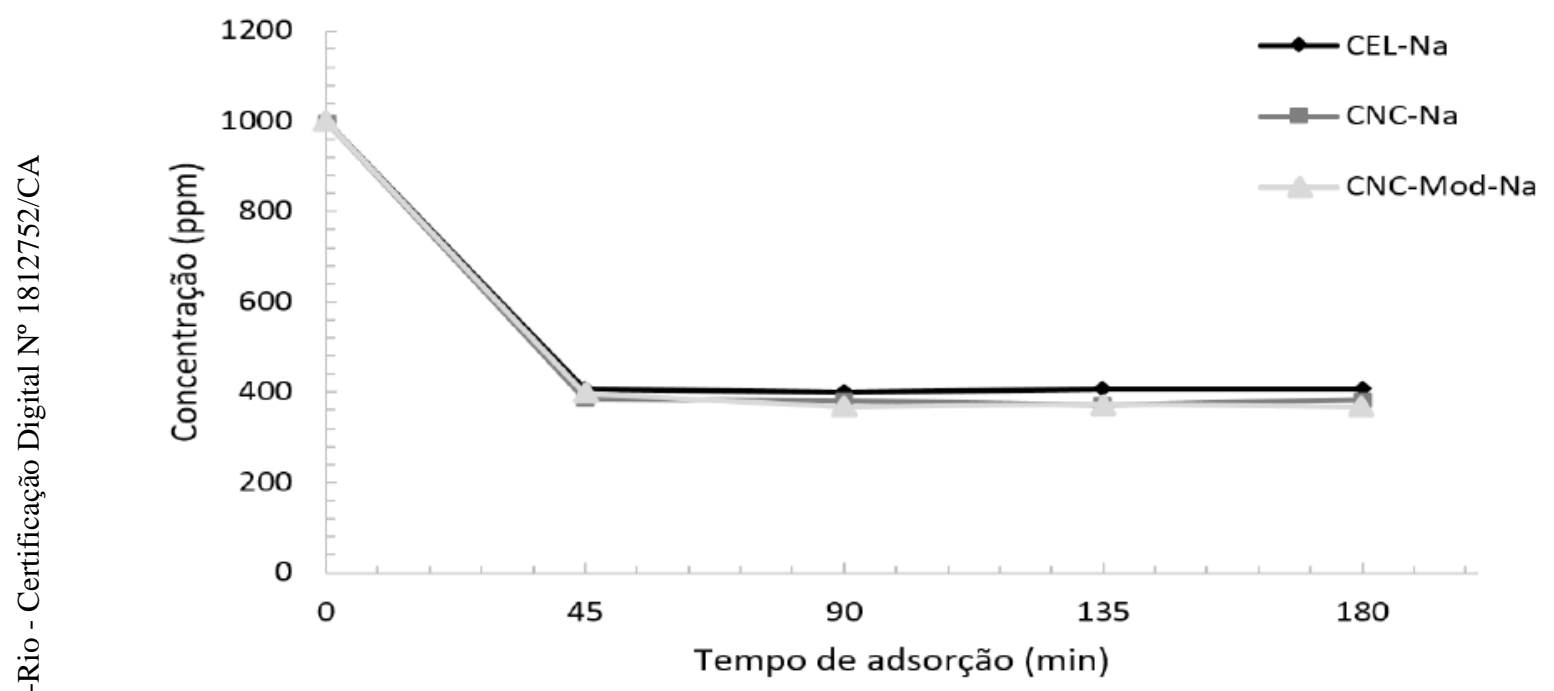

Figura 4.16: Análise de ICP-OES do sobrenadante pós adsorção de sódio em CEL,CNC e CNC-Mod.

86,3\% e o mercúrio apresentou o menor percentual, sendo que, somente para o mercúrio houve maior redução do metal em solução utilizando a amostra de celulose (CEL) quando comparada a CNC, apesar de se tratar de valores próximos, o que pode se enquadrar na margem de erro do equipamento que é aproximadamente $3 \%$ para um intervalo de confiança (incerteza expandida) de $95 \%$. Os valores obtidos e os respectivos erros, com base no erro do equipamento são apresentados na tabela 4.9 .

A partir dos resultados apresentados pelas figuras 4.15, 4.16 e 4.17 observa-se que o percentual adsorvido dos metais foi similar entre as amostras, exceto para a CNC-Mod com o mercúrio, que apresentou recuperação muito 


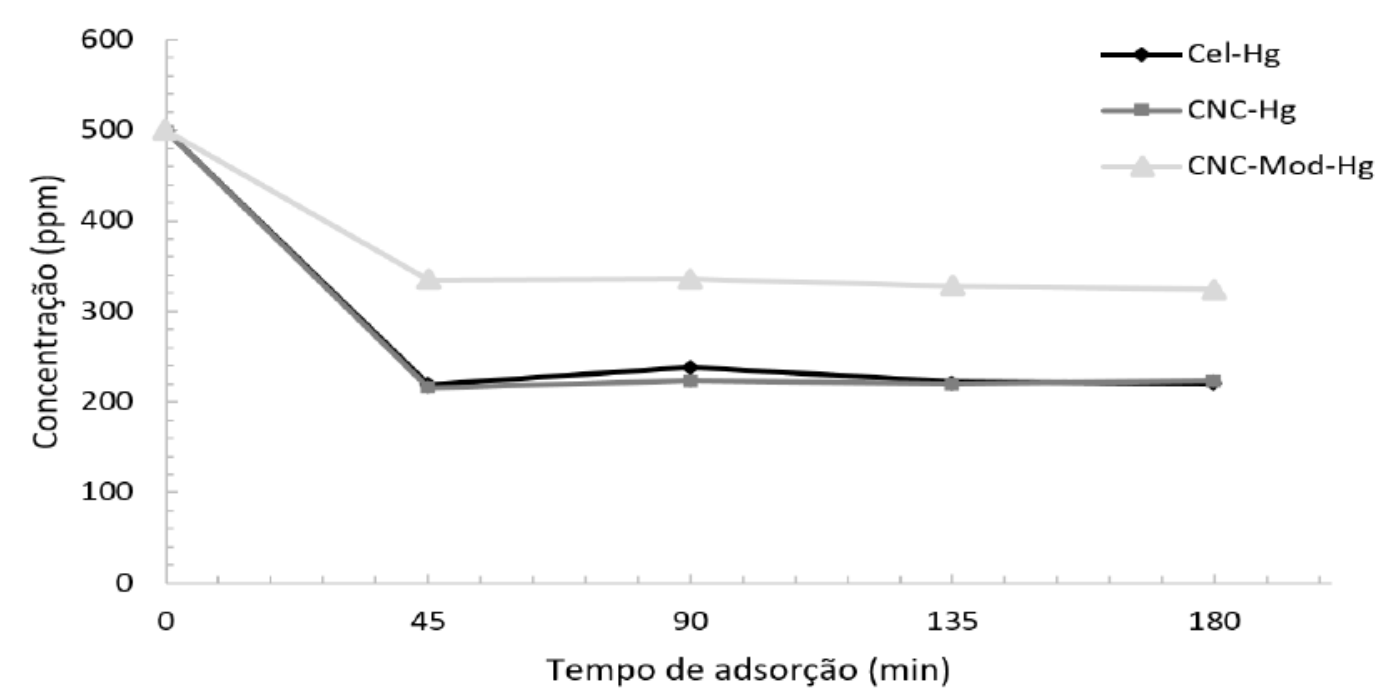

Figura 4.17: Análise de ICP-OES do sobrenadante pós adsorção de mercúrio em CEL,CNC e CNC-Mod.

Tabela 4.9: Concentração final de metais, em mg/L, após 3h de adsorção.

\begin{tabular}{c|ccc} 
& CEL & CNC & CNC-Mod \\
\hline Co & $87 \pm 2,61$ & $68 \pm 2,04$ & $75 \pm 2,25$ \\
$\mathrm{Na}$ & $407 \pm 12,21$ & $382 \pm 11,46$ & $367 \pm 11,01$ \\
$\mathrm{Hg}$ & $220 \pm 6,6$ & $224 \pm 6,72$ & $324 \pm 9,72$ \\
\hline
\end{tabular}

abaixo das outras amostras e metais. Apesar de Hokkanen et al. [43] indicarem a modificação da celulose com grupos carbonila para otimizar as propriedades de adsorção, o resultado obtido não indica melhora significativa que justifique este processo. Deste modo, tanto a obtenção de CNC quanto a sua modificação com ácido cítrico, visando a adsorção de metais, aparentemente não se tornam necessárias para a obtenção de um melhor perfil de adsorção. Contudo, podese verificar a baixa rotação da centrifugação utilizada no processo, $5800 \mathrm{rpm}$, não podendo ser descartada a hipótese da presença de nanocelulose, com metais adsorvidos, no sobrenadante analisado por ICP-OES. Assim, existe a possibilidade de uma maior remoção nos casos da CNC e CNC-Mod, isto pode ser verificado por meio de centrifugação em alta rotação, acima de $10000 \mathrm{rpm}$.

Em todas as amostras, a adsorção parece ter ocorrido de maneira rápida, atingindo um possível equilíbrio em tempo entre zero e 45 minutos de contato. De acordo com Vidal et al. [53] em caso de quimissorção, a energia de ativação da adsorção está relacionada a este fenômeno, assim, para adsorções rápidas a energia de ativação será pequena ou nula e para adsorções lentas a energia de ativação será elevada. Por outro lado, a fisissorção geralmente é um processo rápido somente ocorrendo lentamente em meios porosos. Deste modo, as velocidades de adsorção não podem ser utilizadas como ferramenta para a 
identificação do mecanismo de adsorção.

Visto que a remoção aparenta aumentar rapidamente durante os estágios iniciais de adsorção em todos os metais estudados, e o processo supostamente alcança o equilíbrio antes dos 45 minutos. Sugere-se realizar avaliação com tempos de adsorção entre 0 e 45 minutos para uma melhor compreensão do comportamento cinético do processo de adsorção para as amostras de celulose, CNC e CNC-Mod.

\subsection{1}

\section{MEV e análise termogravimétrica após adsorção de cobalto}

A análise de EDS na amostra de celulose, após o processo de adsorção de cobalto, CEL-Co, não apresentou sinais de ocorrência da adsorção do metal. Neste procedimento, as amostras de CEL, CNC e CNC-Mod foram lavadas duas vezes com água deionizada e agitação vigorosa seguida de centrifugação. Assim, a partir dos resultados obtidos pela análise de ICP-OES, pode-se sugerir ter ocorrido a dessorção do cobalto, possivelmente adsorvido por mecanismo de fisissorção, durante este processo de purificação da amostra.

Na figura 4.18 pode-se observar o mapa de EDS, na figura 4.18.a é apresentada a aglomeração da nanocelulose após o processo de secagem. As figuras 4.18.b a 4.18.e indicam a distribuição dos elementos ao longo da amostra. A adsorção do cobalto na CNC pode ser confirmada, de maneira semi-quantitativa, pelo mapa de EDS de cobalto na figura 4.18.e, e pela tabela 4.10 .

A partir das frações mássicas de cobalto e enxofre obtidas pela análise do EDS, observa-se uma equivalência entre esses elementos, com valores médios de fração mássica de 0,25 e 0,27 respectivamente, o que pode indicar a interação entre os dois elementos, levando a entender a ocorrência do mecanismo de quimissorção para o processo de adsorção CNC-Co. Entretanto, devido à baixa precisão do EDS, cerca de 5\%, esta afirmação somente pode ser confirmada após estudos complementares do comportamento da adsorção do cobalto pela CNC. Análises instrumentais como EXAFS (do inglês extended X-ray absorption fine structure) e XPS (do inglês X-ray photoelectron spectroscopy), são técnicas recomendadas para uma melhor avaliação elementar na amostra estudadas.

Um método para a determinação do comportamento do processo de adsorção seria um estudo termodinâmico, por meio da variação de entalpia do processo, uma vez que, pela literatura, estima-se que o calor envolvido na fisissorção seja menor que $10 \mathrm{kcal} / \mathrm{mol}$ e o calor de quimissorção seja acima de $20 \mathrm{kcal} / \mathrm{mol}$. Outra possibilidade é a avaliação cinética por meio de modelagem 
do processo e avaliação das energias de ativação envolvidas [53].
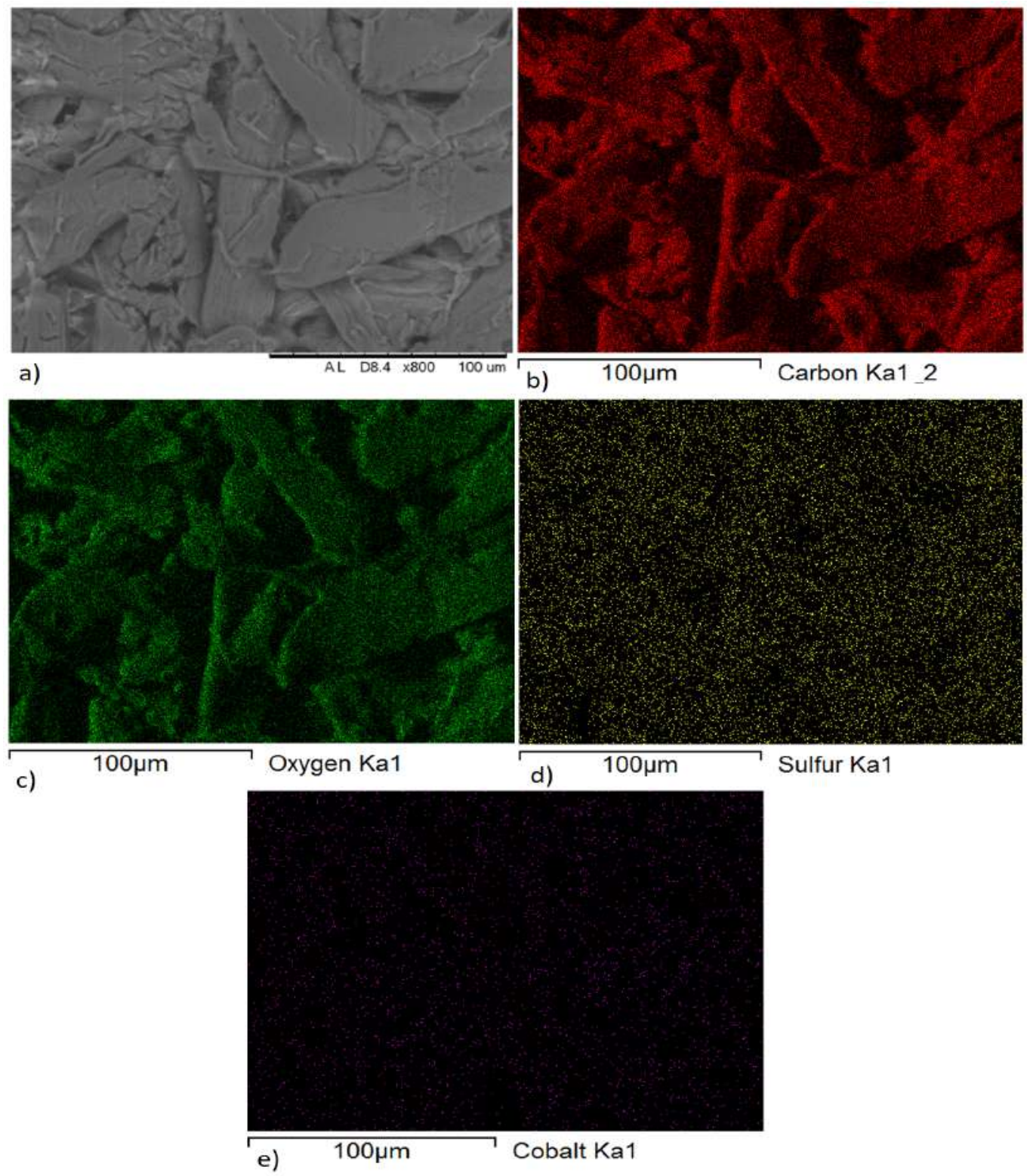

Figura 4.18: Imagens de MEV e mapa de EDS da CNC após adsorção de cobalto a) CNC com aumento de 800x b) Mapa de EDS de carbono c) Mapa de EDS de oxigênio d) Mapa de EDS de enxofre e) Mapa de EDS do cobalto.

A análise de EDS da adsorção de cobalto pela CNC-Mod indicou quantidade do metal próxima de zero como apresentado na tabela 4.11. Porém, a análise de ICP-OES confirma a adsorção do metal. Quando comparado com os espectros de EDS da CNC, os valores percentuais de carbono, e enxofre reduziram e o conteúdo de oxigênio aumentou, o que pode indicar um mecanismo de coordenação do grupo carboxila da CNC-Mod, atribuída à adsorção do cobalto [59]. A figura 4.19 apresenta o mapeamento do espectro 2, apresentado na tabela 4.11, para a CNC-Mod-Co 
Tabela 4.10: Resultados em porcentagem mássica da análise elementar semiquantitativa da adsorção de cobalto pela CNC.

\begin{tabular}{c|ccccc} 
Região & C & O & Al & S & Co \\
\hline Espectro 1 & 48,06 & 50,71 & 0,74 & 0,27 & 0,23 \\
Espectro 2 & 47,77 & 50,83 & 0,90 & 0,24 & 0,26 \\
Espectro 3 & 48,72 & 49,88 & 0,90 & 0,32 & 0,18 \\
Espectro 4 & 49,32 & 49,10 & 1,02 & 0,29 & 0,27 \\
Espectro 5 & 50,94 & 47,90 & 0,64 & 0,25 & 0,27 \\
Espectro 6 & 48,63 & 49,88 & 0,91 & 0,27 & 0,31 \\
\hline Média & 48,91 & 49,72 & 0,85 & 0,27 & 0,25 \\
Desvio padrão & 1,03 & 1,00 & 0,12 & 0,03 & 0,04 \\
\hline
\end{tabular}

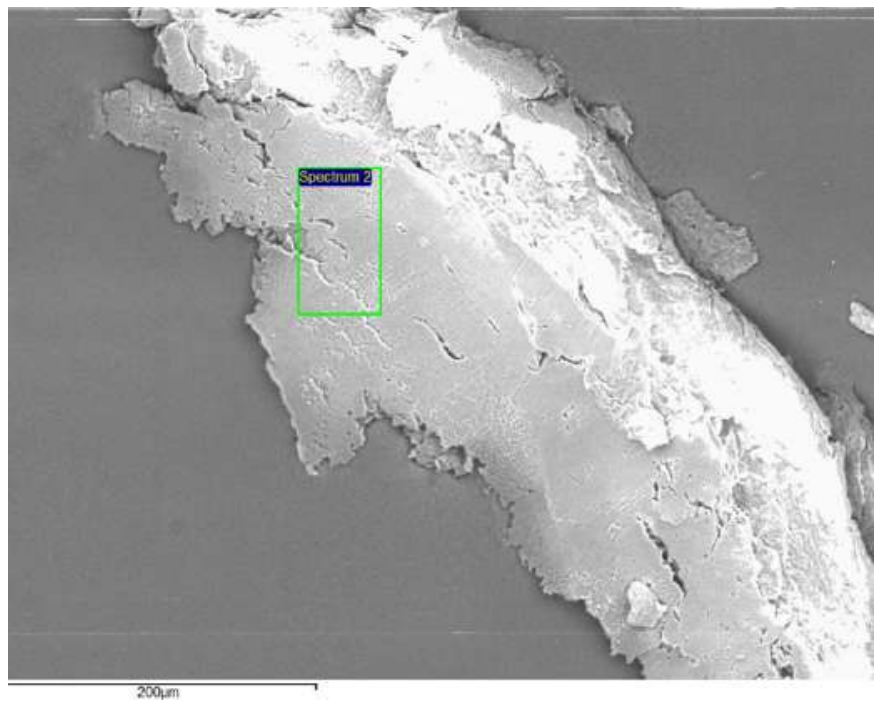

Figura 4.19: Região de mapeamento do espectro 2 da CNC-Mod-Co, amplificação de 500x.

Tabela 4.11: Resultados em porcentagem mássica da análise elementar semiquantitativa da adsorção de cobalto pela CNC-Mod

\begin{tabular}{c|ccccc} 
Região & $\mathbf{C}$ & $\mathbf{O}$ & $\mathbf{A l}$ & $\mathbf{S}$ & $\mathbf{C o}$ \\
\hline Espectro 1 & 45,82 & 53,57 & 0,15 & 0,42 & 0,02 \\
Espectro 2 & 45,98 & 54,14 & 0,09 & 0,44 & 0,03 \\
Espectro 3 & 45,26 & 54,13 & 0,09 & 0,46 & 0,04 \\
Espectro 4 & 45,33 & 54,04 & 0,10 & 0,47 & 0,05 \\
\hline Média & 45,60 & 53,97 & 0,11 & 0,45 & 0,04 \\
Desvio padrão & 0,31 & 0,23 & 0,02 & 0,02 & 0,01 \\
\hline
\end{tabular}

Após o processo de adsorção as amostras de CEL-Co, CNC-Co e CNCMod-Co foram estudadas via termogravimetria, Figura 4.20. Os resultados indicam que após a adsorção de cobalto as amostras de CNC e CNC-Mod apresentaram um comportamento similar, com as curvas das respectivas amostras praticamente se sobrepondo. Observa-se também que o comportamento 
de degradação térmica da CNC e CNC-Mod se apresenta em dois estágios.

$\mathrm{O}$ primeiro estágio se inicia em $202,8^{\circ} \mathrm{C}(9 \min$ e $36 \mathrm{~s})$ e $204,7^{\circ} \mathrm{C}(9$ min e 36 s) e termina em $304,7^{\circ} \mathrm{C}$ e $305,2^{\circ} \mathrm{C}$ para a CNC-Co e CNC-Mod-Co respectivamente. $\mathrm{O}$ segundo estágio repete esta tendência de similaridade com o pico se iniciando próximo a $313^{\circ} \mathrm{C}(14 \mathrm{~min}$ e $18 \mathrm{~s})$ e terminando em $427^{\circ} \mathrm{C}$ (20 min e 6 s) para ambas as amostras. Fazendo uma comparação entre as respectivas curvas de TGA/DTG das amostras de CNC e CNC-Mod antes, Figura 4.14, e após a adsorção Figura 4.20, pode-se inferir que a inserção do cobalto aparentemente melhora as propriedades térmicas da CNC, porém, não altera a resistência a degradação térmica da CNC-Mod. Além disso, constatase a alteração na temperatura inicial de degradação térmica da celulose, após a adsorção de cobalto, com aumento de aproximadamente $5 \%$, de $260,5^{\circ} \mathrm{C}(11$ min e $51 \mathrm{~s}$ ) para $273,8^{\circ} \mathrm{C}$ (12 min e $\left.24 \mathrm{~s}\right)$. Por outro lado, a temperatura final de degradação sofreu uma redução em torno de $2,3 \%$.

A comparação entre a figura 4.20b e 4.14.b indica que os picos de máxima degradação das amostras sofrem alterações. No caso da CNC e CNC-Mod há um aumento na temperatura de máxima degradação do primeiro estágio de $208,6^{\circ} \mathrm{C}(9 \min$ e $45 \mathrm{~s})$ para $263^{\circ} \mathrm{C}(12 \mathrm{~min})$ e de $241^{\circ} \mathrm{C}(11 \mathrm{~min})$ para $275,6^{\circ} \mathrm{C}$ (12 min e $30 \mathrm{~s}$ ) respectivamente. Isto indica uma possível melhora na resistência a degradação térmica dos materiais com a presença de cobalto. O segundo estágio de ambas CNC e CNC-Mod não apresentam alteração. O Pico de máxima degradação reduz de $369,6^{\circ} \mathrm{C}(17$ min e $09 \mathrm{~s})$ na CEL para $337,4^{\circ} \mathrm{C}$ (15 min e 30 s) na CEL-Co. Entretanto o valor de energia de ativação aumenta em cerca de $12 \mathrm{~kJ} / \mathrm{mol}$.

A análise cinética de decomposição térmica, a partir de ajuste do sigmoide e ajuste linear, foi realizada nas amostras após adsorção de cobalto. Os resultados são apresentados na tabela 4.12 .

Tabela 4.12: Parâmetros cinétcos ajustados por regressão linear e sigmoide após a adsorção de cobalto.

\begin{tabular}{ccc} 
Amostra & $\begin{array}{c}\text { Energia de ativação } \\
\text { Ea (kJ/ mol) }\end{array}$ & $\begin{array}{c}\text { Ordem de reação } \\
\mathbf{n}\end{array}$ \\
\hline CEL-Co & 70,86 & 1,64 \\
\hline CNC-Co Pico 1 & 44,04 & 1,64 \\
CNC-Co Pico 2 & 37,08 & 1,53 \\
\hline CNC-Mod-Co P1 & 38,69 & 1,61 \\
CNC-Mod-Co P2 & 37,67 & 1,54 \\
\hline
\end{tabular}

Os valores de energia de ativação e ordem de reação para o segundo pico da CNC-Co e CNC-Mod-Co são próximos, o que pode indicar mecanismos similares de degradação térmica. A amostra de celulose, CEL-Co apresenta 

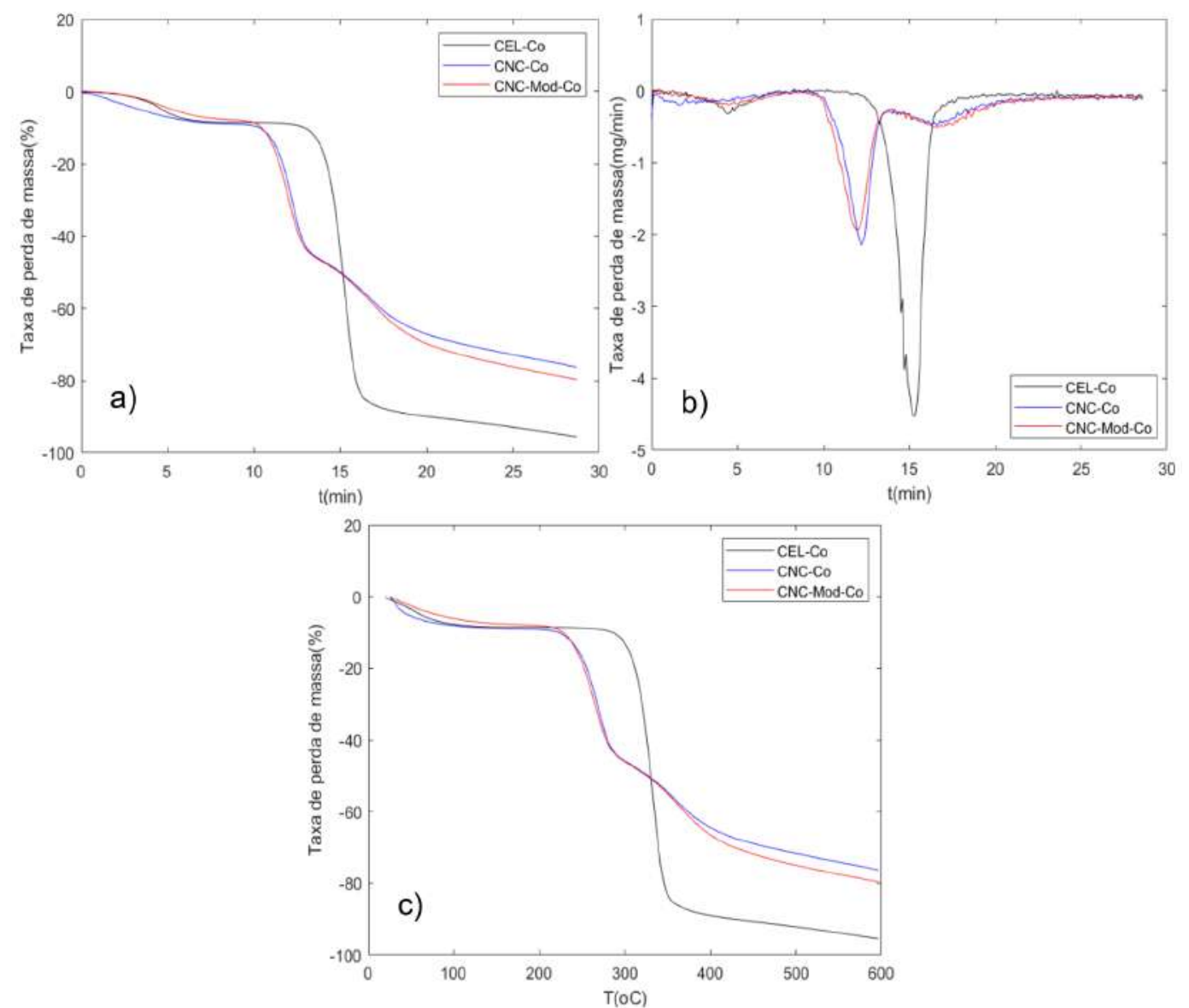

Figura 4.20: Diagrama comparativo da degradação térmica da CEL-Co, CNCCo e CNC-Mod-Co a) tempo de degradação b) DTG c) temperatura.

maior valor de energia de ativação e, portanto, maior estabilidade térmica. A CNC-Mod-Co com conteúdo de sulfato, pico 1, se mostrou menos estável termicamente do que a CNC-Co, o que pode confirmar a hipótese anterior de que a presença do cobalto melhora as propriedades térmicas da CNC com relação a CNC-Mod.

Quando comparada às amostras puras, observa-se aumento significativo na energia de ativação do primeiro pico da CNC-Co, de 14,03 para 44,04 $\mathrm{kJ} / \mathrm{mol}$, que juntamente com a equivalência observada nos dados de EDS, tabela 4.11 podem indicar a interação do cobalto com o grupo sulfato da CNC. Neste caso, o cobalto altera o primeiro estágio de degradação, indicado por Li et al. [85] como o pico relacionado às regiões com maior quantidade de sulfato. O mesmo ocorre com a CNC-Mod com aumento da energia de ativação no primeiro estágio de 22,6 kJ/mol. De maneira similar ao pico da CEL-Co, o segundo estágio da CNC-Co e CNC-Mod-Co apresenta uma redução na energia de ativação. Isto pode confirmar o proposto por Li et al. [85] que este estágio é relacionado às regiões remanescentes da celulose original. 
As quantidades percentuais de água perdida por evaporação, e o resíduo de biocarvão após a degradação térmica são apresentados na tabela 4.13.

Tabela 4.13: Resultados de água evaporada em diferentes temperaturas e massa residual após TGA.

\begin{tabular}{|c|c|c|c|}
\hline Amostra & $\begin{array}{c}\text { Perda de } \\
\text { água } 50^{\circ} \mathrm{C}(\%)\end{array}$ & $\begin{array}{c}\text { Perda de } \\
\text { água } 100^{\circ} \mathrm{C}(\%)\end{array}$ & $\begin{array}{c}\text { Massa } \\
\text { residual (\%) }\end{array}$ \\
\hline CEL-Co & 3,52 & 7,95 & 5,44 \\
\hline CNC-Co & 5,34 & 8,29 & 24,43 \\
\hline CNC-Mod-Co & 2,52 & 6,44 & 21,16 \\
\hline
\end{tabular}

A quantidade de resíduos aumentou cerca de 36,2\% com a adsorção de cobalto na CNC, e 11,2\% na celulose. Por outro lado, houve uma redução de 28,2\% no conteúdo de massa residual após a pirólise na amostra CNC-Mod-Co em relação à CNC-Mod.

\subsection{2}

\section{MEV e análise termogravimétrica após adsorção de sódio}

A análise de EDS da celulose, após a adsorção de sódio, não apresentou valores significativos que indiquem a adsorção do metal, Tabela 4.14. A fração mássica apresentada na análise é próxima a zero, indicando assim, que o processo de lavagem também pode acarretar a dessorção do material. A partir deste efeito, de maneira análoga ao item 4.7.1 pode-se inferir a possível ocorrência da fisissorção como o mecanismo principal de adsorção pela celulose. A figura 4.21 apresenta a região do espectro 1 apresentado na tabela 4.14.

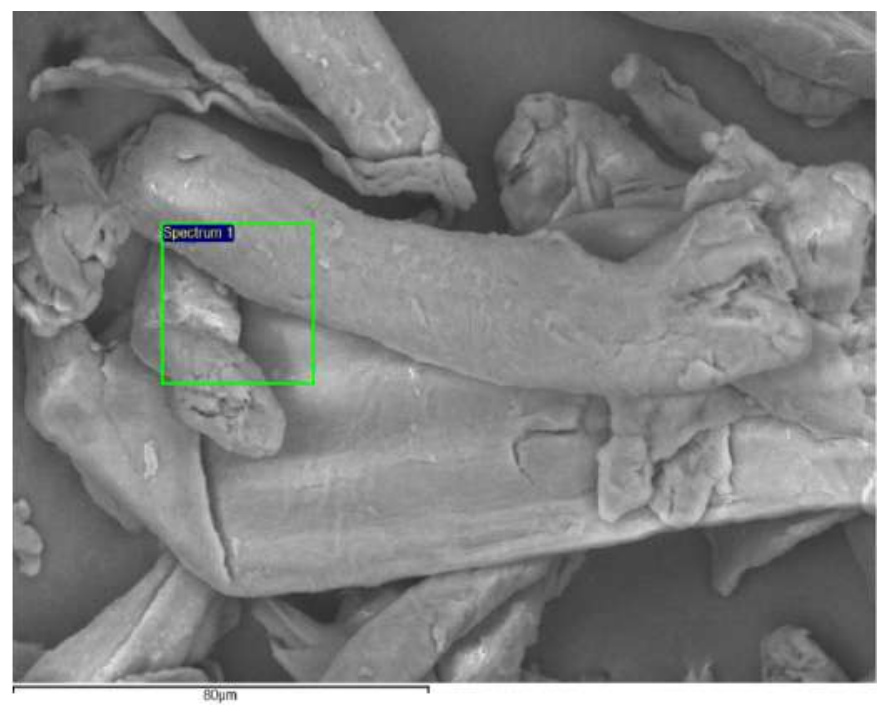

Figura 4.21: Região mapeada da CEL-Na, espectro 1, amplificação de 1000x. 
Tabela 4.14: Porcentagem mássica da análise elementar após adsorção de sódio pela CEL.

\begin{tabular}{c|cccc} 
Região & $\mathbf{C}$ & $\mathbf{O}$ & $\mathbf{A l}$ & $\mathbf{N a}$ \\
\hline Espectro 1 & 46,39 & 53,34 & 0,24 & 0,04 \\
Espectro 2 & 47,28 & 52,21 & 0,50 & 0,01 \\
Espectro 3 & 46,93 & 52,90 & 0,14 & 0,03 \\
\hline Média & 46,87 & 52,82 & 0,03 & 0,29 \\
Desvio padrão & 0,37 & 0,47 & 0,01 & 0,15 \\
\hline
\end{tabular}

A figura 4.22 mostra o mapa de EDS da CNC, a distribuição dos elementos ao redor da amostra é verificada na Figura 4.22.b, 4.22.c, 4.22.d, 4.22. A análise da figura 4.22 juntamente com a tabela 4.15 permite observar a ocorrência da adsorção de sódio.

As frações mássicas obtidas, semi-quantitativamente, pela análise elementar apresentam novamente uma equivalência entre o conteúdo de sódio e o enxofre. Isto pode indicar que o sitio ativo da CNC é a hidroxila do grupo sulfato e que possivelmente uma reação de substituição, adsorção química, está ocorrendo, como a reação apresentada por Börjesson et al. [45].

Tabela 4.15: Porcentagem mássica da análise elementar após adsorção de sódio pela CNC.

\begin{tabular}{c|ccccc} 
Região & $\mathbf{C}$ & $\mathbf{O}$ & $\mathbf{N a}$ & $\mathbf{A l}$ & $\mathbf{S}$ \\
\hline Espectro 1 & 48,67 & 50,52 & 0,22 & 0,29 & 0,30 \\
Espectro 2 & 47,81 & 51,70 & 0,22 & 0,27 & 0,27 \\
Espectro 3 & 48,18 & 51,07 & 0,26 & 0,22 & 0,27 \\
\hline Média & 48,22 & 51,10 & 0,23 & 0,26 & 0,28 \\
Desvio padrão & 0,35 & 0,48 & 0,02 & 0,03 & 0,01 \\
\hline
\end{tabular}




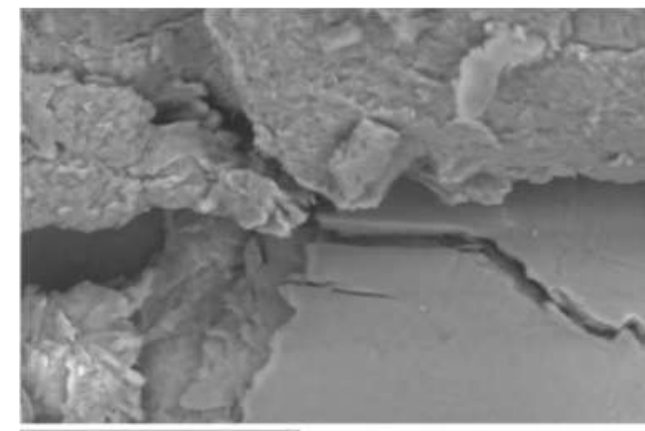

a)

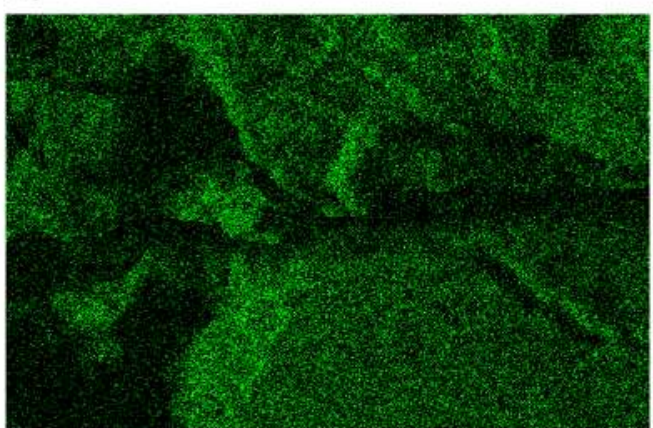

c)
Oxygen Ka1

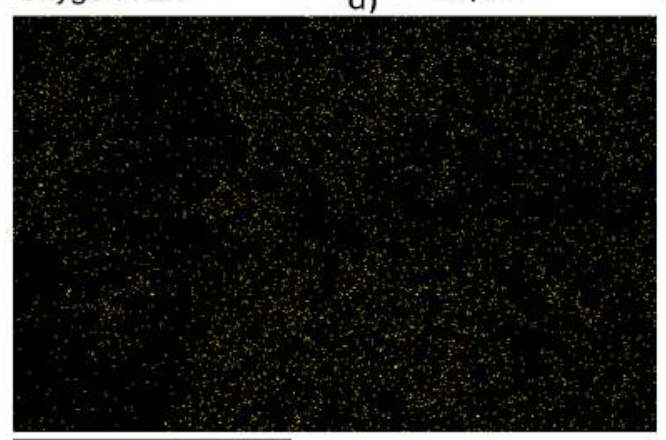

e)

Sodium Ka1_2

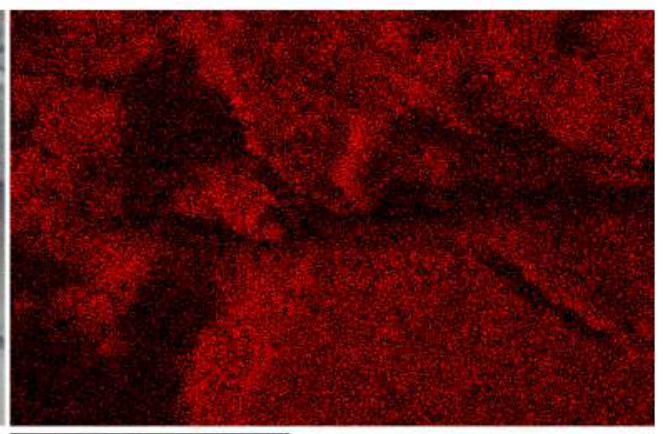

b)

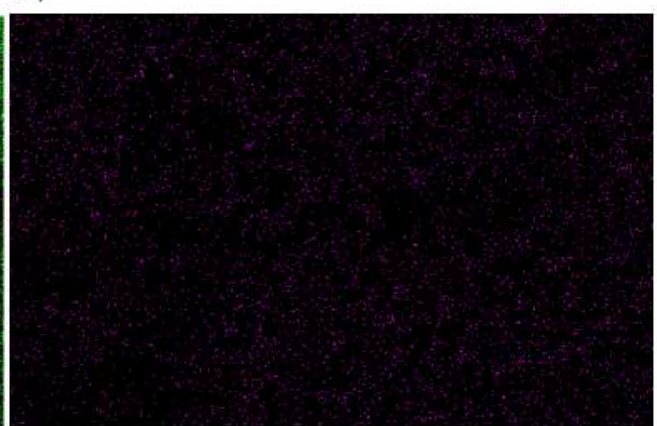

Sulfur Ka1

Figura 4.22: MEV e mapa de EDS da CNC-Na a) CNC com aumento de 800x b) Mapa de EDS de carbono c) Mapa de EDS de oxigênio d) Mapa de EDS de enxofre e) Mapa de EDS do cobalto.

O mapa de EDS da CNC-Mod-Na é apresentado na figura 4.23. E as quantidades apresentadas de cada elemento podem ser observadas pela tabela 4.16. A CNC-Mod se apresentou com eficiência de adsorção de sódio próxima à da CNC, o que pode ser confirmada pela análise de ICP-OES figura $4.16 \mathrm{e}$ tabela 4.9 .

Os resultados da análise termogravimétrica da CEL-Na, CNC-Na e CNCMod-Na, apresentados na Figura 4.24 indicam uma mudança no mecanismo de degradação térmica da CNC e da CNC-Mod, que antes da adsorção ocorriam em duas etapas, passando a acontecer somente em etapa única, e com perfil similar ao apresentado pena CEL-Na e celulose.

Os picos da CNC-Na e CNC-Mod-Na se sobrepõem possivelmente indicando mecanismo de degradação térmica similar, o que pode ser confirmado 

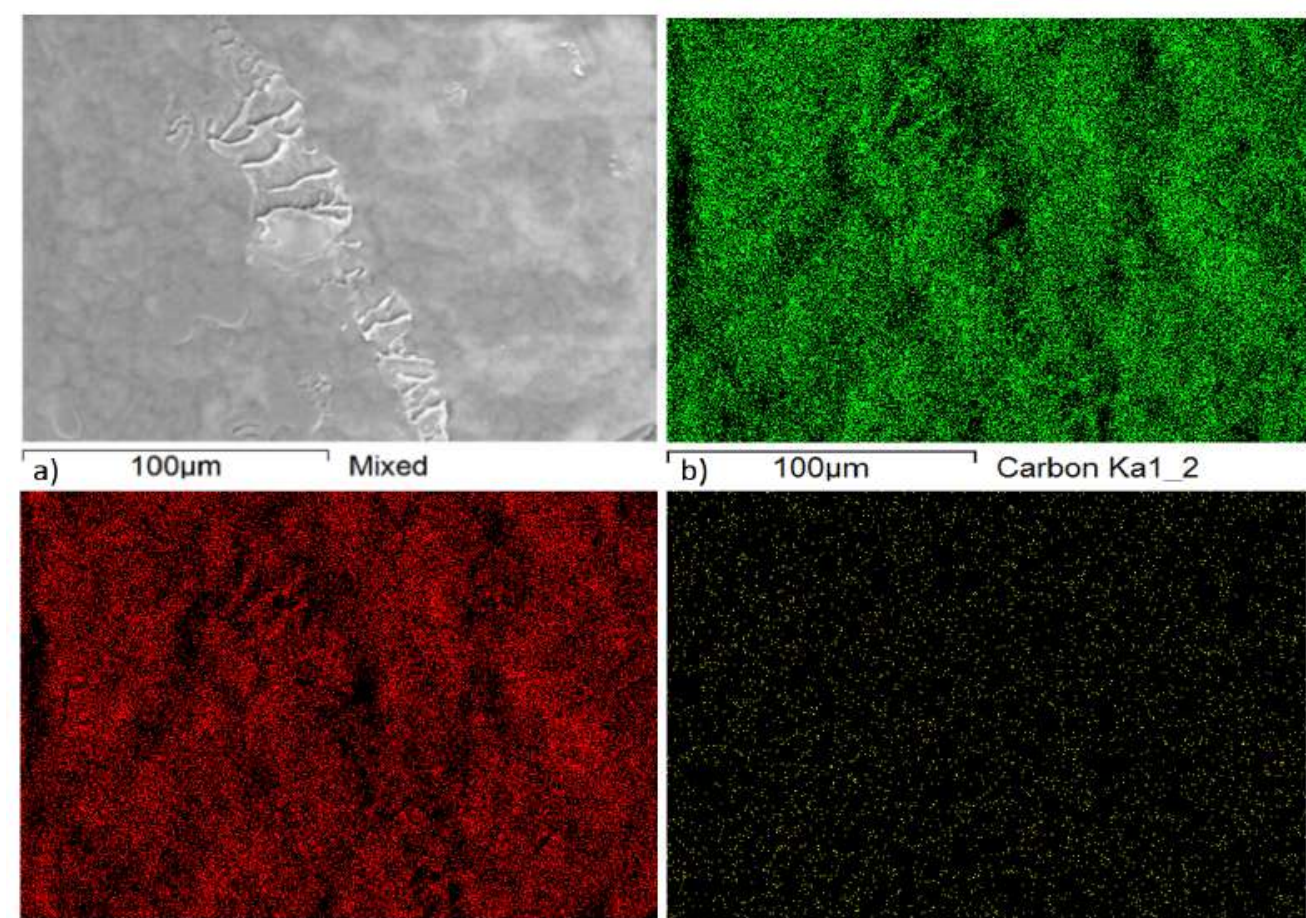

Carbon Ka1 2

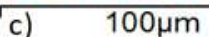

Oxygen Ka1
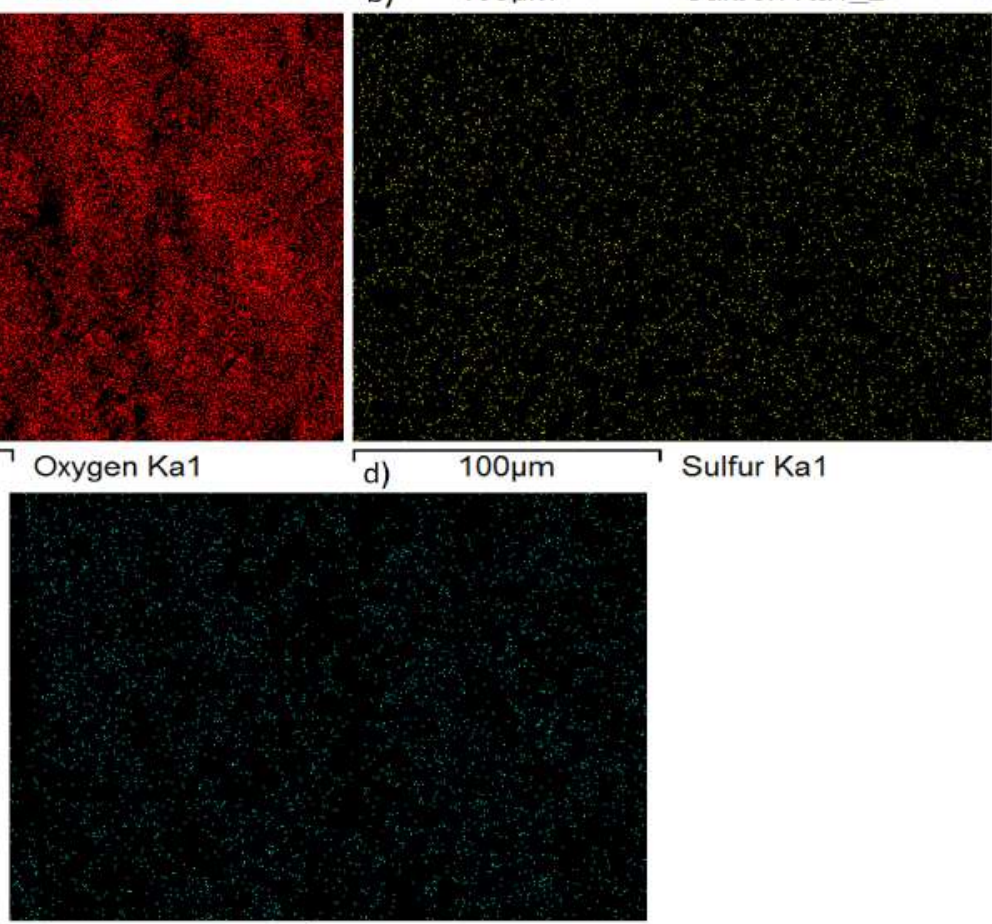

Sulfur Ka1

e) $100 \mu \mathrm{m}$

Sodium Ka1_2

Figura 4.23: MEV e mapa de EDS da CNC-Mod-Na a) CNC-Mod-Na com aumento de 800x b) Mapa de EDS de carbono c) Mapa de EDS de oxigênio d) Mapa de EDS de enxofre e) Mapa de EDS do sódio.

Tabela 4.16: Porcentagem mássica da análise elementar após adsorção de sódio pela CNC-Mod.

\begin{tabular}{c|ccccc} 
Região & $\mathbf{C}$ & $\mathbf{O}$ & $\mathbf{N a}$ & $\mathbf{A l}$ & $\mathbf{S}$ \\
\hline Espectro 1 & 66,20 & 32,34 & 0,47 & 0,47 & 0,52 \\
Espectro 2 & 47,11 & 51,93 & 0,23 & 0,49 & 0,24 \\
Espectro 3 & 47,03 & 51,86 & 0,25 & 0,56 & 0,30 \\
Espectro 4 & 47,61 & 51,40 & 0,23 & 0,53 & 0,24 \\
\hline Média & 51,99 & 46,88 & 0,30 & 0,51 & 0,33 \\
Desvio padrão & 8,21 & 8,40 & 0,10 & 0,03 & 0,12
\end{tabular}

pelos dados cinéticos de energia de ativação e ordem de reação apresentados na tabela 4.17. Além disso, para as três amostras a degradação se inicia próxima a $210^{\circ} \mathrm{C}(9 \mathrm{~min}$ e $48 \mathrm{~s})$. De maneira similar ao comportamento térmico apre- 
sentado pelas amostras de celulose pura, Figura 4.14, e celulose com cobalto adsorvido, Figura 4.20, a amostra com sódio adsorvido tem o maior valor de energia de ativação, indicando maior estabilidade térmica frente as amostras de CNC e CNC-Mod com e sem metais adsorvidos.

O pico de máxima degradação da celulose, CEL-Na, figura 4.24.b apresenta perfil similar ao apresentado pela celulose,CEL, figura 4.14.b ocorrendo em $370,9^{\circ} \mathrm{C}$ (17 min e 12 s). Isto pode indicar que o sódio ou não interagiu com a celulose, ou foi retirado por dessorção no preparo da amostra para a análise em questão. Como a análise de ICP-OES do sobrenadante indica a adsorção do sódio pela celulose, a aplicação de outro método quantitativo para a amostra sólida de CEL-Na, como o ICP-MS, pode ser realizada para a confirmação da presença de sódio. A máxima degradação da CNC-Na e CNC-Mod-Na ocorrem ambas próximas a $307^{\circ} \mathrm{C}(14 \mathrm{~min})$.
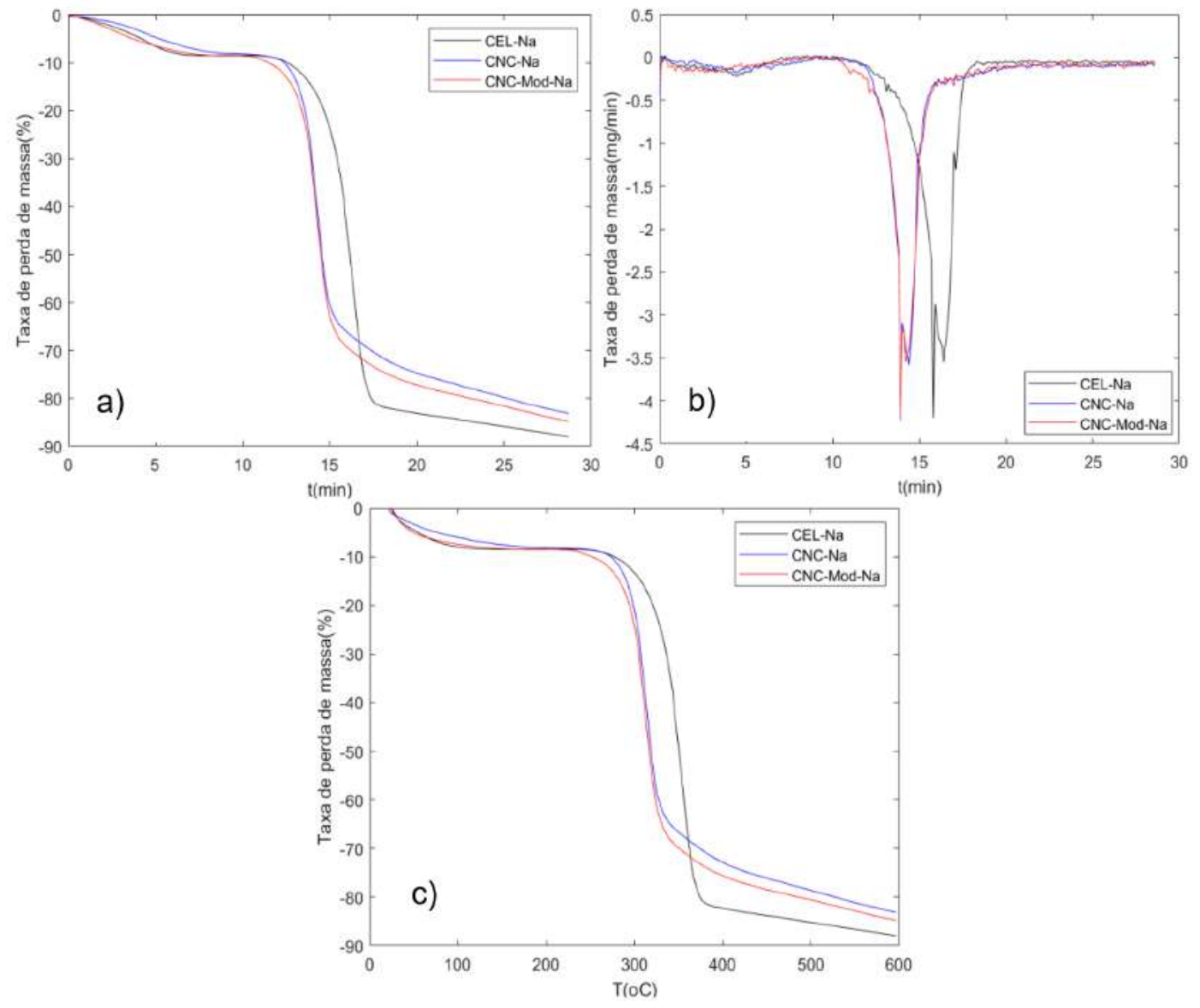

Figura 4.24: Diagrama comparativo da degradação térmica das amostras CELNa, CNC-Na e CNC-Mod-Na a) tempo de degradação b) DTG c) temperatura.

O resíduo final da CEL-Na, Tabela 4.18, aumentou significativamente, de $4.89 \%$ na CEL, tabela 4.8, para 12,93\% na CEL-Na. Entretanto para a CNC-Na a quantidade se manteve constante se comparada à CNC, e obteve-se 
Tabela 4.17: Parâmetros cinétcos ajustados por regressão linear e sigmoide após a adsorção de sódio.

\begin{tabular}{ccc} 
Amostra & $\begin{array}{c}\text { Energia de ativação } \\
\mathbf{E a}(\mathbf{k J} / \mathbf{m o l})\end{array}$ & $\begin{array}{c}\text { Ordem de reação } \\
\mathbf{n}\end{array}$ \\
\hline CEL-Na & 57,24 & 1,63 \\
\hline CNC-Na & 32,85 & 1,35 \\
\hline CNC-Mod-Na & 31,81 & 1,35 \\
\hline
\end{tabular}

Tabela 4.18: Resultados de perda água em diferentes temperaturas e massa residual após TGA das amostras CEL-Na, CNC-Na e CNC-Mod-Na.

\begin{tabular}{|c|c|c|c|}
\hline Amostra & $\begin{array}{c}\text { Perda de } \\
\text { água } 50^{\circ} \mathrm{C}(\%)\end{array}$ & $\begin{array}{c}\text { Perda de } \\
\text { água } 100^{\circ} \mathrm{C}(\%)\end{array}$ & $\begin{array}{c}\text { Massa } \\
\text { residual (\%) }\end{array}$ \\
\hline CEL-Na & 4,43 & 8,11 & 12,93 \\
\hline CNC-Na & 3,35 & 6,29 & 17,73 \\
\hline CNC-Mod-Na & 4,96 & 7,63 & 16,04 \\
\hline
\end{tabular}

um conteúdo de biocarvão $27 \%$ menor do que a CNC-Co. A amostra de CNCMod-Na apresentou a menor quantidade de massa residual quando comparado com a CNC-Mod e com a CNC-Mod-Co.

\subsection{3}

\section{MEV e análise termogravimétrica após adsorção de mercúrio}

De maneira similar ao comportamento de adsorção de cobalto e sódio pelas amostras de celulose (CEL-Co e CEL-Na), a análise de EDS não indicou adsorção de mercúrio pela mesma. Além disso. a CNC-Hg e a CNC-ModHg também não resultaram em quantidade significativa de mercúrio. Por outro lado, a análise de ICP-OES confirma que houve a adsorção do metal pelas amostras. O que pode indicar uma possível adsorção física, normalmente fraca, e a consequente ocorrência de dessorção do mercúrio nos processos de purificação. Entretanto, tal afirmação somente pode ser considerada após avaliação por outras técnicas como ICP-MS, EXAFS ou XPS. A figura 4.25 apresenta a imagem de $\mathrm{MEV}$ da $\mathrm{CNC}-\mathrm{Hg}$ com a região do espectro $1 \mathrm{em}$ destaque.

A análise de EDS da amostra de CNC-Mod indicou uma aparente contaminação por sódio na amostra o que pode ter impedido, em certo grau a adsorção do mercúrio. A figura 4.26 apresenta a imagem de $\mathrm{MEV}$ da CNC-Mod-Hg, observa-se a alta tendencia da CNC-Mod-Hg de se aglomerar formando uma espécie de membrana. A presença de sódio, foi verificada por meio de análise pontual, espectro 1, apresentado pela figura 4.27.

O comportamento demonstrado pelas amostras na análise termogravi- 


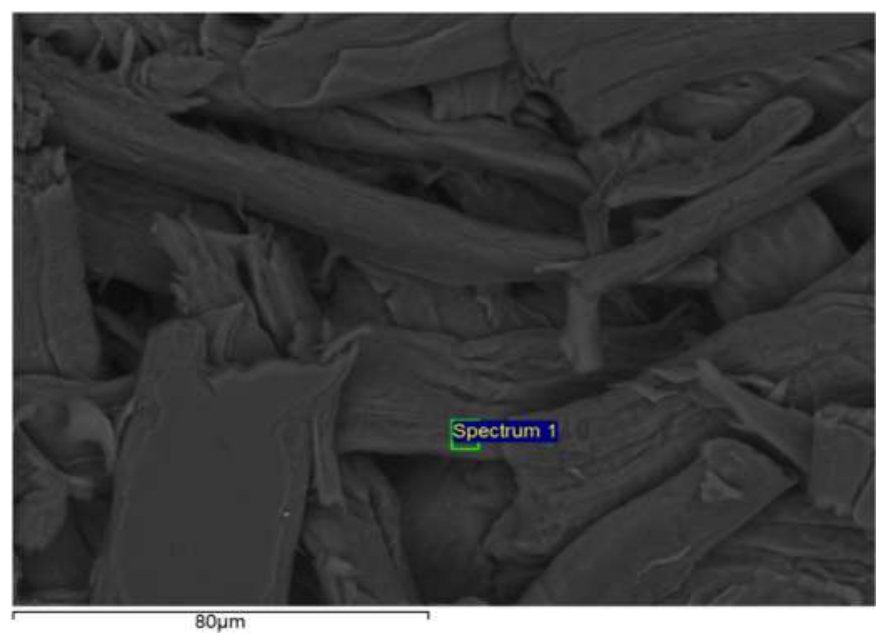

Figura 4.25: Região da CNC-Hg mapeada pelo EDS, espectro 1. Amplificação 1000x.

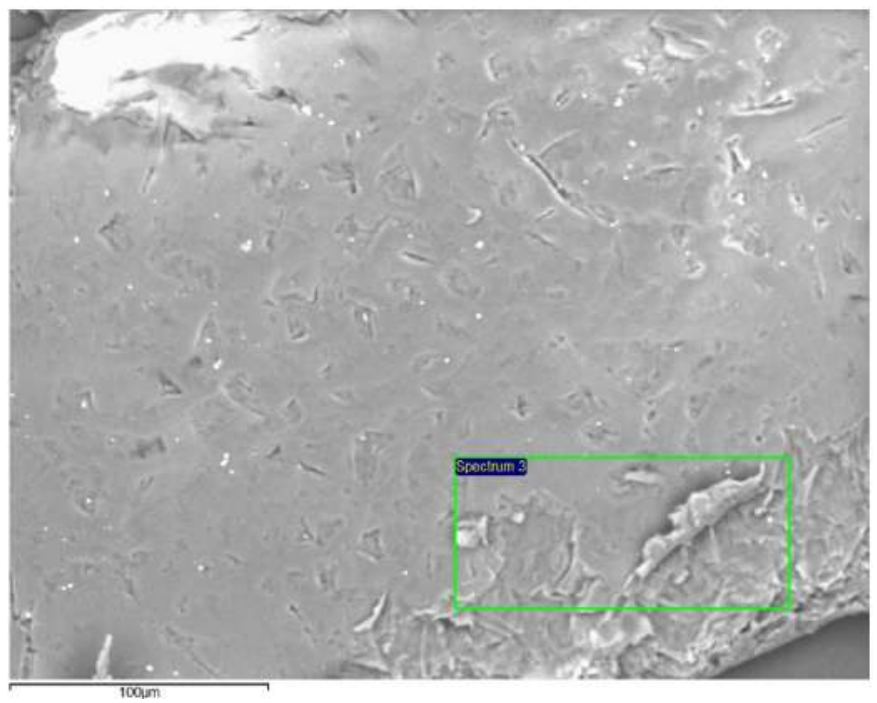

Figura 4.26: Região mapeada, espectro 3, da CNC-Mod-Hg. Amplificação 800x.

métrica da adsorção de mercúrio, Figura 4.29 e os dados cinéticos, tabela 4.21, inferem em mecanismos aparentemente diferentes. A degradação térmica da CNC-Mod-Hg ocorreu em dois estágios, sendo o segundo estágio, pico 2, com comportamento diferente dos apresentados pelas amostras CNC-Mod e CNCMod-Co. Análises posteriores devem ser realizadas para a melhor compreensão deste comportamento. A CNC-Mod-Hg inicia o processo de degradação térmica por volta de $206^{\circ} \mathrm{C}\left(9 \mathrm{~min}\right.$ e $42 \mathrm{~s}$ ), a CNC-Hg têm início em $208^{\circ} \mathrm{C}$ (9 min e 42 s) e a CEL-Hg em $251^{\circ} \mathrm{C}(11$ min e $24 \mathrm{~s})$.

O valor de energia de ativação da CEL-Hg aumenta em 8,2 kJ/mol e 9,8 kJ/mol em relação as amostras CEL e CEL-Na respectivamente. Porém, quando comparada com a CEL-Co observa-se uma diferença de somente 3.8 kJ/mol. O pico único da $\mathrm{CNC}-\mathrm{Hg}$ apresenta energia de ativação maior que 


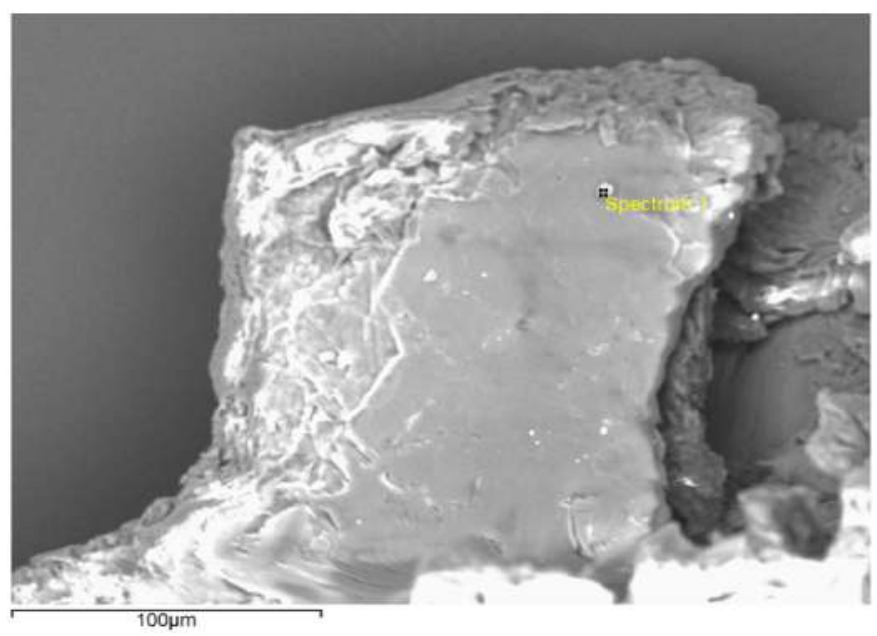

Figura 4.27: Espectro pontual da CNC-Mod-Hg indicando a presença de cristais com sódio. Amplificação 800x.

os primeiros estágios da $\mathrm{CNC}$, e CNC-Na podendo indicar que o mercúrio interage com os grupos sulfatos, além disso, a redução, praticamente integral, do segundo estágio da CNC-Hg pode indicar também uma possível interação com a estrutura remanescente da celulose original.

O primeiro pico de máxima degradação térmica da CNC-Mod-Hg apresenta valor muito superior ao primeiro pico da CNC-Mod com uma diferença de $48 \mathrm{~kJ} / \mathrm{mol}$. Entretanto, o valor de energia de ativação do segundo estágio da CNC-Mod-Hg é $18 \mathrm{~kJ} / \mathrm{mol}$ menor do que o segundo pico da CNC-Mod. Estes resultados indicam possíveis mudanças de mecanismos para os dois estágios.

Tabela 4.19: Parâmetros cinétcos ajustados por regressão linear e sigmoide após a adsorção de mercúrio.

\begin{tabular}{ccc} 
Amostra & $\begin{array}{c}\text { Energia de ativação } \\
\text { Ea }(\mathbf{k J} / \mathbf{m o l})\end{array}$ & $\begin{array}{c}\text { Ordem de reação } \\
\mathbf{n}\end{array}$ \\
\hline CEL-Hg & 67,04 & 1,65 \\
\hline CNC-Hg & 25,12 & 1,42 \\
\hline CNC-Mod-Hg P1 & 64,22 & 1,75 \\
CNC-Mod-Hg P2 & 26,42 & 1,47
\end{tabular}

Tabela 4.20: Resultados de perda água em diferentes temperaturas e massa residual após TGA das amostras CEL-Hg, CNC-Hg e CNC-Mod-Hg.

\begin{tabular}{|c|c|c|c|}
\hline Amostra & $\begin{array}{c}\text { Perda de } \\
\text { água } 50^{\circ} \mathrm{C}(\%)\end{array}$ & $\begin{array}{c}\text { Perda de } \\
\text { água } 100^{\circ} \mathrm{C}(\%)\end{array}$ & $\begin{array}{c}\text { Massa } \\
\text { residual (\%) }\end{array}$ \\
\hline CEL-Hg & 4,42 & 8,75 & 6,52 \\
\hline CNC-Hg & 3,16 & 6,75 & 16,76 \\
\hline CNC-Mod-Hg & 4,00 & 7,52 & 23,7 \\
\hline
\end{tabular}



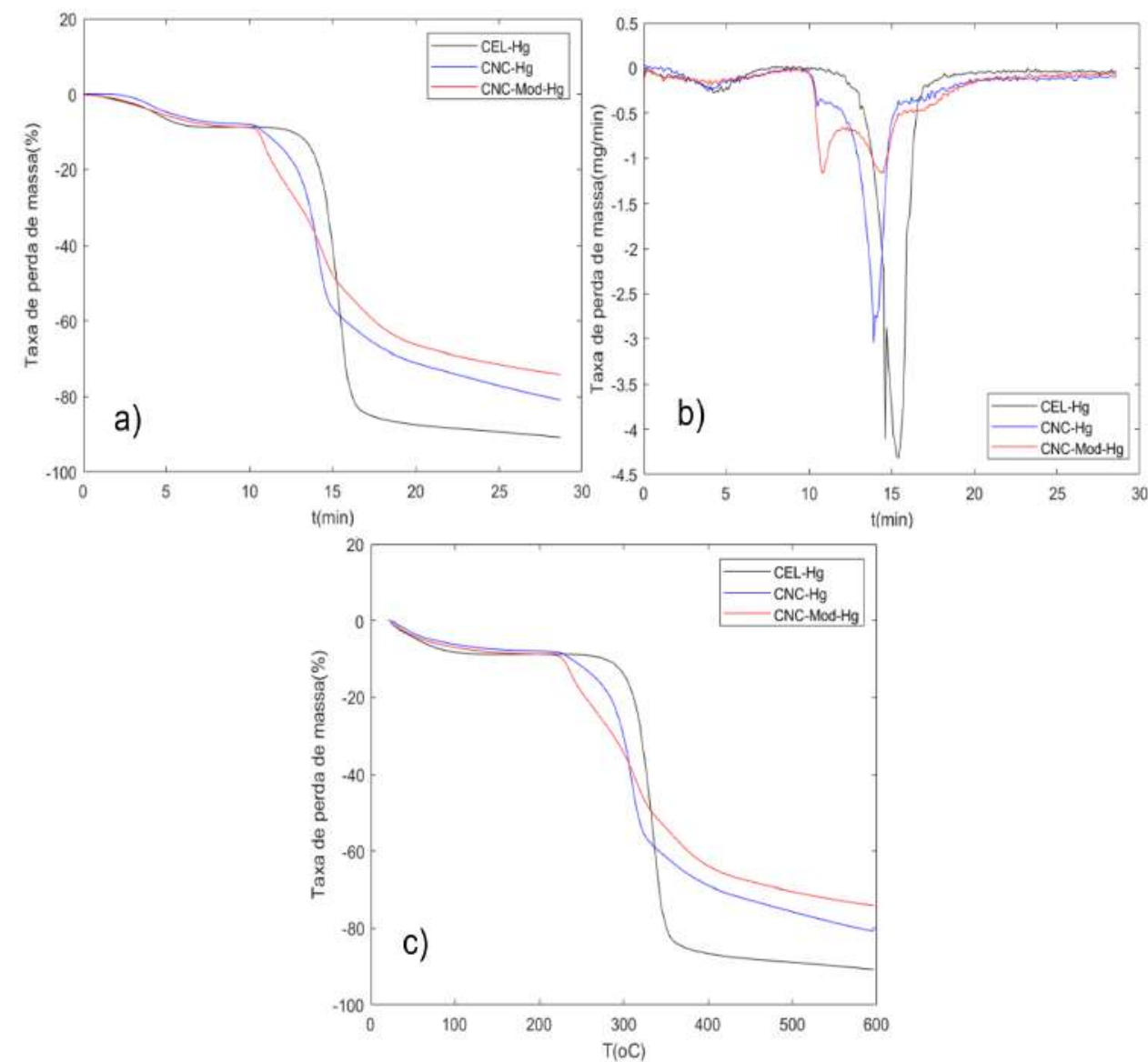

Figura 4.28: Diagrama comparativo da degradação térmica das amostras CELHg, CNC-Hg e CNC-Mod-Hg a) tempo de degradação b) DTG c) temperatura.

A amostra CEL-Hg, em relação a CEL e CEL-CO não apresentou aumento significativo no conteúdo de resíduos após a pirólise, Tabela 4.22. Deste modo, o melhor resultado obtido para as amostras de celulose foi a CEL$\mathrm{Na}$, indicando que o sódio pode agir como retardador de chamas na celulose. De maneira análoga, a CNC-Hg, comparada a CNC e CNC-Na não apresenta alteração na quantidade de massa residual. Sendo assim, diferentemente da celulose, o cobalto pode agir com maior potencial retardante de chamas na CNC. Para a CNC-Mod, em todos os casos, a adição de metais não acrescentou no conteúdo de resíduos, tendo a funcionalização da CNC produzido maior porcentagem de biocarvão com aumento de $64,3 \%$. 


\section{5}

\section{Conclusão}

- O processo de obtenção da CNC por hidrólise com ácido sulfúrico foi bem-sucedida, o que pode ser confirmada pela análise de AFM com a presença de partículas em formato de agulha. Além disso, a análise de DRX mostra a alteração no índice de cristalinidade, o que pode indicar que a hidrólise se inicia nas regiões com provaveis defeitos cristalinos da celulose. Ainda que a análise por FTIR não apresente a presença de sulfatos devido à sobreposição dos picos, análises como, TGA (pela redução na resistência a degradação térmica e mudança do mecanismo) e EDS (pela distribuição do elemento enxofre ao longo da amostra) podem confirmar a presença do grupo sulfato na estrutura da celulose possivelmente formando ésteres de sulfato.

- A funcionalização da $\mathrm{CNC}$ se mostrou um procedimento relativamente simples, sendo realizada à temperatura ambiente e sem pré-tratamento. Entretanto, o mecanismo da reação ainda não é bem compreendido, podendo ocorrer tanto com a hidroxila do grupo sulfato quanto com a hidroxila nativa da celulose. A modificação pode ser confirmada por análises de como FTIR (alteração no espectro) e TGA (alteração no mecanismo de degradação térmica). A análise de AFM revela a alteração na tendência a formação de aglomerados, o que pode indicar a modificação. Entretanto, outras técnicas como a RMN podem ser aplicadas para esta confirmação.

- Análises de AFM apresentaram dimensões médias da CNC de 10,01 \pm 3,59 nm de diâmetro e 63,89 $\pm 53,43 \mathrm{~nm}$ de comprimento. Com maior faixa de distribuição de comprimento entre 20 e $50 \mathrm{~nm}$ e de diâmetro entre 7 e $10 \mathrm{~nm}$. Devido a aglomeração das partículas da CNC-Mod não foi possível definir suas dimensões.

- A análise de ICP-OES da solução sobrenadante após a adsorção confirmou a adsorção em diferentes níveis para todos os cátions metálicos avaliados $\left(\mathrm{Co}^{2+}, \mathrm{Na}^{+}\right.$e $\left.\mathrm{Hg}^{2+}\right)$ e em todas as amostras CEL, CNC e CNCMod. Um resultado de destaque é a ocorrencia do equilíbrio da adsorção em um tempo curto, menor que 45 minutos e em temperatura ambiente. 
- O cobalto apresentou o maior índice de adsorção em todas as amostras estudadas, obtendo valores superiores a $82 \%$ (CEL). Tendo a CNC adsorvido cerca de $86 \%$ do cátion em solução, seguida da CNC-Mod com $85 \%$.

- Apesar de ter adsorvido o mercúrio, todas as amostras não apresentaram eficiência para este metal. Os valores percentuais de adsorção estão entre $35 \%$ (CNC) e $56 \%$ (CEL).

- A adsorção de sódio em todas as amostras foi em torno de 60\%. Apesar de não apresentar tanta eficiência quanto o cobalto, pode-se considerar um resultado aceitável, dada a dificuldade de remoção de sais de sódio de soluções por outros métodos covencionais como a nano e ultrafiltração e o alto gasto energético com métodos como a osmose inversa e destilação.

- Para cada cátion metálico em cada uma das amostras, observou-se um comportamento diferente de degradação térmica pela análise termogravimétrica. A CNC-Co e CNC-Mod-Co apresentaram comportamento ligeiramente similar. Como também a CNC-Na e CNC-Mod-Na. Não ocorrendo o mesmo entre a CNC-Hg e CNC-Mod-Hg.

- A presença de sulfato em ambas a CNC e CNC-Mod reduziu a estabilidade térmica em comparação com a celulose.

- A análise de EDS em diversos casos não apresentou conteúdo de metais adsorvidos no sólido, principalmente para a celulose. Este fato pode ser explicado pelo processo de lavagem e centrifugação da amostra após a adsorção. Podendo ter ocorrido a dessorção dos metais neste processo. 


\section{6}

\section{Trabalhos futuros}

Sugere-se considerar os seguintes tópicos para futuras pesquisas:

- Realizar ensaios de BET para avaliar a área superficial e consequentemente, a capacidade de adsorção das amostras.

- Realizar análise de ICP-MS com ablação a laser, XPS ou EXAFS para avaliar as amostras sólidas após a adsorção e quantificar os íons adsorvidos.

- Utilizar o mesmo procedimento de preparo de amostra do AFM para as análises de MEV para evitar a aglomeração das fibras.

- Analisar as amostras com MET, para melhor visualização das regiões cirstalinas da CNC.

- Realizar adsorção com tempos inferiores a 45 min e avaliar os modelos cinéticos e os diferentes mecanismos de adsorção da celulose, CNC e CNC-Mod.

- Promover a adsorção com solução sintética com diversos metais, como $\mathrm{Fe}^{2+}, \mathrm{Cu}^{2+}$ simulando possíveis efluentes. E avaliar a seletividade das amostras CEL, CNC e CNC-Mod.

- Comparar os efeitos nas propriedades da CNC e CNF após a funcionalização com ácido cítrico.

- Realizar adsorção com concentrações variáveis de metais.

- Realizar processo de lavagem mais brando nas amostras após adsorção e verificar, por meio de EDS, a presença dos elementos na amostra.

- Estudar a funcionalização em função da temperatura visando avaliar a melhor condição para o processo.

- Analisar o resíduo de carbono fixo após a TGA por meio de EDS e DRX para verificar a possível obtenção de nano partículas dos metais estudados. 


\section{Referências bibliográficas}

[1] DIAS, MARCOS ANTONIO AND DOS SANTOS DINIZ, MARCO AURÉLIO AND PLACCA, JOSÉ AVELINO. O panorama da gestão da demanda de água no brasil. Caderno Meio Ambiente e Sustentabilidade -, 12(7):3645, 2018.

[2] UNESCO. The United Nations world water development report 2015: water for a sustainable world. Technical report, 2015.

[3] UNESCO. Fatos e dados Não deixar ninguém para trás World Water Assessment Programme United Nations Educational, Scientific and Cultural Organization Sustainable Development Goals water and sanitation United Nations Educational, Scientific and Cultural Organizatio. Technical report, 2018.

[4] ZHOU, Y.; JIN, Q.; HU, X.; ZHANG, Q. ; MA, T.. Heavy metal ions and organic dyes removal from water by cellulose modified with maleic anhydride. Journal of Materials Science, 47(12):5019-5029, 2012.

[5] YU, X.; TONG, S.; GE, M.; WU, L.; ZUO, J.; CAO, C. ; SONG, W.. Adsorption of heavy metal ions from aqueous solution by carboxylated cellulose nanocrystals. Journal of Environmental Sciences (China), 25(5):933-943, 2013.

[6] TRAKULSUJARITCHOK, T.; NOIPHOM, N.; TANGTREAMJITMUN, N. ; SAEENG, R.. Adsorptive features of poly(glycidyl methacrylateco-hydroxyethyl methacrylate): Effect of porogen formulation on heavy metal ion adsorption. Journal of Materials Science, 46(16):53505362, 2011.

[7] VOLESKY, B.; HOLAN, Z.. Biosorption of heavy metals. Biotechnolo. Prog., (11):235-250, 1995.

[8] FAKHRE, N. A.; IBRAHIM, B. M.. The use of new chemically modified cellulose for heavy metal ion adsorption. Journal of Hazardous Materials, 343:324-331, 2018. 
[9] DEANS, J. R.; DIXON, B. R. N. G.; COD, C.; ST, P. O. B. M. ; BAY, B.. Uptake of $\mathrm{Pb} \mathrm{2}+$ and $\mathrm{Cu} 2+$ by novel biopolymers. 26(4):3-6, 1992.

[10] BRADESCO, D.. Desempenho do setor de papel e celulose. Technical report, 2019.

[11] MARTIN, C.. Indústria de celulose e papel registra bons resultados em 2017. Revista O papel, 5:48, 2018.

[12] KANG, H.; LIU, R. ; HUANG, Y.. Graft modification of cellulose: Methods, properties and applications. Polymer, 70:A1-A16, 2015.

[13] DUFRESNE, A.. Nanocellulose: From nature to high performance tailored materials, 2. Edition. 2017.

[14] KARGARZADEH, H.; AHMAD, I.; THOMAS, S. ; DUFRESNE, A.. Methods for extraction of nanocelulose from various sources, volumen 1, p. 1-49.

[15] SANTI, T.. Nanotecnologia: a oportunidade de crescimento do setor de celulose no mercado. Revista O papel, 11:86, 2018.

[16] DAUD, JANNAH B.AND LEE, K.-Y.. Surface Modification of Nanocellulose, volumen 1 , p. 111-122.

[17] MILLER, J.. Nanocellulose: State of the Industry, December, 2015. TAPPI Nano, p. 10, 2015.

[18] MATHIAS, S. L.; MENEZES, A. J.; LONGARESI, R. H. ; DA SILVA, M. P.. Caracterização E Obtenção De Nanocristais De Celulose De Diferentes Estádios Fenológicos Da Planta De Milho (Zea Mays L.). Anais do $14^{\circ}$ Congresso Brasileiro de Polímeros, p. 1132-1136, 2017.

[19] VASCONCELOS, N. F.; PINHEIRO, J. A.; BRÍGIDA, A. I. S.; FILHO, M. S. M. S. ; ROSA, M. F.. OTIMIZAÇÃO DO PROCESSO DE OBTENÇÃO DE NANOCELULOSE DO PSEUDOCAULE DA BANANEIRA POR HIDRÓLISE ÁCIDA. In: VII WORKSHOP DE NANOTECNOLOGIA APLICADA AO AGRONEGÓCIO, p. 334-336. Embrapa, 2013.

[20] WULANDARI, W. T.; ROCHLIADI, A. ; ARCANA, I. M.. Nanocellulose prepared by acid hydrolysis of isolated cellulose from sugarcane bagasse. IOP Conference Series: Materials Science and Engineering, 107(1), 2016. 
[21] TEODORO, K. B.; DE ELIANGELA, M. T.; CORRÊA, A. C.; DE CAMPOS, A.; MARCONCINI, J. M. ; MATTOSO, L. H.. Whiskers de fibra de sisal obtidos sob diferentes condições de hidrólise ácida: Efeito do tempo e da temperatura de extração. Polimeros, 21(4):280-285, 2011.

[22] TAIPINA, M. D. O.. Nanocristais De Celulose: Obtenção, Caracterização E Modificação De Superfície. PhD thesis, 2012.

[23] DE M. TEIXEIRA, E.; DE OliVEIRA, C.; MATTOSO, L.; CORRÊA, A. ; PALADIN, P.. Cotton nanofibers obtained by different hydrolytic acid conditions | Nanofibras de algodão obtidas sob diferentes condições de hidrólise ácida. Polimeros, 20(4), 2010.

[24] ERIKSEN, $\varnothing$.; SYVERUD, K. ; GREGERSEN, $\varnothing$.. The use of microfibrillated cellulose produced from kraft pulp as strength enhancer in TMP paper. Nordic Pulp and Paper Research Journal, 23(3):299-304, 2008.

[25] ALILA, S.; BESBES, I.; VILAR, M. R.; MUTJÉ, P. ; BOUFI, S.. Nonwoody plants as raw materials for production of microfibrillated cellulose (MFC): A comparative study. Industrial Crops and Products, 41(1):250-259, 2013.

[26] ABDUL KHALIL, H. P.; DAVOUDPOUR, Y.; ISLAM, M. N.; MUSTAPHA, A.; SUDESH, K.; DUNGANI, R. ; JAWAID, M.. Production and modification of nanofibrillated cellulose using various mechanical processes: A review. Carbohydrate Polymers, 99:649-665, 2014.

[27] LI, J.; WEI, X.; WANG, Q.; CHEN, J.; CHANG, G.; KONG, L.; SU, J. ; LIU, Y.. Homogeneous isolation of nanocellulose from sugarcane bagasse by high pressure homogenization. Carbohydrate Polymers, 90(4):1609-1613, 2012.

[28] CHIRAYIL, C. J.; MATHEW, L. ; THOMAS, S.. Review of recent research in nano cellulose preparation from different lignocellulosic fibers. Reviews on Advanced Materials Science, 37(1-2):20-28, 2014.

[29] NUNES, T. F. G.. Produção , Caracterização e Aplicação de Nanofibras de Celulose. p. 81, 2014.

[30] HABIBI, Y.; LUCIA, L. A. ; ROJAS, O. J.. Cellulose nanocrystals: Chemistry, self-assembly, and applications. Chemical Reviews, 110(6):3479-3500, 2010. 
[31] IOELOVICH, M.. Study of Conversion of Cellulose Into Micro-and Nanocrystalline Particles During Acidic Hydrolysis. 20(December 2018):3-9, 2018.

[32] BACAKOVA, L.; PAJOROVA, J.; BACAKOVA, M.; SKOGBERG, A.; KALLIO, P.; KOLAROVA, K. ; SVORCIK, V.. Versatile application of nanocellulose: From industry to skin tissue engineering and wound healing. Nanomaterials, 9(2), 2019.

[33] WANG, Z.; PAN, R.; RUAN, C.; EDSTRÖM, K.; STRØMME, M. ; NYHOLM, L.. Redox-Active Separators for Lithium-Ion Batteries. Advanced Science, 5(3), 2018.

[34] PAN, R.; XU, X.; SUN, R.; WANG, Z.; LINDH, J.; EDSTRÖM, K.; STRØMME, M. ; NYHOLM, L.. Nanocellulose Modified Polyethylene Separators for Lithium Metal Batteries. Small, 14(21):1-9, 2018.

[35] ZHOU, X.; LIU, Y.; DU, C.; REN, Y.; LI, X.; ZUO, P.; YIN, G.; MA, Y.; CHENG, X. ; GAO, Y.. Free-Standing Sandwich-Type Graphene/Nanocellulose/Silicon Laminar Anode for Flexible Rechargeable Lithium Ion Batteries. ACS Applied Materials and Interfaces, 10(35):29638-29646, 2018.

[36] KANG, Y. J.; CHUN, S. J.; LEE, S. S.; KIM, B. Y.; KIM, J. H.; CHUNG, H.; LEE, S. Y. ; KIM, W.. All-solid-state flexible supercapacitors fabricated with bacterial nanocellulose papers, carbon nanotubes, and triblock-copolymer ion gels. ACS Nano, 6(7):6400-6406, 2012.

[37] SINGH, K.; ARORA, J. K.; SINHA, T. J. M. ; SRIVASTAVA, S.. Functionalization of nanocrystalline cellulose for decontamination of Cr(III) and Cr(VI) from aqueous system: Computational modeling approach. Clean Technologies and Environmental Policy, 16(6):11791191, 2014.

[38] XU, T.; JIANG, Q.; GHIM, D.; LIU, K.-K.; SUN, H.; DERAMI, H. G.; WANG, Z.; TADEPALLI, S.; JUN, Y.-S.; ZHANG, Q. ; OTHERS. Catalytically active bacterial nanocellulose-based ultrafiltration membrane. Small, 14(15):1-8.

[39] METREVELI, G.; WÅGBERG, L.; EMMOTH, E.; BELÁK, S.; STRØMME, M. ; MIHRANYAN, A.. A Size-Exclusion Nanocellulose Filter Paper 
for Virus Removal. Advanced Healthcare Materials, 3(10):1546-1550, 2014.

[40] GUSTAFSSON, O.; GUSTAFSSON, S.; MANUKYAN, L. ; MIHRANYAN, A.. Significance of Brownian motion for nanoparticle and virus capture in nanocellulose-based filter paper. Membranes, 8(4), 2018.

[41] ZHAN, H.; PENG, N.; LEI, X.; HUANG, Y.; LI, D.; TAO, R. ; CHANG, C.. UV-induced self-cleanable $\mathrm{TiO} 2 /$ nanocellulose membrane for selective separation of oil/water emulsion. Carbohydrate Polymers, 201:464-470, 2018.

[42] FERRAZ, N.; CARLSSON, D. O.; HONG, J.; LARSSON, R.; FELLSTRÖM, B.; NYHOLM, L.; STRØMME, M. ; MIHRANYAN, A.. Haemocompatibility and ion exchange capability of nanocellulose polypyrrole membranes intended for blood purification. Journal of the Royal Society Interface, 9(73):1943-1955, 2012.

[43] HOKKANEN, S.; BHATNAGAR, A. ; SILLANPÄÄ, M.. A review on modification methods to cellulose-based adsorbents to improve adsorption capacity. Water Research, 91:156-173, 2016.

[44] FERREIRA, B. C.; GIL, L. F.; GURGEL, L. V. ; FREITAS, R. P.. Obtaining a new carboxylated derivative of microcrystalline cellulose: An easy and solvent-free synthesis. Revista Virtual de Quimica, 9(1):431451, 2017.

[45] BÖRJESSON, M.; SAHLIN, K.; BERNIN, D. ; WESTMAN, G.. Increased thermal stability of nanocellulose composites by functionalization of the sulfate groups on cellulose nanocrystals with azetidinium ions. Journal of Applied Polymer Science, 135(10):1-10, 2018.

[46] BANSAL, M.; RAM, B.; CHAUHAN, G. S. ; KAUSHIK, A.. L-Cysteine functionalized bagasse cellulose nanofibers for mercury(II) ions adsorption. International Journal of Biological Macromolecules, 112:728736, 2018.

[47] LOW, K. S.; LEE, C. K. ; MAK, S. M.. Sorption of copper and lead by citric acid modified wood. Wood Science and Technology, 38(8):629640, 2004.

[48] RODRIGUES, R. F.; TREVENZOLI, R. L.; SANTOS, L. R. G.; LEÃO, V. A. ; BOTARO, V. R.. Adsorção de metais pesados em serragem de 
madeira tratada com ácido cítrico. Engenharia Sanitaria e Ambiental, 11(1):21-26, 2006.

[49] AITH, F. M. A.; ROTHBARTH, R.. O estatuto jurídico das águas no Brasil. Estudos Avancados, 29(84):163-177, 2015.

[50] Constituição da República Federativa do Brasil. Senado, Brasília, DF, 1988.

[51] Constituição (1988). proposta de emenda constitucional $\mathbf{n}^{\circ} \mathbf{2 5 8}$, de 4 de agosto de 2016. dá nova redação ao art. $6^{\circ}$ da constituição federal, para introduzir o direito humano ao acesso à terra e à agua como direito fundamental. Lex, out./dez. 2016.

[52] DA SILVA, K. M. D.; REZENDE, L. C. S. H.; DA SILVA, C. A.; BERGAMASCO, R. ; GONÇALVES, D. S.. Caracterização físico-química da fibra de coco verde para a adsorção de metais pesados.pdf. Engevista, 15:43-50, 2013.

[53] VIDAL, C. B.; DE LIMA, A. C. A.; RAULINO, G. S. C.; MELO, D. D. Q. ; DO NASCIMENTO, R. F.. Princípios básicos, volumen 1, p. 11-22. Imprensa Universitária UFC, Fortaleza-CE, 2014.

[54] DE LIMA, A. C. A.; VIDAL, C. B.; BEZERRA, C. W. B.; MELO, D. D. Q.; RAULINO, G. S. C.; DO NASCIMENTO, R. F. ; NETO, V. D. O. S.. Termodinâmica de Adsorção, volumen 1, p. 11-22. Imprensa Universitária UFC, Fortaleza-CE, 2014.

[55] FOUST, A. S.; WENZEL, L.; CLUMP, C.; MAUS, L. ; ANDERSEN, L.. Princípios das operações unitárias, $2^{\mathbf{a}}$ edição. LTC-Livros Técnicos e Científicos, Editora AS, RJ, 1982.

[56] VELAZQUEZ-JIMENEZ, L. H.; PAVLICK, A. ; RANGEL-MENDEZ, J. R.. Chemical characterization of raw and treated agave bagasse and its potential as adsorbent of metal cations from water. Industrial Crops and Products, 43(1):200-206, 2013.

[57] WANG, N.; JIN, R. N.; OMER, A. M. ; KUN OUYANG, X.. Adsorption of $\mathrm{Pb}(\mathrm{II})$ from fish sauce using carboxylated cellulose nanocrystal: Isotherm, kinetics, and thermodynamic studies. International Journal of Biological Macromolecules, 102:232-240, 2017.

[58] SUOPAJÄRVI, T.; LIIMATAINEN, H.; KARJALAINEN, M.; UPOLA, H. ; NIINIMÄKI, J.. Lead adsorption with sulfonated wheat pulp nanocelluloses. Journal of Water Process Engineering, 5:136-142, 2015. 
[59] ANIRUDHAN, T. S.; DEEPA, J. R. ; CHRISTA, J.. Nanocellulose/nanobentonite composite anchored with multi-carboxyl functional groups as an adsorbent for the effective removal of Cobalt(II) from nuclear industry wastewater samples. Journal of Colloid and Interface Science, 467:307-320, 2016.

[60] GURGEL, L. V. A.; PERIN DE MELO, J. C.; DE LENA, J. C. ; GIL, L. F.. Adsorption of chromium (VI) ion from aqueous solution by succinylated mercerized cellulose functionalized with quaternary ammonium groups. Bioresource Technology, 100(13):3214-3220, 2009.

[61] JAIN, P.; VARSHNEY, S. ; SRIVASTAVA, S.. Synthetically modified nano-cellulose for the removal of chromium: A green nanotech perspective. IET Nanobiotechnology, 11(1):45-51, 2017.

[62] LIU, P.; BORRELL, P. F.; BO ${ }^{\vee} \mathrm{ZI}^{\vee} \mathrm{C}, \mathrm{M}$.; KOKOL, V.; OKSMAN, K. ; MATHEW, A. P.. Nanocelluloses and their phosphorylated derivatives for selective adsorption of $\mathrm{Ag}+, \mathrm{Cu} 2+$ and $\mathrm{Fe} 3+$ from industrial effluents. Journal of Hazardous Materials, (294):177-185, 2015.

[63] XIE, K.; JING, L.; ZHAO, W. ; ZHANG, Y.. Adsorption Removal of Cu21 and Ni21 from Waste Water Using Nano-Cellulose Hybrids Containing Reactive Polyhedral Oligomeric Silsesquioxanes. Journal of Applied Polymer Science, 122:2864-2868, 2011.

[64] ANIRUDHAN, T. S.; SHAINY, F. ; DEEPA, J. R.. Effective removal of Cobalt(II) ions from aqueous solutions and nuclear industry wastewater using sulfhydryl and carboxyl functionalised magnetite nanocellulose composite: batch adsorption studies. Chemistry and Ecology, 35(3):235-255, 2019.

[65] SPEYER, R.. Differential thermal analysis. Thermal Analysis of Materials, p. 35-85, 1994.

[66] BONDANCIA, T. J.. Biorrefinaria florestal : uma proposta para integração dos processos de obtenção de nanocelulose e etanol 2G a partir da polpa de celulose de eucalipto. São Paulo, p. 137, 2016.

[67] LI, Y.-Y.; WANG, B.; MA, M.-G. ; WANG, B.. The Influence of Pretreatment Time and Sulfuric Acid on Cellulose Nanocrystals. BioResources, 13(2), 2018. 
[68] SEGAL, L.; CREELY, J. J.; MARTIN, A. E. ; CONRAD, C. M.. An Empirical Method for Estimating the Degree of Crystallinity of Native Cellulose Using the X-Ray Diffractometer. Textile Research Journal, 29(10):786-794, 1959.

[69] JIN, E.; GUO, J.; YANG, F.; ZHU, Y.; SONG, J.; JIN, Y. ; ROJAS, O. J.. On the polymorphic and morphological changes of cellulose nanocrystals (CNC-I) upon mercerization and conversion to CNC-II. Carbohydrate Polymers, 143:327-335, 2016.

[70] REID, M. S.; VILLALOBOS, M. ; CRANSTON, E. D.. Benchmarking Cellulose Nanocrystals : From the Laboratory to Industrial Production Department of Chemical Engineering , McMaster University. Langmuir, 33(7):1583-1598, 2017.

[71] MORÁN, J. I.; ALVAREZ, V. A.; CYRAS, V. P. ; VÁZQUEZ, A.. Extraction of cellulose and preparation of nanocellulose from sisal fibers. Cellulose, 15(1):149-159, 2008.

[72] KVIEN, I.; TANEM, B. S. ; OKSMAN, K.. Characterization of cellulose whiskers and their nanocomposites by atomic force and electron microscopy. Biomacromolecules, 6(6):3160-3165, 2005.

[73] HEYDARZADEH, H.; NAJAFPOUR, G. ; NAZARI-MOGHADDAM, A.. Catalyst-free conversion of alkali cellulose to fine carboxymethyl cellulose at mild conditions. World Applied Sciences Journal, 6(4):564569, 2009.

[74] KUNUSA, W. R.; ISA, I.; LALIYO, L. A. ; IYABU, H.. Ftir, xrd and sem analysis of microcrystalline cellulose (mcc) fibers from corncorbs in alkaline treatment. In: JOURNAL OF PHYSICS: CONFERENCE SERIES, volumen 1028, p. 012199. IOP Publishing, 2018.

[75] MOHAMED, M. A.; SALLEH, W. N.; JAAFAR, J.; ASRI, S. E. ; ISMAIL, A. F.. Physicochemical properties of "green"nanocrystalline cellulose isolated from recycled newspaper. RSC Advances, 5(38):2984229849, 2015.

[76] CHATTOPADHYAY, D.; PATEL, B. H.. Synthesis, Characterization and Application of Nano Cellulose for Enhanced Performance of Textiles. Journal of Textile Science \& Engineering, 06(02):8, 2016.

[77] SHURVELL, H.. Spectra-structure correlations in the mid-and farinfrared. Handbook of vibrational spectroscopy, 2006. 
[78] JANDURA, P.; KOKTA, B. V. ; RIEDL, B.. Fibrous long-chain organic acid cellulose esters and their characterization by diffuse reflectance FTIR spectroscopy, solid-state CP/MAS 13C-NMR, and X-ray diffraction. Journal of Applied Polymer Science, 78(7):1354-1365, 2000.

[79] BICHARA, L. C.; LANÚS, H. E.; FERRER, E. G.; GRAMAJO, M. B. ; BRANDÁN, S. A.. Vibrational study and force field of the citric acid dimer based on the SQM methodology. Advances in Physical Chemistry, 2011, 2011.

[80] QUELlMALZ, A.; MIHRANYAN, A.. Citric Acid Cross-Linked Nanocellulose-Based Paper for Size-Exclusion Nanofiltration. ACS Biomaterials Science and Engineering, 1(4):271-276, 2015.

[81] SCHWANNINGER, M.; RODRIGUES, J. C.; PEREIRA, H. ; HINTERSTOISSER, B.. Effects of short-time vibratory ball milling on the shape of FT-IR spectra of wood and cellulose. Vibrational Spectroscopy, 36(1):23-40, 2004.

[82] BORYSIAK, S.; GARBARCZYK, J.. Applying the WAXS method to estimate the supermolecular structure of cellulose fibres after mercerisation. Fibres and Textiles in Eastern Europe, 11(5):104-106, 2003.

[83] PARK, S.; BAKER, J. O.; HIMMEL, M. E.; PARILLA, P. A. ; JOHNSON, D. K.. Cellulose crystallinity index: measurement techniques and their impact on interpreting cellulase performance. Biotechnology for Biofuels, 3(10):10, 2010.

[84] ROMAN. M; WINTER. WT. Effect of Sulfate Groups from Sulfuric Acid Hydrolysis on the Thermal Degradation Behavior of Bacterial Cellulose. Biomacromolecules, 5:1671-1677, 2004.

[85] LI, R.; FEI, J.; CAI, Y.; LI, Y.; FENG, J. ; YAO, J.. Cellulose whiskers extracted from mulberry: A novel biomass production. Carbohydrate Polymers, 76(1):94-99, 2009.

[86] WANG, N.; DING, E. ; CHENG, R.. Thermal degradation behaviors of spherical cellulose nanocrystals with sulfate groups. Polymer, 48(12):3486-3493, 2007. 


\section{A \\ Código Matlab da função do ajuste de sigmoide e cálculo de energia de ativação}

$\mathrm{r}=8.31451$;

load dadostgcelna.txt

load dadostgcelnap1.txt

$[\operatorname{tr}, \mathrm{fi}]=\operatorname{calctrfi}($ dadostgcelna $)$

$\mathrm{dm}=$ dadostgcelnap1(:,3);

$\mathrm{t}=$ dadostgcelnap1(:,2);

nexp=length $(\mathrm{dm})$;

dm0degrau=dadostgcelnap1 $(1,3)$;

dminf=dadostgcelnap1(nexp,3);

$\mathrm{f}=\operatorname{zeros}(\operatorname{nexp}, 1)$;

fcalc $=$ zeros $($ nexp, 1$)$;

$\operatorname{xexp}=\operatorname{zeros}(\operatorname{nexp}, 1)$;

yexp=zeros(nexp,1);

for $\mathrm{k}=1$ :nexp

$\mathrm{f}(\mathrm{k})=(\operatorname{dm}(\mathrm{k})-\mathrm{dm} 0 \operatorname{degrau}) /($ dminf-dm0degrau $)$;

end

[matff,matdfdtf,matd2fdt2,fobj] = ajustasigmoide(t,f)

for $\mathrm{k}=1$ :nexp

fcalc $(\mathrm{k})=\operatorname{matff}(\mathrm{k}, 1)$;

end

$[\mathrm{rq}]=$ calcular2 $($ fcalc, $\mathrm{f})$ 
Apêndice A. Código Matlab da função do ajuste de sigmoide e cálculo de energia de ativação

figure(1)

$\operatorname{plot}\left(\mathrm{t}, \mathrm{f}, \mathrm{rs}^{\prime}, \mathrm{t}, \mathrm{fcalc},{ }^{\prime} \mathrm{k}\right.$ ')

$[$ nexp,c] $=\operatorname{size}($ matff $)$;

for $\mathrm{k}=1$ :nexp

$\operatorname{xexp}(\mathrm{k})=\left((\mathrm{fi} * \operatorname{matff}(\mathrm{k}, 2)+\mathrm{tr})^{2}\right) * \operatorname{mat} d f d t f(k, 1) /(1-\operatorname{mat} f f(k, 1)) ;$

yexp $(k)=\left((f i * \text { matf } f(k, 2)+t r)^{2}\right) *($ matd $2 f d t 2(k, 1) /$ matdf $d t f(k, 1))$;

end

figure(2)

plot(xexp,yexp,'rs')

$[$ xexps,yexps $]=$ datasmothx $($ xexp,yexp);

figure(3)

plot(xexps,yexps,'gs')

$[$ par,n,ea $]=$ ajustedados $(\operatorname{xexps,yexps,fi)}$

nexps=length(xexps);

[ycalc,rq $]=$ calculay $($ par,nexps,xexps,yexps);

figure(4)

plot(xexps,yexps,'rs',xexps,ycalc,'k')

$\% \% \%$ function $[\operatorname{tr}, \mathrm{fi}]=$ calctrfi(datatg)

$\mathrm{t}=\operatorname{datatg}(:, 2)$;

$\mathrm{y}=\operatorname{datatg}(:, 1)$;

parpol=polyfit $(\mathrm{t}, \mathrm{y}, 1)$;

$\mathrm{fi}=\operatorname{parpol}(1)$;

$\operatorname{tr}=\operatorname{parpol}(2)$;

end

function [matff,matdfdt,matd2fdt2,fobj] = ajustasigmoide $(\mathrm{t}, \mathrm{f})$

\%Define a função sigmoide, a(1) controla a suavidade da curva e a(2)

\%controla em qual momento há a mudança de concavidade fcn $=@(a, t)$ 
Apêndice A. Código Matlab da função do ajuste de sigmoide e cálculo de energia de ativação

1./ $(1+\exp (-\mathrm{a}(1) *(\mathrm{t}-\mathrm{a}(2))))$;

\%Define a função objetivo

erro $=@(a) \operatorname{sum}\left((\mathrm{f}-\mathrm{fcn}(\mathrm{a}, \mathrm{t})) \cdot^{2}\right)$;

$\%$ Chuteinicial

$x 0=[0.5,(t(1)+t($ end $)) / 2] ;$

\%Minimiza para achar os parâmetros a(1) e a(2) $[\mathrm{x}$, fobj] $=$ fminse$\operatorname{arch}($ erro, $\mathrm{x} 0)$;

\%Calcula a função, primeira e segunda derivadas a partir dos parâmetros obtidos pela minimização

$\mathrm{f}_{c}$ alc $=1 . /(1+\exp (-x(1) *(t-x(2)))) ;$

$d f_{c} a l c=\left((x(1) * \exp (x(1) *(x(2)-t))) \cdot /(\exp (x(1) *(x(2)-t))+1) .^{2}\right) ;$

$d 2 f_{c} a l c=\left(\left(2 * x(1)^{2} * \exp (2 * x(1) *(x(2)-t))\right) \cdot /(\exp (x(1) *(x(2)-t))+\right.$ 1). $\left.{ }^{3}-\left(x(1)^{2} * \exp (x(1) *(x(2)-t))\right) \cdot /(\exp (x(1) *(x(2)-t))+1) .^{2}\right)$;

\footnotetext{
$\mathrm{n}=\operatorname{length}(\mathrm{t})$;

matff=zeros $(\mathrm{n}, 2)$;

matdfdt $=$ zeros $(\mathrm{n}, 2)$;

$\operatorname{matd} 2 \mathrm{fdt} 2=\operatorname{zeros}(\mathrm{n}, 2)$;
}

for $\mathrm{k}=1: \mathrm{n}$

$\operatorname{matff}(\mathrm{k}, 2)=\mathrm{t}(\mathrm{k})$;

$\operatorname{matff}(\mathrm{k}, 1)=\mathrm{f}_{c} a l c(k)$;

$\operatorname{matdf} d t(k, 2)=t(k)$;

$\operatorname{matdf} d t(k, 1)=d f_{c} a l c(k)$;

matd $2 f d t 2(k, 2)=t(k)$;

$\operatorname{matd} 2 f d t 2(k, 1)=d 2 f_{c} a l c(k)$;

end

end

function $[\mathrm{xs}, \mathrm{ys}]=\operatorname{datasmothx}(\mathrm{x}, \mathrm{y})$

$\mathrm{n}=$ length $(\mathrm{x})$;

$\mathrm{xmin}=8 \mathrm{E} 3$;

$\mathrm{ns}=0$;

for $\mathrm{k}=1: \mathrm{n}$

if $\mathrm{x}(\mathrm{k})>=\mathrm{xmin}$

$\mathrm{ns}=\mathrm{ns}+1$; 
Apêndice A. Código Matlab da função do ajuste de sigmoide e cálculo de energia de ativação

else

end

end

$\mathrm{xs}=\operatorname{zeros}(\mathrm{ns}, 1)$;

ys=zeros (ns, 1$)$;

$\mathrm{j}=0$;

for $\mathrm{k}=1 \mathrm{n}$

if $\mathrm{x}(\mathrm{k})>=\mathrm{xmin}$

$\mathrm{j}=\mathrm{j}+1$;

$y s(j)=y(k)$;

$\mathrm{xs}(\mathrm{j})=\mathrm{x}(\mathrm{k})$;

else

end

end

end

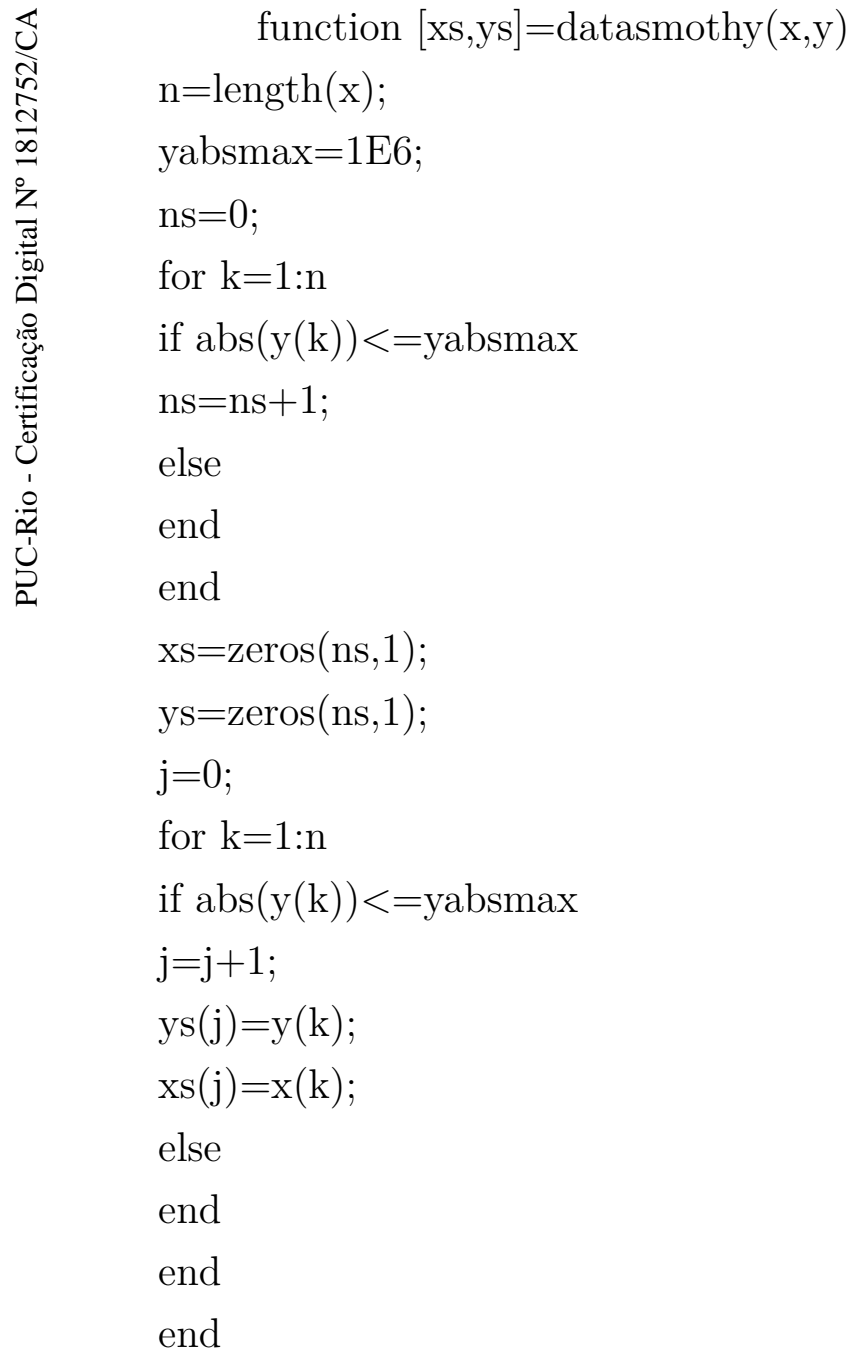


Apêndice A. Código Matlab da função do ajuste de sigmoide e cálculo de energia de ativação

function $[$ par,n,ea $]=\operatorname{ajustedados}(\mathrm{x}, \mathrm{y}, \mathrm{fi})$

$\mathrm{r}=8.31451$

par

$=\operatorname{polyfit}(\mathrm{x}, \mathrm{y}, 1)$;

$\mathrm{n}=-\operatorname{par}(1)$;

ea $=\operatorname{par}(2) *$ r $/$ fi;

ea $=e^{*} 1 \mathrm{e}-3$;

end

function $[$ ycalc,rq] =calculay(par,nexps,xexpss,yexpss) ycalc=zeros(nexps,1); $\mathrm{ym}=0$

for $\mathrm{k}=1$ :nexps

$\mathrm{ym}=\mathrm{ym}+\operatorname{yexpss}(\mathrm{k})$;

end

$\mathrm{ym}=\mathrm{ym} / \mathrm{nexps}$;

$\mathrm{st}=0$;

for $\mathrm{k}=1$ :nexps

$\mathrm{st}=\mathrm{st}+(\mathrm{yexpss}(\mathrm{k})-\mathrm{ym})^{2}$;

end

sres $=0 ;$

for $\mathrm{k}=1$ :nexps

$\operatorname{ycalc}(\mathrm{k})=\operatorname{par}(1) * \operatorname{xexpss}(\mathrm{k})+\operatorname{par}(2)$;

sres $=\operatorname{sres}+(\operatorname{ycalc}(\mathrm{k})-\operatorname{yexpss}(\mathrm{k}))^{2}$;

end

$r q=1-($ sres $/$ st $)$;

$\operatorname{disp}(r q)$

end

function $[\mathrm{rq}]=$ calcular2(fcalc,f)

$\mathrm{ym}=0$;

nexps=length(f);

for $\mathrm{k}=1$ :nexps

$\mathrm{ym}=\mathrm{ym}+\mathrm{f}(\mathrm{k})$; 
Apêndice A. Código Matlab da função do ajuste de sigmoide e cálculo de energia de ativação

end

$\mathrm{ym}=\mathrm{ym} / \mathrm{nexps} ;$

st $=0$;

for $\mathrm{k}=1$ :nexps

$\mathrm{st}=\mathrm{st}+(\mathrm{f}(\mathrm{k})-\mathrm{ym})^{2}$;

end

sres $=0$;

for $\mathrm{k}=1$ :nexps

sres $=$ sres $+(\text { fcalc }(k)-f(k))^{2}$;

end

$\mathrm{rq}=1-(\mathrm{sres} / \mathrm{st}) ;$

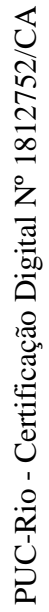

$\operatorname{disp}(\mathrm{rq})$

end 


\section{B}

Gráficos do ajuste sigmoide e ajuste linear realizado na análise cinética de degradação Térmica da CEL, CNC e CNC-Mod.
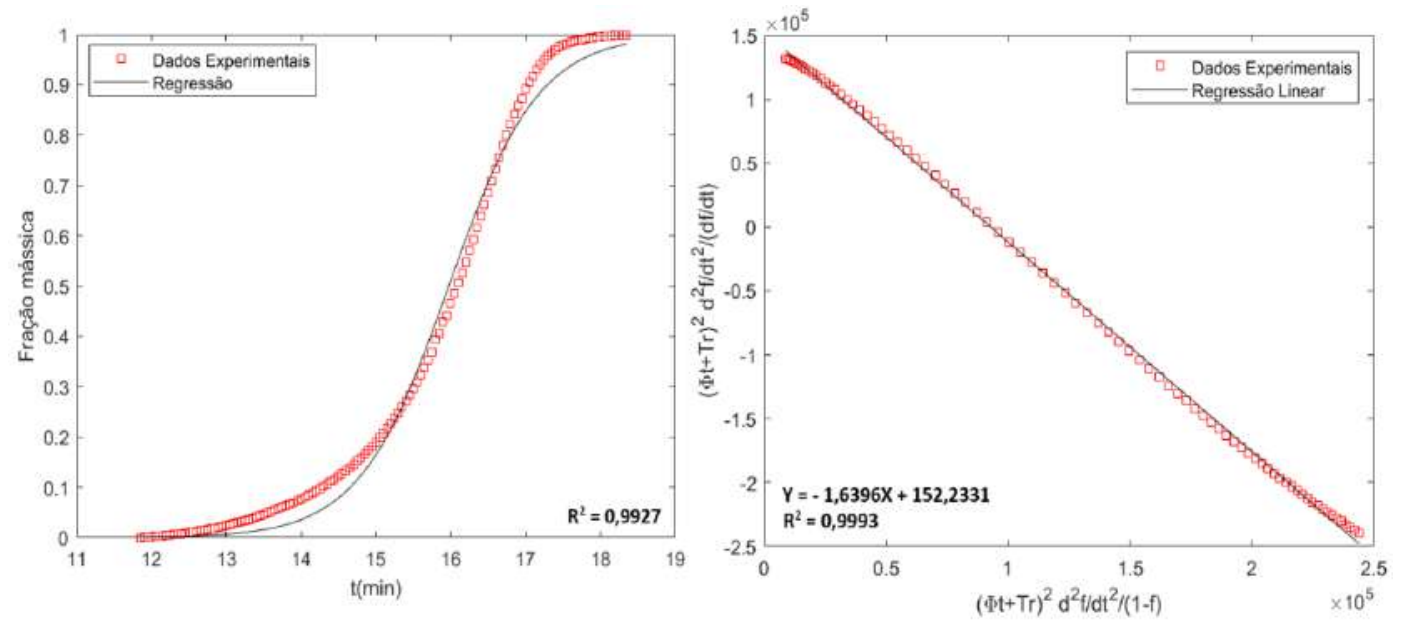

Figura B.1: Ajuste sigmoide e ajuste linear realizado na análise cinética de degradação térmica da celulose 
Apêndice B. Gráficos do ajuste sigmoide e ajuste linear realizado na análise cinética de degradação Térmica da CEL, CNC e CNC-Mod.

a)

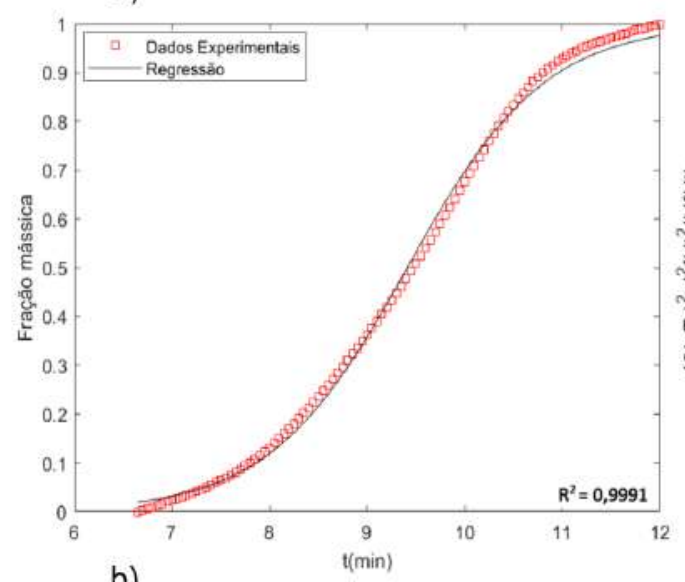

b)

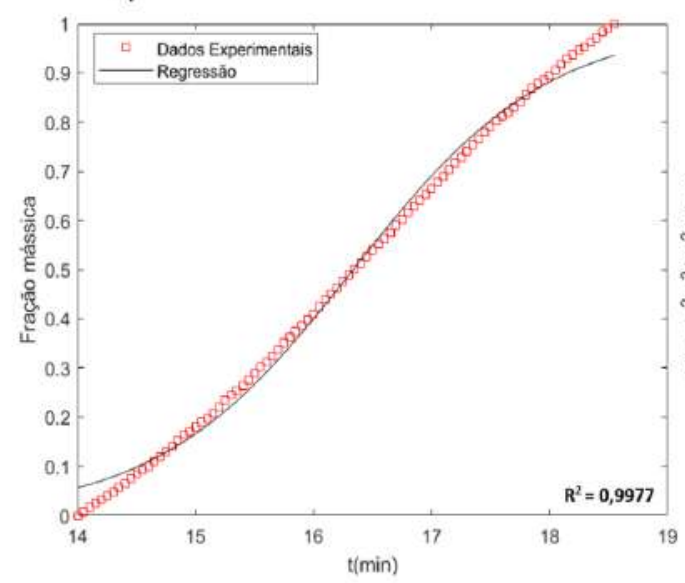

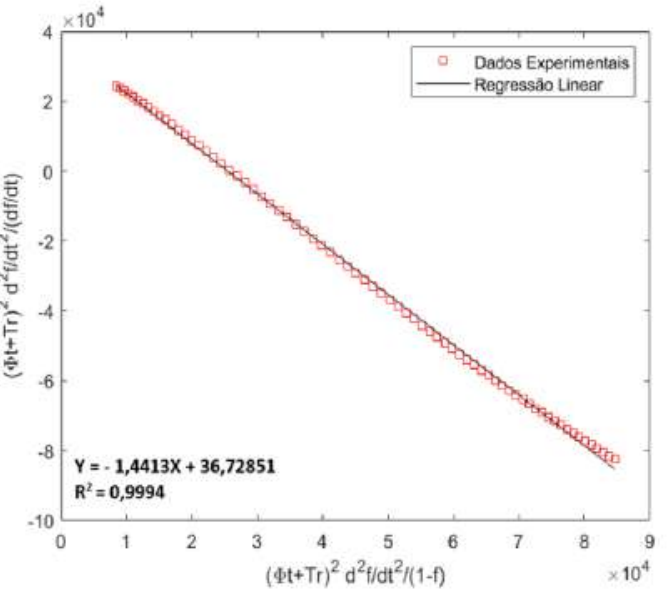

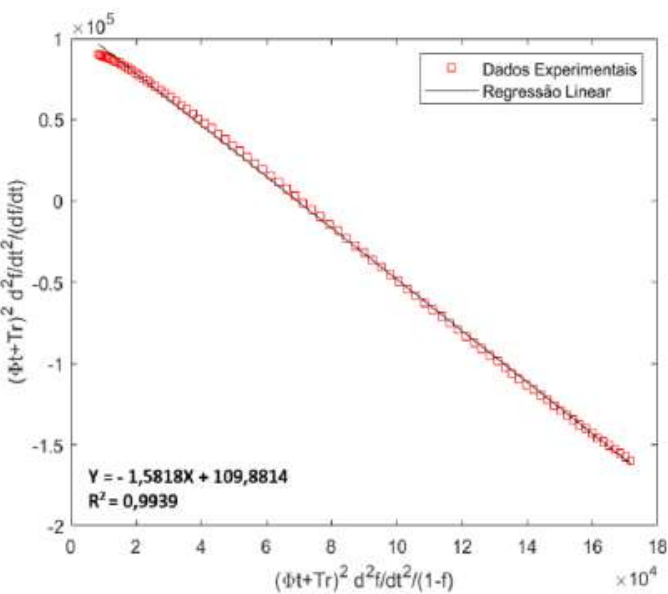

Figura B.2: Ajuste sigmoide e ajuste linear realizado na análise cinética de degradação térmica da CNC a) primeiro pico b) segundo pico. 
Apêndice B. Gráficos do ajuste sigmoide e ajuste linear realizado na análise cinética de degradação Térmica da CEL, CNC e CNC-Mod.

a)

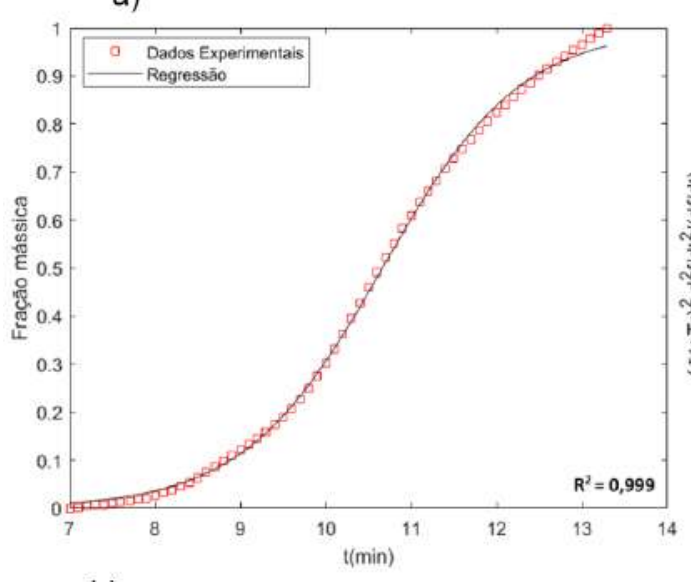

b)

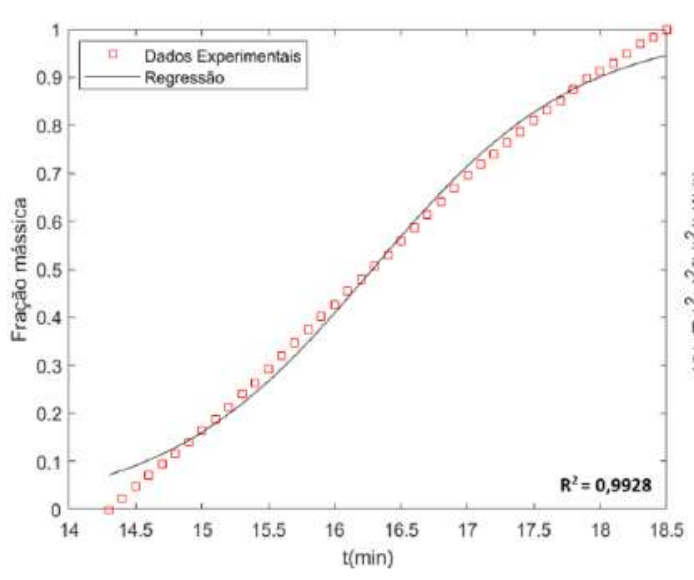

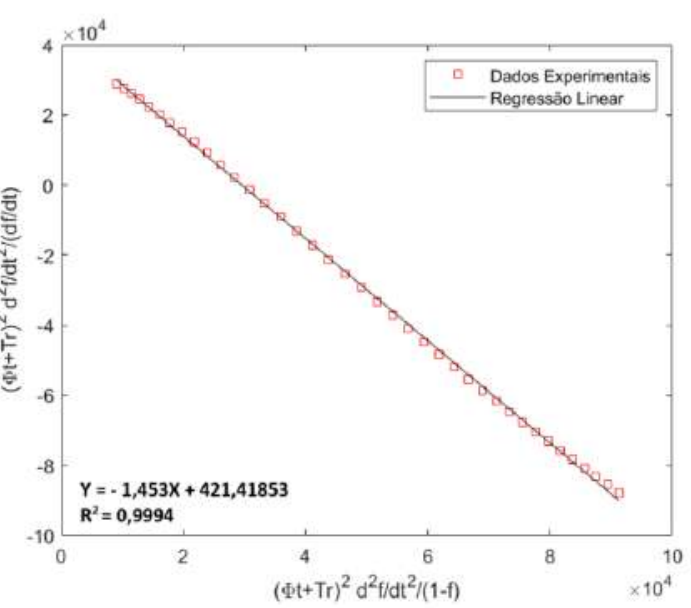

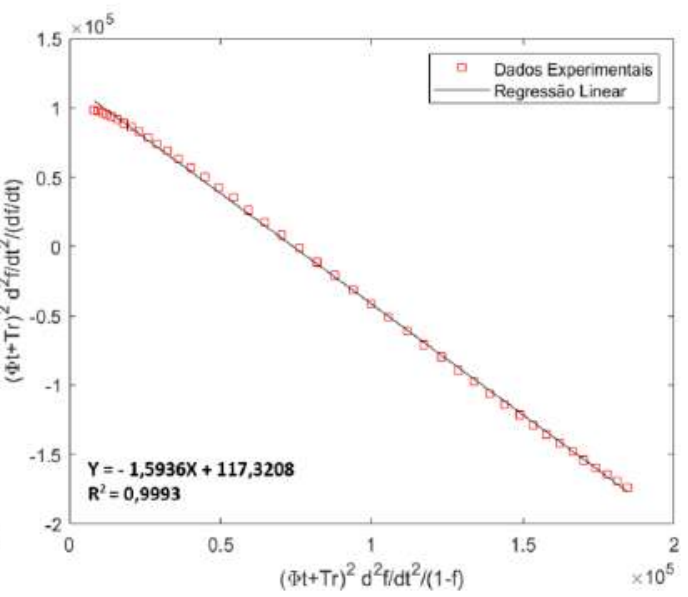

Figura B.3: Ajuste sigmoide e ajuste linear realizado na análise cinética de degradação térmica da CNC-Mod a) primeiro pico b) segundo pico. 
C

Gráficos do ajuste sigmoide e ajuste linear realizado na análise cinética de degradação térmica da CEL, CNC e CNC-Mod após a adsorção de cobalto.
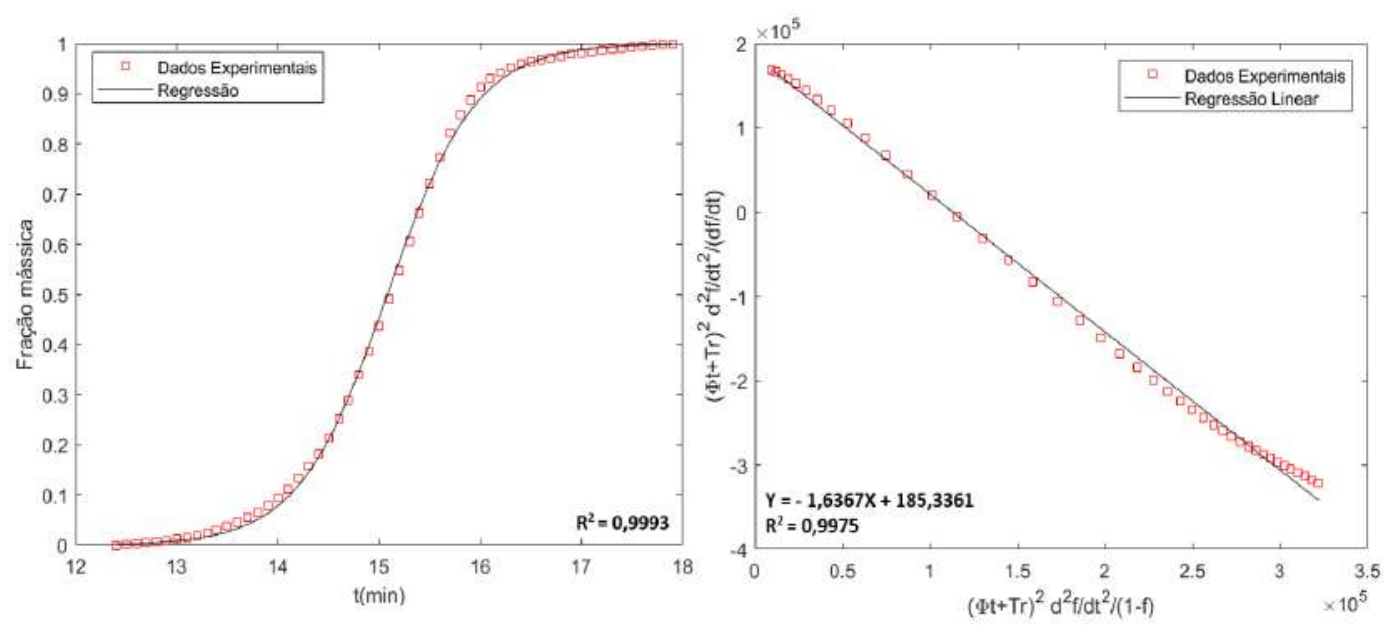

Figura C.1: Ajuste sigmoide e ajuste linear realizado na análise cinética de degradação térmica da CEL-Co. 
Apêndice C. Gráficos do ajuste sigmoide e ajuste linear realizado na análise cinética de degradação térmica da CEL, CNC e CNC-Mod após a adsorção de cobalto.

a)

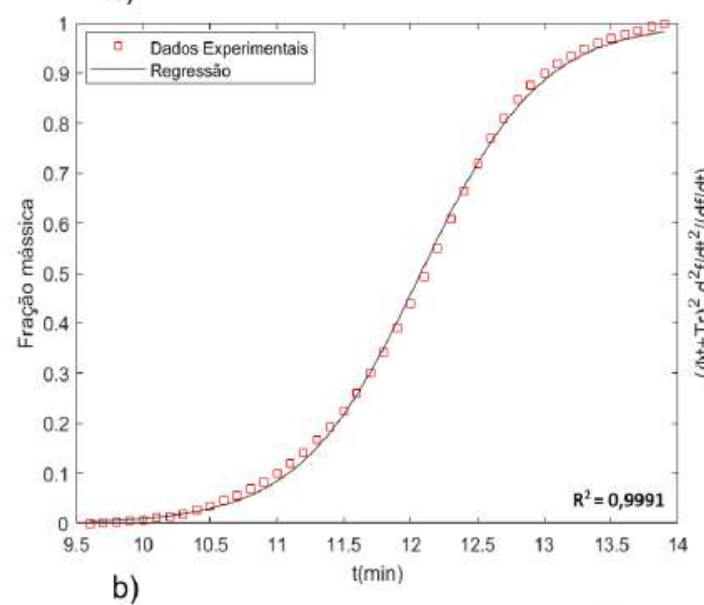

b)

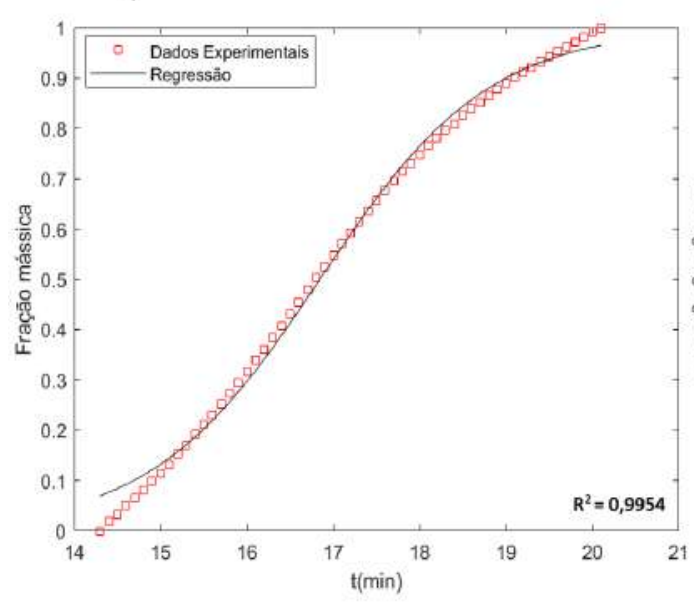

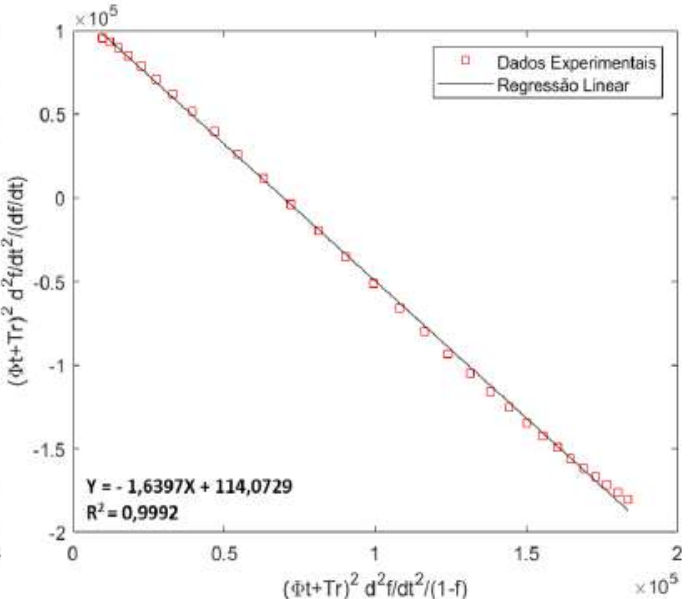

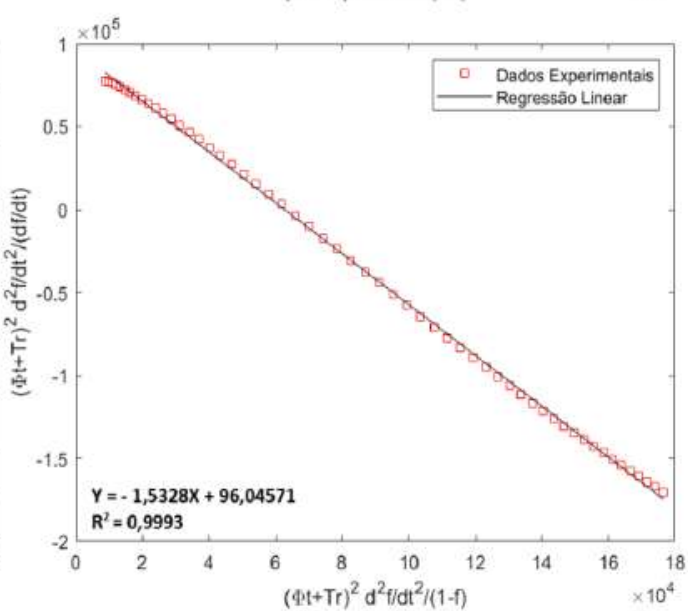

Figura C.2: Ajuste sigmoide e ajuste linear realizado na análise cinética de degradação térmica da CNC-Co a) primeiro pico b) segundo pico. 
Apêndice C. Gráficos do ajuste sigmoide e ajuste linear realizado na análise cinética de degradação térmica da CEL, CNC e CNC-Mod após a adsorção de cobalto.

a)

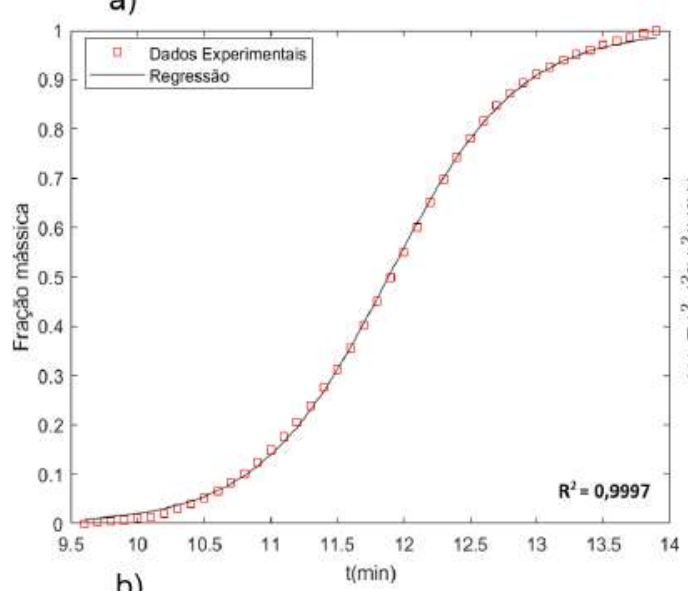

b)

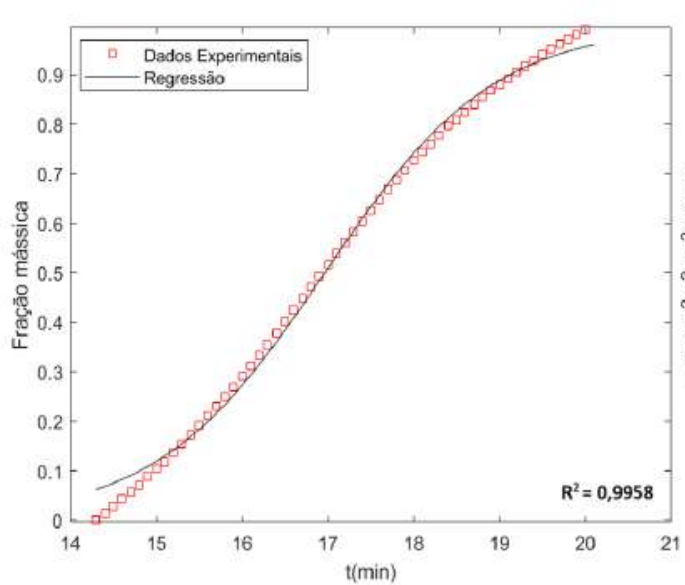

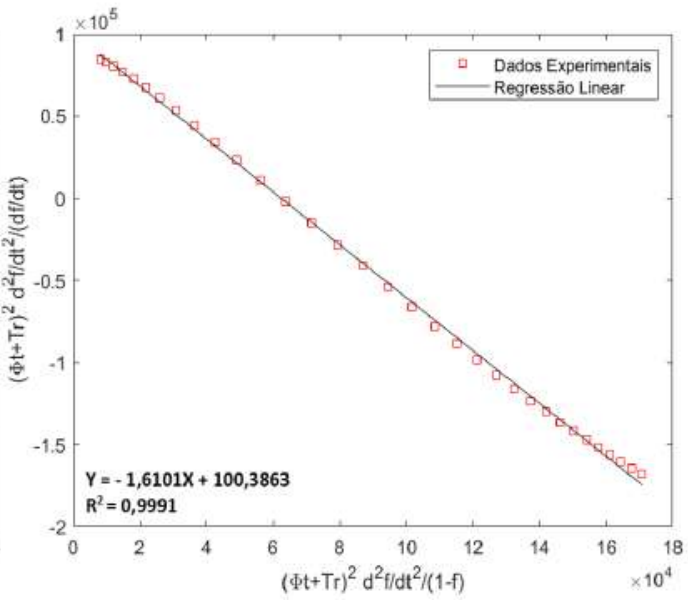

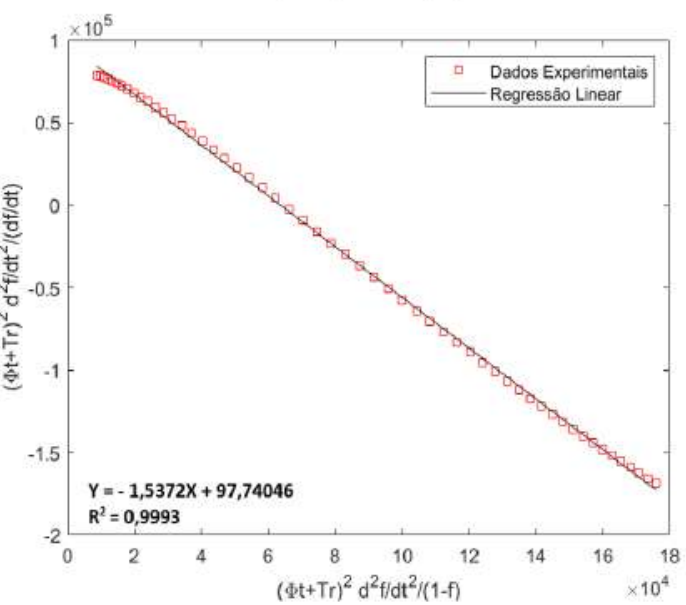

Figura C.3: Ajuste sigmoide e ajuste linear realizado na análise cinética de degradação térmica da CNC-Mod-Co a) primeiro pico b) segundo pico. 
D

Gráficos do ajuste sigmoide e ajuste linear realizado na análise cinética de degradação térmica da CEL, CNC e CNC-Mod após a adsorção de sódio.
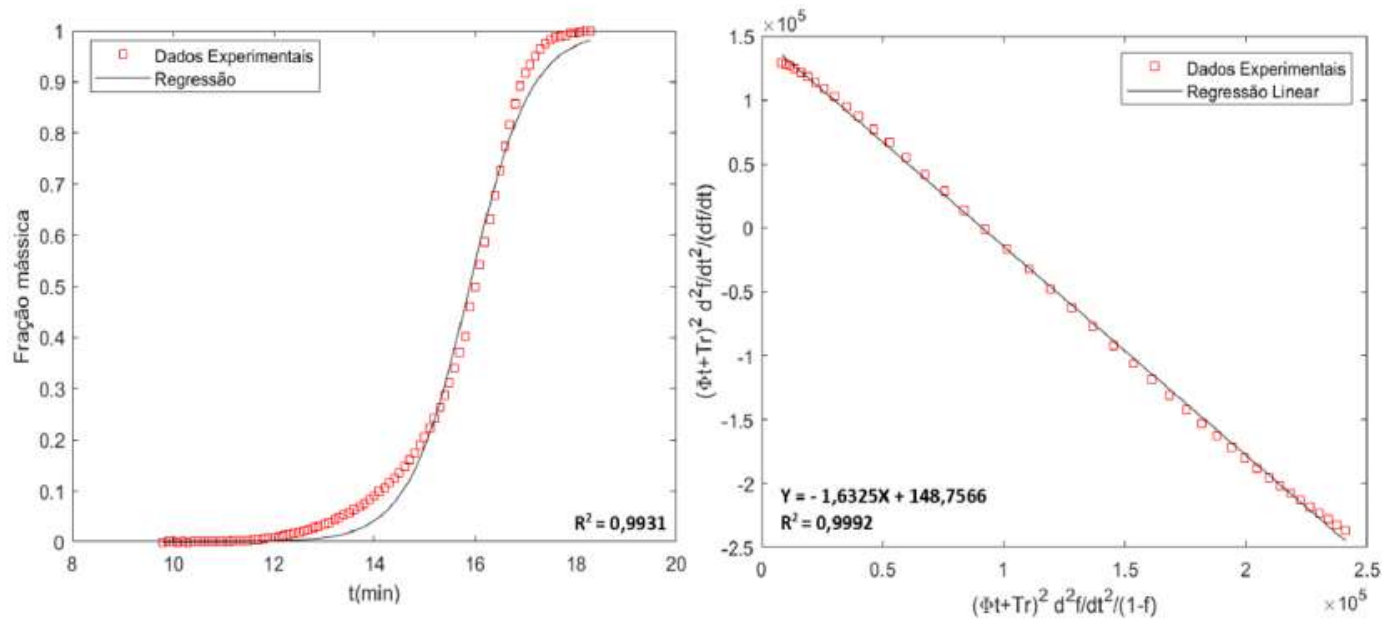

Figura D.1: Ajuste sigmoide e ajuste linear realizado na análise cinética de degradação térmica da CEL-Na. 
Apêndice D. Gráficos do ajuste sigmoide e ajuste linear realizado na análise cinética de degradação térmica da CEL, CNC e CNC-Mod após a adsorção de sódio.
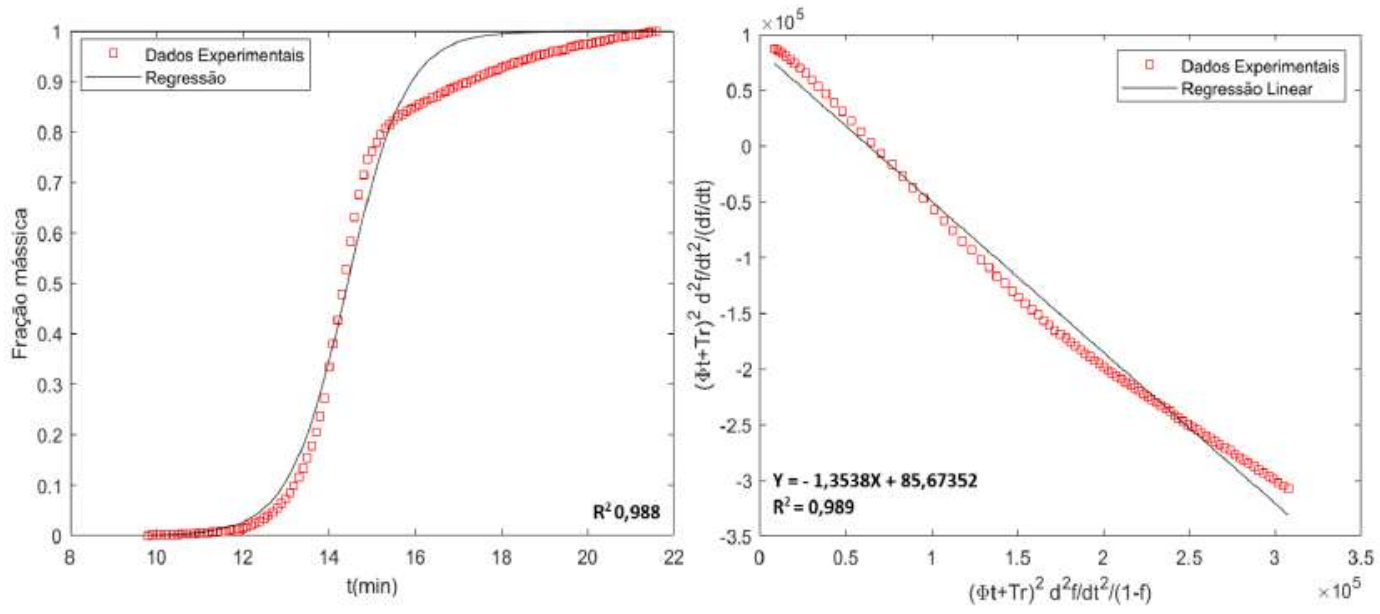

Figura D.2: Ajuste sigmoide e ajuste linear realizado na análise cinética de degradação térmica da CNC-Na.
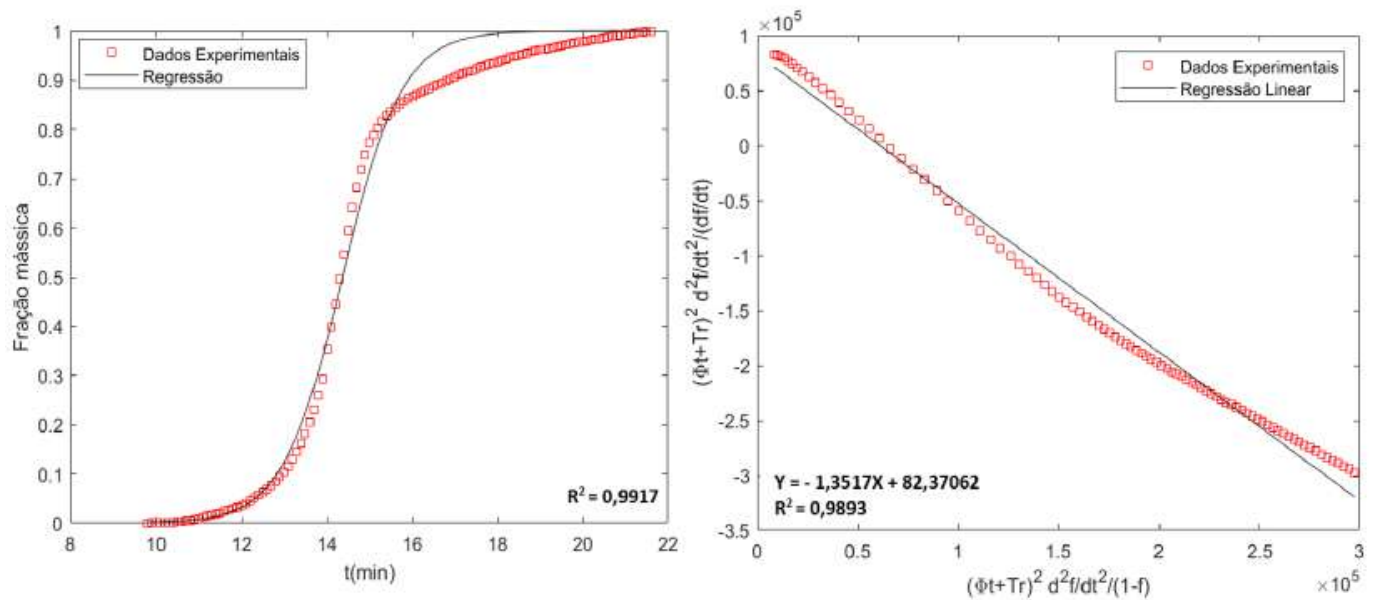

Figura D.3: Ajuste sigmoide e ajuste linear realizado na análise cinética de degradação térmica da CNc-Mod-Na. 


\section{E}

Gráficos do ajuste sigmoide e ajuste linear realizado na análise cinética de degradação térmica da CEL, CNC e CNC-Mod após a adsorção de mercúrio.
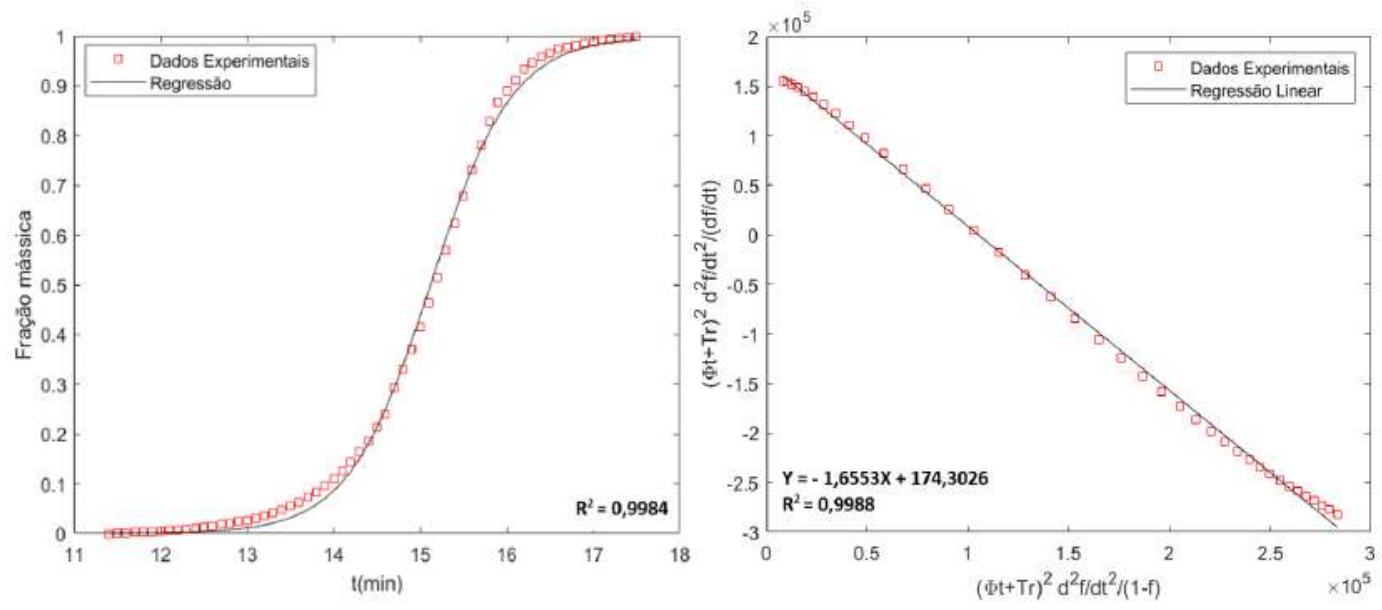

Figura E.1: Ajuste sigmoide e ajuste linear realizado na análise cinética de degradação térmica da CEL-Hg. 
Apêndice E. Gráficos do ajuste sigmoide e ajuste linear realizado na análise cinética de degradação térmica da CEL, CNC e CNC-Mod após a adsorção de mercúrio.
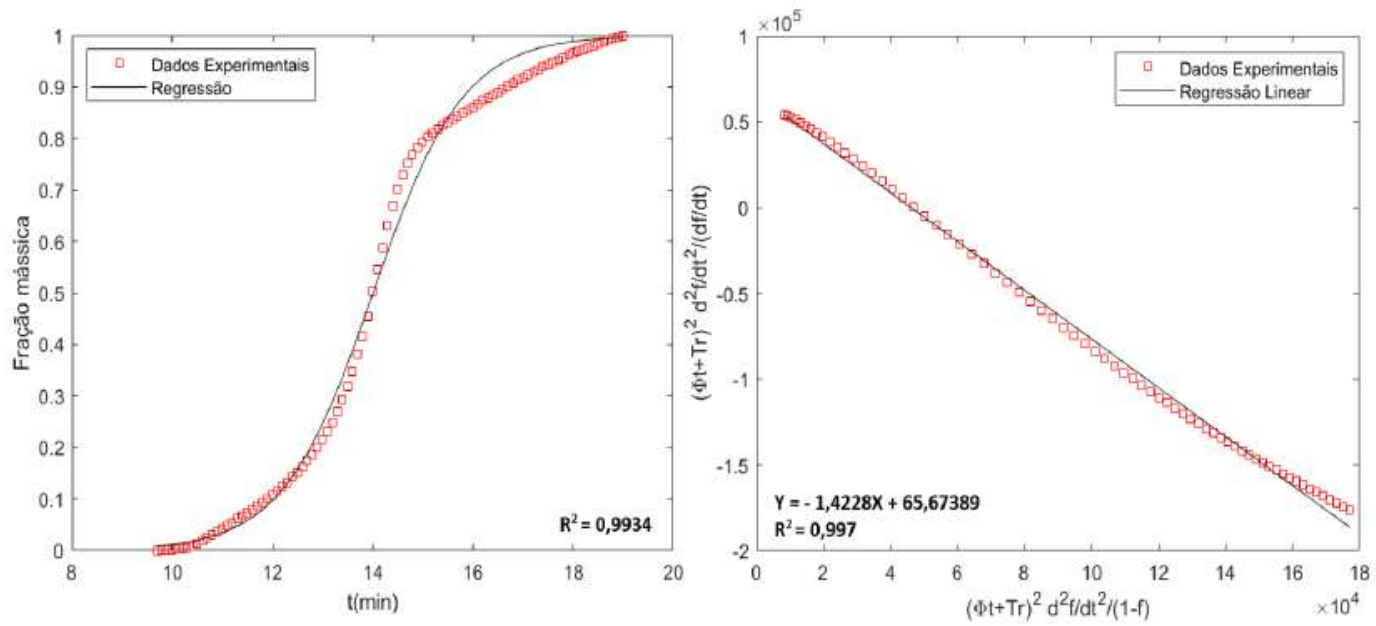

Figura E.2: Ajuste sigmoide e ajuste linear realizado na análise cinética de degradação térmica da $\mathrm{CNC}-\mathrm{Hg}$..
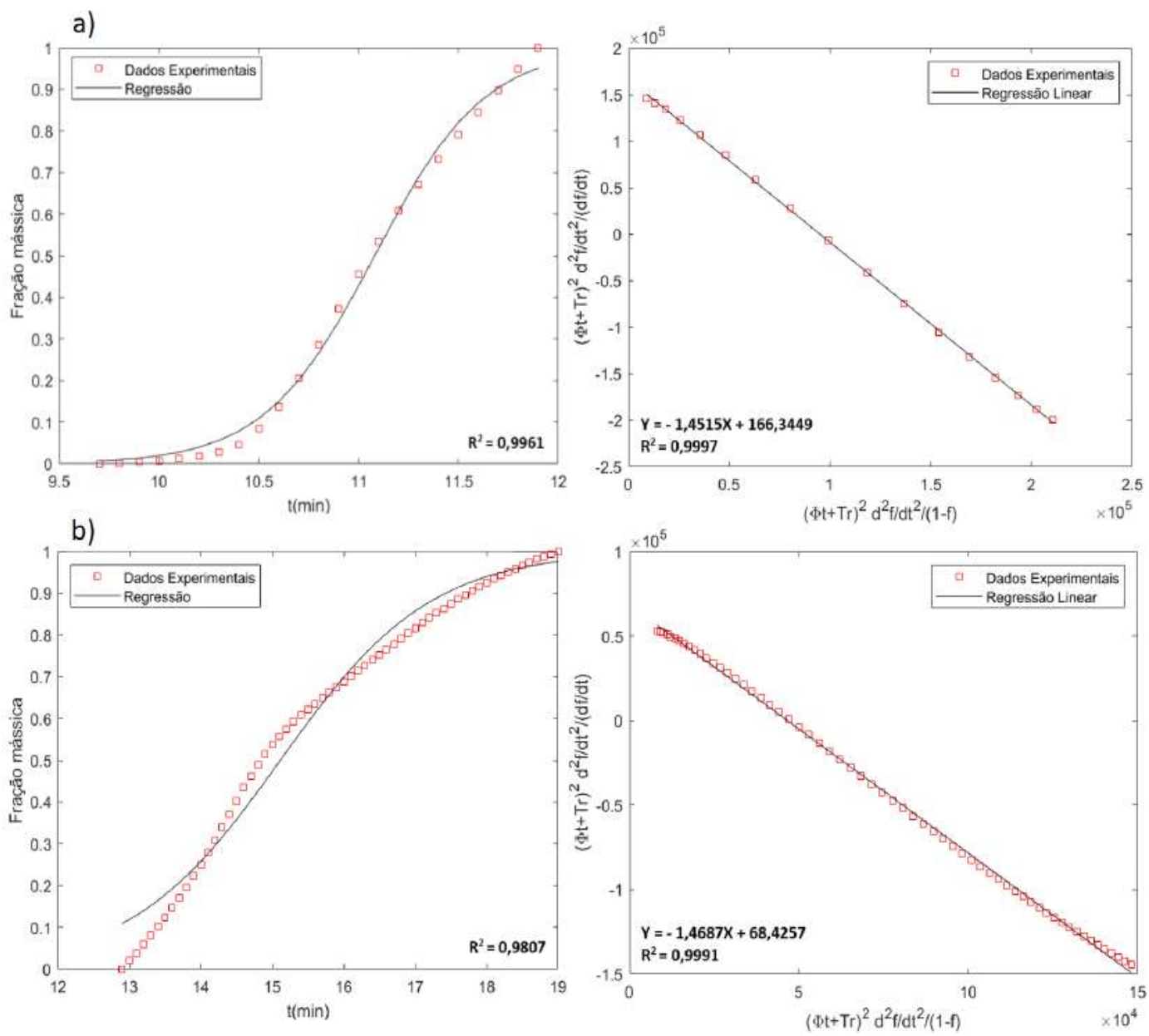

Figura E.3: Ajuste sigmoide e ajuste linear realizado na análise cinética de degradação térmica da CNC-Mod-Hg a) primeiro pico b) segundo pico. 